\author{
DAVID I. LAIBSON
}

Harvard University

ANDREA REPETTO

Universidad de Chile

JEREMY TOB ACMAN

Harvard University

\title{
Self-Control and Saving for Retirement
}

In Lake Wobegone we believe in salting money away, not only as an investment but also to remove it as a temptation.

Garrison Keillor

Some experts have called for easing penalties on early withdrawals from savings plans, believing people will invest more if they know they can get their money if they need it. But most Americans appear wary of such changes, fearful of the temptation to raid their own nest eggs. Sixty percent of Americans say it is better to keep, rather than loosen, legal restrictions on retirement plans so that people don't use the money for other things. Only 36 percent prefer to make it easier for people to tap such savings before their retirement.

Public Agenda ${ }^{2}$

We thank George Akerlof, Christopher Carroll, Eric Engen, William Gale, Robert Hall, and James Poterba for extremely helpful conversations and advice. We are also grateful for the valuable input of Robert Barro, Steve Bergantino, Olivier Blanchard, John Campbell, Daniel Dulitzky, Benjamin Friedman, Drew Fudenberg, Ken Judd, John Shea, Jonathan Skinner, David Wise, and Richard Zeckhauser, and participants of seminars at Harvard University, Stanford University, and the University of Maryland, and of the Brookings Panel meeting. Laibson acknowledges financial support from the National Science Foundation, the MacArthur Foundation, and a National Bureau of Economic Research Aging Fellowship; and Repetto, from an Alfred P. Sloan Graduate Fellowship.

1. Quoted in Laura Pedersen-Pietersen, "From Lake Wobegone and Beyond, A Round Table on Economics and Finance,'New York Times, February 8, 1998, p. C4.

2. Farkas and Johnson (1997, p. 28). 
CONSUMERS FACE TWO challenges: making good decisions and sticking to them. Economists have adopted optimistic assumptions on both counts. The consumers in mainstream economic models are assumed both to be exceptionally good decisionmakers and to be able to carry out their plans. These economic assumptions are dubious, particularly in regard to saving for retirement.

First, economists overestimate sophistication in decisionmaking. In fact, numerous studies have documented the very low level of financial sophistication of the typical American consumer. ${ }^{3}$ In a 1996 poll of nonretired Americans over the age of twenty-six, the Employee Benefit Research Institute (EBRI) found that only 32 percent had "tried to figure out how much money [they would] need to have saved by the time [they retired] so that [they could] live comfortably in retirement.", ${ }_{4}$

Second, economists assume that intentions and actions are aligned. But examples of a systematic gap between intentions and actions abound. Consider the two pack a day cigarette smoker who decided to quit years ago but, despite ongoing attempts, still has not kicked the habit. Consider the employee who perpetually arrives late at work, resolving day after day to get up a little earlier in the future. In New Year's resolutions, one commits to eat more healthily, exercise more regularly, and watch television less frequently, but many of these promises fail. Such failures consistently arise in problems involving delayed gratification. The consumer resolves, plans, desires to avoid an activity associated with instantaneous gratification, but subsequently succumbs to the temptation. Few people claim to have the opposite type of problem: smoking too few cigarettes, getting to work too early, or watching too little television. ${ }^{5}$ Indeed, such problems are so unusual that many

3. See, for example, Bernheim (1994, 1995); Farkas and Johnson (1997).

4. 1996 Retirement Confidence Survey, cosponsored by the Employee Benefit Research Institute, Matthew Greenwald and Associates, and the American Savings Education Council; cited by Farkas and Johnson (1997, p. 34).

5. The eating disorder anorexia nervosa may represent one of the few counterexamples to this claim. However, it is not clear that it should be conceptualized as a reversal of the delay of gratification problem. Anorexia nervosa is associated with both short-term disutility (hunger, malaise) and long-term disutility (malnutrition, death). Hence rather than yielding too much long-term felicity at the expense of short-term felicity, the disorder leads to lower utility flows at all times. "Workaholics" may provide a better, although still imperfect, example of behavior that is characterized by too much investment. 
of them do not even seem intuitively plausible. People have a systematictendency to err-as judged by their own standards-in the direction of instantaneous gratification.

The gap between intentions and actions is also evident in life-cycle saving, and this is the focus of our paper. Three types of evidence document the troubling temptation of immediate gratification. ${ }^{6}$ First, popular and professional financial advice highlights the value of using external commitments to prevent overconsumption. ${ }^{7}$ From the New York Times, for example: "Use whatever means possible to remove a set amount of money from your bank account each month before you have a chance to spend it." ${ }_{8}$ Or from American Express: "If you wait until the end of the month to put money into your investments, you'll probably encounter months in which there's nothing left over. To keep this from happening, pay yourself first by having money set aside from each paycheck into a savings account or 401(k) plan." ${ }^{9}$ Financial planners routinely advise their clients to cut up credit cards, to leave them at home or in a safe deposit box, to use excess withholding as a forced saving device, and to use Christmas clubs, vacation clubs, and other low-interest, low-liquidity goal clubs to regulate saving flows. ${ }^{10}$ And in 1995 American consumers deposited their holiday savings in roughly 10 million Christmas club accounts. ${ }^{11}$ Their use of such commitment devices implies that consumers have, and are aware of, problems of self-control.

Self-reports about preferred consumption paths provide a second type of evidence for the gap between intentions and actions. Consumers report a preference for flat or rising real consumption paths, even when the real interest rate is zero and the budget constraint is made explicit-

6. This evidence is reviewed in Laibson (1998).

7. Such advice may be directed primarily at people who have a problem saving, and so may not be generalizable.

8. Deborah M. Rankin, "How to Get Ready for Retirement: Save, Save, Save," New York Times, March 13, 1993, p. 33 ("Your Money" column).

9. American Express Financial Advisors (1996, p. 14).

10. For interesting evidence on the relatively widespread use of intentional overwithholding, even in the absence of penalties for underwithholding, see Shapiro and Slemrod (1995).

11. Simmons Market Research Bureau (1996). 
that is, higher future consumption implies lower current consumption. ${ }^{12}$ But they actually implement downward-sloping consumption paths when they are not effectively liquidity constrained. ${ }^{13}$ Moreover, in the late 1990s the typical baby boomer household is saving well below the rate required to finance a standard of living in retirement comparable to that it currently enjoys. ${ }^{14}$

Survey data contrasting actual and normative saving rates provide the third type of evidence for the gap between intentions and actions. A 1997 survey by Public Agenda finds that 76 percent of respondents believe that they should be saving more for retirement. ${ }^{15}$ Of those who feel that they are at a point in their lives when they "should be seriously saving already," only 6 percent report being "ahead" in their saving, while 55 percent report being "behind." 16 The report concludes: "The gaps between people's attitudes, intentions, and behavior are troubling and threaten increased insecurity and dissatisfaction for people when they retire. Americans are simply not doing what logic - and their own reasoning - suggests that they should be doing." ${ }_{17}$ These findings echo a 1993 Luntz Webber-Merrill Lynch survey of baby boomers (that is, consumers between the ages of twenty-nine and forty-seven). ${ }^{18}$ Respondents were asked, "What percentage of your annual household income do you think you should save for retirement? ('Target saving')"; and then, "What percentage of your annual household income are you now saving for retirement? ('Actual saving')." The median reported gap between target and actual saving is 10 percent and the mean gap is 11.1 percent; 77.2 percent of respondents believe that they are saving too little for retirement, and 70.7 percent believe that the shortfall represents at least 5 percent of

12. Barsky and others (1997). See Loewenstein and Sicherman (1991) for related evidence.

13. Gourinchas and Parker (1997).

14. Bernheim (1995). Bernheim points out that this calculation assumes a best case scenario: he assumes that all savings are available for retirement, and that mortality rates, tax rates, social security benefits, medicare benefits, and health care costs do not change during the next fifty years. For a critique of his calculations, see William G. Gale, "Will the Baby Boom be Ready for Retirement?", Brookings Review, Summer 1997, pp. 4-9.

15. Farkas and Johnson (1997, p. 9).

16. Farkas and Johnson (1997, p. 33).

17. Farkas and Johnson (1997, p. 27).

18. Analyzed in Bernheim (1995), from which the following numbers are taken. 
income. Only 4.7 percent of respondents report that they are saving above their target rate.

Standard economic theories allow consumers to make mistakes but imply that those mistakes will not be systematic: they will tend not to lie in the same direction. By contrast, the evidence reviewed above indicates that most consumers view themselves as saving too little. Such systematic, self-acknowledged error contradicts the standard economic model of the maximizing consumer. ${ }^{19}$ This paper explores an alternative model, from the psychology literature, that can make sense of the apparent conflicts between attitudes, intentions, and behavior in the domain of saving.

Research on both animal and human behavior has led psychologists to conclude that short-run discount rates are much higher than long-run rates. Such preferences are formally modelled with discount functions that are generalized hyperbolas: events $\tau$ periods away are discounted with factor $(1+\alpha \tau)^{-\gamma / \alpha}$, with $\alpha, \gamma>0$. This discount structure sets up a conflict between today's preferences and those that will be held in the future, implying that preferences are dynamically inconsistent. For example, from today's perspective, the discount rate between two far off periods, $t$ and $t+1$, is a long-term low discount rate; however, from the time $t$ perspective, it is a short-term high discount rate. This type of "change" in preference is reflected in many common experiences. For example, today one may desire to start an aggressive saving plan next month (that is, to act patiently next month), but when next month rolls around, one will want to postpone any sacrifice by another month.

Hence hyperbolic consumers will report a gap between what they feel they should save and what they actually do save. Normative saving rates will lie above actual saving rates, since short-run preferences for instantaneous gratification will undermine a consumer's effort to implement long-run optimal plans. However, the hyperbolic consumer is not doomed to be an underachiever. Commitment devices such as pensions and illiquid assets can help the hyperbolic consumer commit to the patient, welfareenhancing course of action. The availability of illiquid assets is thus a

19. There is an alternative interpretation of this evidence. Consumers may report that they are behind in their saving because they would like to have more savings, ceteris paribus (that is, they would like to have more savings, holding current consumption constant). However, this interpretation would not explain why consumers prefer rising consumption paths-holding the net present value of the consumption stream constantbut actually implement downward-sloping consumption paths. 
critical determinant of national saving rates, as well as of consumer welfare. But too much illiquidity can be problematic. Consumers face substantial uninsurable labor income risk and need liquid assets to smooth their consumption. Hyperbolic agents seek financial instruments that strike the right balance between commitment and flexibility.

The hyperbolic model helps us to analyze the problem of undersaving in the United States. It enables economists to assess the likely magnitude of undersaving and to identify the types of financial instruments that will alleviate the problem. For example, one goal of this paper is to evaluate tax-deferred defined contribution (DC) pension plans. We ask whether these instruments increase national saving and consumer welfare, and whether they are more effective in an economy populated by consumers with problems of self-control.

To answer such questions, we develop and calibrate a numerical simulation model. We build our framework on three organizing principles. The first two echo the approach of Eric Engen, William Gale, and John Scholz, who also use a simulation model to evaluate the efficacy of taxdeferred DC pension plans. ${ }^{20}$ First, our model adopts the standard technological assumptions of mainstream consumption models, such as those originally developed by Christopher Carroll and Angus Deaton. ${ }^{21}$ These authors assume a realistic income process and incomplete markets: consumers cannot borrow against uncertain future labor income. Second, we include two illiquid retirement assets in a consumer's portfolio: an illiquid defined benefit pension plan and a partially illiquid DC plan. The third assumption - the fundamental innovation in our paper-is that consumers have hyperbolic discount functions. We show that the hyperbolic assumption has important implications for both positive and normative conclusions about saving behavior. Our analysis complements the large and active empirical literature on the efficacy of tax-deferred saving instruments such as Individual Retirement Accounts (IRAs) and 401(k) plans. ${ }^{22}$ We do not come down firmly on one side or the other, but instead find that one's conclusions about the efficacy of these instruments depend critically on poorly identified features of consumer preferences.

As we are the first to simulate the behavior of a hyperbolic consumer

20. Engen, Gale, and Scholz (1994).

21. See Carroll (1992) and Deaton (1991).

22. For reviews of this literature, see Hubbard and Skinner (1996); Poterba, Venti, and Wise (1995); Engen, Gale, and Scholz (1996). 
facing a realistic life-cycle decision problem, we evaluate the empirical validity of the hyperbolic model before turning to the efficacy of taxdeferred DC pension plans. We first describe the hyperbolic discount function and motivate our use of it. Then we present our simulation model. Next, we describe our calibration decisions, compare our choices with those of Engen, Gale, and Scholz, and discuss some of the theoretical problems that constrain our calibration choices. We then show that the calibrated one asset (that is, no DC pension plan) hyperbolic economy is nearly indistinguishable from the equivalent exponential economy. However, we do identify two phenomena that differ between the calibrated one asset hyperbolic and exponential economies: hyperbolic consumers are more likely to face binding liquidity constraints and they are expected to exhibit the missing precautionary saving effects documented by Karen Dynan. $^{23}$

When we introduce a second asset, a DC pension modeled after a 401(k), we find that hyperbolic consumers show a greater responsiveness than exponential consumers, reflected in both larger saving effects and larger welfare effects. Our results are sensitive to the calibration of the coefficient of relative risk aversion: higher values significantly reduce the DC plan effects in both exponential and hyperbolic economies. We discuss the robustness of our findings and conclude with directions for future research.

\section{Hyperbolic Discount Functions}

There is a systematic conflict between actors' long- and short-term preferences. When two alternative rewards are far away in time, decisionmakers will generally act relatively patiently: for example, I prefer to take a thirty-minute work break in 101 days, rather than a fifteenminute break in one hundred days. But when both rewards are brought forward in time, decisionmakers reverse their preferences, becoming more impatient: I prefer to take a fifteen-minute break right now, rather than a thirty-minute break tomorrow. Evidence of such reversals has been found in experiments using a wide range of real rewards, including

23. Dynan (1993). 
money, durable goods, fruit juice, sweets, video rentals, relief from noxious noise, and access to video games. ${ }^{24}$

A number of authors have used multiple-self frameworks to model this gap between short- and long-term preferences. ${ }^{25}$ They highlight the conflict between the long-run desire to be patient and the short-run desire for instantaneous gratification. This conflict can be captured in a particularly parsimonious fashion by allowing discount functions to decline at a steeper rate in the short run than in the long run. The data support this intuition. When researchers use subject choices to estimate the shape of the discount function, the estimates consistently approximate generalized hyperbolas: events $\tau$ periods away are discounted with factor $(1+\alpha \tau)^{-\gamma / \alpha}$, with $\alpha, \gamma>0 .{ }^{26}$ This observation was first made by Shin-Ho Chung and Richard Herrnstein in relation to animal behavior. ${ }^{27}$ Their conclusions were later shown to apply to human subjects as well. ${ }^{28}$

Figure 1 graphs the standard exponential discount function (assuming the discount factor $\delta=0.951$ ), the generalized hyperbolic discount function (assuming $\alpha=25 \times 10^{4}, \gamma=10^{4}$ ), and the quasi-hyperbolic discount function-an analytically convenient approximation of the generalized hyperbola. The quasi-hyperbolic function is a discrete time function with values $\left\{1, \beta \delta, \beta \delta^{2}, \beta \delta^{3}, \ldots\right\}$; figure 1 plots the case of $\beta$ $=0.85$ and $\delta=0.964 .{ }^{29}$ The discrete points of the quasi-hyperbolic

24. See, for example, Solnick and others (1980); Navarick (1982); Millar and Navarick (1984); King and Logue (1987); Kirby and Herrnstein (1995); Kirby and Marakovic (1995, 1996); Kirby (1997); Read and others (1998). For a partisan review of this literature, see Ainslie (1992); for a critique, see Mulligan (1997).

25. See, for example, Thaler and Shefrin (1981); Schelling (1984); Loewenstein and Prelec (1992); Hoch and Loewenstein (1991); Akerlof (1991); Ainslie (1992); Laibson (1994, 1996, 1997a); O’Donoghue and Rabin (1997a, 1997b).

26. See Loewenstein and Prelec (1992) for an axiomatic derivation of this discount function.

27. Chung and Herrnstein (1967) claim that the appropriate discount function is an exact hyperbola: events $\tau$ periods away are given a weight that is directly proportional to $1 / \tau$. This discount function describes well-defined preferences as long as time-dated goods are evaluated strictly before the good is actually consumed. The exact hyperbola generates the same discount rates as the generalized hyperbola when $\alpha=\gamma \rightarrow \infty$.

28. See Ainslie (1992) for a survey.

29. This discount function was first analyzed by Phelps and Pollak (1968). However, their application is one of imperfect intergenerational altruism, and the discount factors apply to nonoverlapping generations of a dynasty. Following Laibson (1997a), we apply this discount function to an intrapersonal problem and assume that the horizon is finite. 
Figure 1. Exponential, Hyperbolic, and Quasi-Hyperbolic Discount Functions ${ }^{a}$

Value of discount function

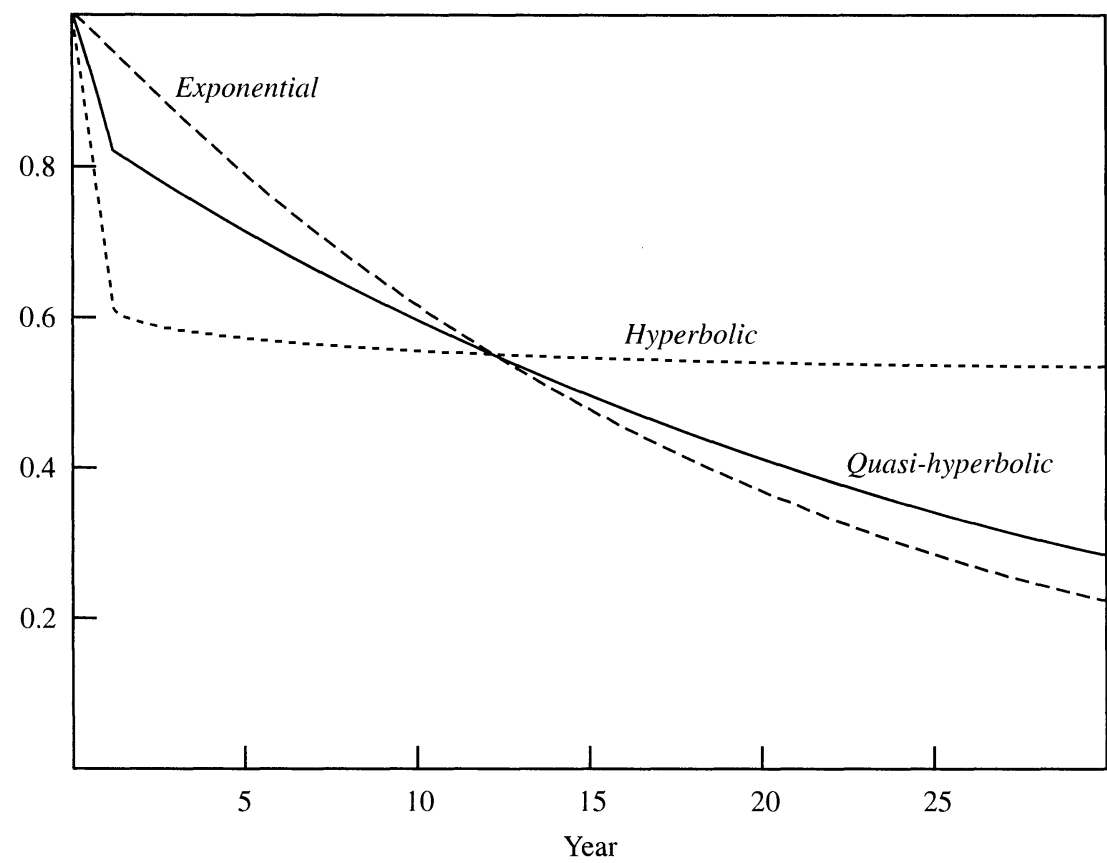

a. Figure plots three discount functions: exponential: $\delta^{\tau}$, with $\delta=0.951$, and $\tau$ representing the year; hyperbolic: $(1+\alpha \tau)^{-\gamma / t}$, with $\alpha=25 \times 10^{4}$ and $\gamma=10^{4}$; and quasi-hyperbolic: $\left\{1, \beta \delta, \beta \delta^{2}, \beta \delta^{3}, \ldots\right\}$, with $\beta=0.85$ and $\delta=0.964$.

function have been joined in figure 1 . When $0<\beta<1$, the quasihyperbolic discount structure mimics the qualitative properties of the hyperbolic discount function, while maintaining most of the analytical tractability of the exponential discount function. We return to this point below.

Hyperbolic discount functions imply discount rates that decline as the discounted event is moved further away in time. Events in the near future are discounted at a higher implicit discount rate than events in the distant future. Given a discount function, $f(\tau)$, the instantaneous discount rate $\tau$ periods in the future is defined as

Phelps and Pollak assume an infinite horizon, which admits a continuum of equilibria; see Laibson (1994). 


$$
-\frac{f^{\prime}(\tau)}{f(\tau)}
$$

Hence an exponential discount function, $\delta^{\tau}$, is characterized by a constant discount rate, $\ln (1 / \delta)$, while the generalized hyperbolic discount function is characterized by an instantaneous discount rate that falls as $\tau$ rises:

$$
\frac{\gamma}{1+\alpha \tau}
$$

Psychologists and economists believe that such declining discount rates, even if unanticipated, are important in generating problems of selfregulation. ${ }^{30}$

These problems arise because hyperbolic discount functions induce dynamically inconsistent preferences. From the perspective of period 0 , the relevant discount rate for trade-offs in period $t$ is $\gamma /(1+\alpha t)$. However, from the perspective of period $t$, the relevant discount rate for trade-offs at period $t$ is $\gamma /(1+\alpha \cdot 0)$, which is greater than $\gamma /(1+$ $\alpha t$ ). Hence an individual's preferences at period 0 differ from the same individual's preferences at period $t$. Self 0 prefers patient trade-offs at period $t$, but self $t$ disagrees. In this sense, the hyperbolic consumer is involved in a decision that sets up an intrapersonal strategic struggle. Early selves would like to commit later selves to honor the preferences of those early selves; however, later selves do their best to maximize their own interests. Economists have modeled this situation as an intrapersonal game played among the consumer's temporally situated selves.

Hyperbolic discount functions have recently been used to explain a wide range of anomalous economic choices, including procrastination, deadlines, drug addiction, retirement timing, and undersaving. ${ }^{31}$ But despite the new developments in this literature, hyperbolic models are still much cruder than their exponential analogs. Intrapersonal games involve much greater analytic complexity than analogous nonstrategic intertemporal maximization, and this has hindered the development of rich, and hence realistic, hyperbolic analysis. This paper partly closes

30. See Ainslie (1975, 1986, 1992); Prelec (1989); Loewenstein and Prelec (1992); O’Donoghue and Rabin (1997a, 1997b).

31. See, for example, Akerlof (1991); Barro (1997); Diamond and Köszegi (1998); Laibson (1994,1996,1997a); O'Donoghue and Rabin (1997a, 1997b). 
the gap by introducing a hyperbolic model whose richness matches contemporary exponential models of consumption over the life cycle. Our approach represents a behavioral alternative that can be calibrated, and its quantitative empirical predictions can be compared directly with those of the leading exponential consumption models. The model can also generate quantitative forecasts and welfare analysis for policy proposals.

\section{The Model}

In the rest of this paper, we develop and evaluate a simulation model of the behavior of hyperbolic consumers. Simulations are a critical tool for forecasting the long-term effects of newly implemented policies and for evaluating the short- and long-term effects of untested policy proposals. Our simulation approach has a major shortcoming that we wish to flag in advance: we adopt the standard economic assumption of unlimited sophistication in problem solving. The consumers in our model solve perfectly a complex backwards induction problem when making choices about consumption and asset allocation.

We chose this approach for two reasons. First, the assumption of perfect rationality is the natural benchmark for an economist. We make this assumption not because it necessarily aptly describes consumer behavior, but rather because it represents the starting point for all economic analysis. Second, even if one wanted to weaken assumptions about consumer sophistication, it is not clear how to do so in a parsimonious and realistic fashion. While economists and psychologists have a great deal of evidence that consumers are not perfectly rational, they do not necessarily know what alternative to rationality should be adopted. There are no well-developed bounded rationality models applicable to the problem of life-cycle saving. ${ }^{32}$

We are sympathetic to one alternative, first proposed by Robert

32. We are keenly interested in the recent developments in the reinforcement learning literature; for example, Erev and Roth (1998); Camerer and Ho (1997). However, such reinforcement models are difficult to apply to the analysis of saving decisions, since it is not clear why, or even if, saving decisions are rewarding in the short run. Perhaps the lack of short- and medium-run reinforcement provides an explanation for undersaving. 
Strotz and more recently studied by George Akerlof and Edward O'Donoghue and Matthew Rabin. ${ }^{33}$ These authors suggest that decisionmakers with dynamically inconsistent preferences make current choices under the false belief that later selves will act in the interests of the current self. This modeling approach assumes that consumers do not foresee that they will hit the snooze button on their alarm clocks, despite the fact that they have consistently done so in the past. O'Donoghue and Rabin call such consumers naifs. The naif assumption strikes us as extreme, and perhaps no more believable than the assumption of perfect sophistication. Both naifs and sophisticates are assumed to solve perfectly a backwards induction problem: the naifs with rosy beliefs about the good behavior of future selves ("I will not procrastinate on the next project"), and the sophisticates with correct beliefs ("I always procrastinate"'). Neither approach seems precisely correct to us, but we focus on the sophisticate model. ${ }^{34}$

\section{An Individual's Consumption Problem}

Taking our cue from the contemporary consumption literature, we explicitly model the rich array of constraints and stochastic income events that consumers face. Such rich models are not analytically tractable, and therefore they require numerical analysis. Our simulation framework follows most closely the work of Engen, Gale, and Scholz; we highlight the assumptions that distinguish our analysis from theirs. We divide the presentation of the model into seven domains: demographics, income, bequests, asset allocation, taxes, preferences, and equilibrium.

DEMOGRAPHICS. The economy is populated by consumers who face a time-varying, exogenous hazard rate of survival $s_{t}$, where $t$ indexes age. Consumers live for a maximum of $\mathrm{T}+\mathrm{N}$ periods, where $\mathrm{T}$ and $\mathrm{N}$ are exogenous variables that represent the maximum lengths of preretirement life and retirement, respectively. If a consumer is alive at age $20 \leq t \leq \mathrm{T}$, that consumer is in the workforce. If a consumer is alive at age $\mathrm{T}<t \leq \mathrm{T}+\mathrm{N}$, that consumer is retired. We assume that

33. Strotz (1956); Akerlof (1991); O’Donoghue and Rabin (1997a, 1997b).

34. Had we chosen the naif model, we would probably have found smaller effects of DC plans for hyperbolic consumers. Naifs do not value the commitment properties of DC plans, because they think that future selves will act in the interest of the current self. 
economic life begins at twenty and do not model consumption decisions before this age.

We divide our population into three educational categories: consumers without a high school diploma, high school graduates, and college graduates. We take education to be exogenous and assign a different preretirement life $(\mathrm{T})$, retirement duration $(\mathrm{N})$, labor income process, and bequest process to each category.

LABOR INCOME. Labor effort is supplied inelastically. Let $Y_{t}$ represent labor income when $20 \leq t \leq \mathrm{T}$, and defined benefit pension income when $\mathrm{T}<t \leq \mathrm{T}+\mathrm{N}$. Let $y_{t} \equiv \ln \left(Y_{t}\right)$. We refer to $y_{t}$ as labor income, regardless of whether it is a preretirement wage payment or a postretirement defined benefit pension payment. During working life,

$$
y_{t}=f^{w}(t)+u_{t}^{w},
$$

where $f^{W}(t)$ is a cubic polynomial in age, $u_{t}^{W}=\alpha u_{t-1}^{W}+\epsilon_{t}^{W}$, and $\epsilon_{t}^{W}$ is normally distributed, $N\left(0, \sigma_{W}^{2}\right)$. During retirement,

$$
y_{t}=f^{R}(t)+u_{t}^{R},
$$

where $f^{R}(t)$ is linear in age and $u_{t}^{R}$ is distributed $N\left(0, \sigma_{R}^{2}\right)$. The elements of the income process - $f^{W}(\cdot), \alpha, \sigma_{W}, f^{R}(\cdot)$, and $\sigma_{R}$ - vary across educational categories.

Except for the stochastic component of retirement income, our labor income process replicates that used by Glenn Hubbard, Jonathan Skinner, and Stephen Zeldes, and Engen, Gale, and Scholz. ${ }^{35}$ We choose not to use the integrated labor income process adopted by Carroll, since we cannot take advantage of his technique of eliminating a state variable. ${ }^{36} \mathrm{We}$ are prevented from doing so by the fact that our problem is not scalable, because we consider simulations with investment-capped tax-deferred assets-for example, IRAs or $401(\mathrm{k}) \mathrm{s}$ - and fixed tax brackets.

BEQUESTS. Consumers receive bequests throughout their lives. We would have liked to make bequests a state variable, but to keep the model computationally tractable (the model already has three state variables: labor income, liquid assets, and assets in a DC pension plan), we instead assume that bequests at time $t$ are independent of the history of bequests. We believe that this assumption creates relatively little

35. Hubbard, Skinner, and Zeldes (1995); Engen, Gale, and Scholz (1994).

36. Carroll (1992). 
distortion in our results, since for the typical real world consumer, the timing and magnitudes of bequests are difficult to predict far in advance, and the number of bequests received over a lifetime should be modeled as a stochastic variable. In an ideal model, the probability of bequest realizations would be negatively autocorrelated.

We assume that the hazard rate of receiving a bequest depends solely on the age of the consumer and not on the prior history of bequests:

$$
p(t)=\operatorname{Prob}\left(q<h(t) \mid q \sim N\left(0, \sigma^{2}\right)\right),
$$

where $\mathrm{h}(\cdot)$ is a cubic polynomial. This is a standard probit formulation. Conditional on receiving a bequest, the natural logarithm of the value of the bequest, $\ln \left(B_{t}\right) \equiv b(t)$, is given by

$$
b(t)=g(t)+\eta_{t},
$$

where $g(t)$ is a cubic polynomial in age, and $\eta_{t}$ is distributed $N\left(0, \sigma_{B}^{2}\right)$. The polynomials $h(\cdot)$ and $g(\cdot)$ vary across education categories.

Our bequest process contrasts with that of Engen, Gale, and Scholz, who assume deterministic and homogenous bequests. In their model, all forty-five year olds receive identical bequests, regardless of educational level, and consumers at all other ages receive no bequests.

ASSETS AND THE DYNAMIC BUDGET CONSTRAINT. We have discussed above the income flows associated with defined benefit pensions; those flows appear in $Y_{t}$. We now consider DC pensions and regular liquid assets. We focus on the special case in which the DC pension is a stylized version of an IRA or a 401(k).

Let $X_{t}$ represent liquid asset holdings at age $t$. Let $Z_{t}$ represent the DC plan. The dynamic budget constraint is given by

$$
X_{t+1}+Z_{t+1}=R\left(X_{t}+Z_{t}+Y_{t}+M_{t}-C_{t}-T_{t}+B_{t+1}\right),
$$

where $R$ is the gross pretax interest rate, $1+r ; B_{t+1}$ is bequests, received on January 1 of year $t+1 ; Y_{t}$ is labor income, received on December 31 of year $t ; M_{t}$ is the employer matching contribution to the DC plan, received on December 31 of year $t$; $C_{t}$ is consumption, chosen on December 31 of year $t$; and $T_{t}$ is taxes, including penalties for preretirement withdrawals from the DC plan, chosen on December 31 of year $t$.

Let $I_{t}$ represent the employee contribution to the DC plan. Thus the dynamic budget constraint can be expressed 


$$
\begin{aligned}
X_{t+1}+Z_{t+1}=R\left[X_{t}+\left(Z_{t}+I_{t}\right.\right. & \left.+M_{t}\right) \\
& \left.+Y_{t}-I_{t}-C_{t}-T_{t}+B_{t+1}\right],
\end{aligned}
$$

where $Z_{t+1}=R\left(Z_{t}+I_{t}+M_{t}\right)$.

Our assumptions about the DC plan, including the matching provisions, are motivated by existing $401(\mathrm{k})$ regulations and are summarized as follows:

$-I_{t} \leq \$ 10,000$.

-If $I_{t} \leq 0$, then $M_{t}=0$.

-If $I_{t}>0$, then $M_{t}=\min \left\{\phi I_{t}, \phi \psi Y_{t}\right\}$.

-If $I_{t}<0$ and $t<60$, then the consumer pays a tax penalty of $\omega I_{t}$.

-If $I_{t}<0$, then the consumer declares additional taxable income of $I_{t}$.

$-I_{t} \leq 0$ if $t>\mathrm{T}$.

In words, these rules imply that the employee contribution must be less than or equal to $\$ 10,000$; if the employee contribution is negative, matching does not occur; if the employee contribution is positive, matching is equal to $\phi$ times the employee contribution, capping out at $\phi \psi Y_{t}$; if the employee withdraws money from the $401(\mathrm{k})$ before age sixty, then the employee pays a tax penalty of $100 \omega$ percent of the withdrawal; withdrawals from the $401(\mathrm{k})$ count as taxable income; and no further contributions to the $401(\mathrm{k})$ are allowed after retirement. ${ }^{37}$

We assume that employers offset their match payments with a reduction in preretirement labor income payments. This reduction applies to all workers, whether or not they contribute to the DC plan. Specifically, we reduce all preretirement labor income payments by a fixed percentage, $\Lambda$, such that match payments plus labor income payments in the new steady state with the DC plan are equal to labor income payments in the original steady state with no DC plan. We perform this calculation separately for each educational group. Note that the size of the adjustment depends on the saving decisions of consumers, so that we have to calculate a different adjustment factor for each simulation. Finding $\Lambda$ requires numerically solving a fixed point problem: $\Lambda$ has to be adjusted to offset the level of realized match payments, and the equilibrium level of realized match payments depends on the value of $\Lambda$.

37. The assumption about the employee contribution cap may be too generous, as many workers are constrained by limits set by the firm below the IRS limit of approximately $\$ 10,000$. 
Following Engen, Gale, and Scholz, we assume that in all periods, both the $X$ assets and the $Z$ assets are bounded below by zero:

$$
\begin{aligned}
& X_{t} \geq 0 \\
& Z_{t} \geq 0 .
\end{aligned}
$$

These assumptions do not preclude borrowing against $X$ collateral to invest in a DC plan, since the collateral and the debt are both in the $X$ account. However, we rule out borrowing that uses the $Z$ asset as collateral. While many 401(k) plans do have facilities for this type of borrowing, they are generally highly restrictive, as discussed below.

TAXES. Consumers face a progressive tax structure. Taxable income is

$$
Y_{t}-I_{t}+\left(\frac{r}{R}\right) X_{t},
$$

which captures the tax deductible nature of contributions to the DC plan. Recall that $R$ and $r$ are the gross and net interest rates, respectively.

PREFERENCES. The total utility of self $t$ is given by

$$
U_{t}=u\left(C_{t}\right)+\beta \sum_{i=1}^{\mathrm{T}+\mathrm{N}-t} \delta^{i}\left(\prod_{j=1}^{i} s_{t+j}\right) u\left(C_{t+i}\right),
$$

where $u(\cdot)$ is an isoelastic utility function with coefficient of relative risk aversion $\rho$. Recall that $s_{t}$ is the probability of surviving to age $t$ conditional on being alive at age $t-1$. These preferences imply no bequest motive, and hence realized bequests are purely accidental. ${ }^{38}$

To develop an intuition for the parameters $\beta$ and $\delta$, consider the special case in which $s_{t}$ is equal to unity for all $t$. Self $t$ 's preferences reduce to

$$
U_{t}=u\left(C_{t}\right)+\beta \sum_{i=1}^{\mathrm{T}+\mathrm{N}-t} \delta^{i} u\left(C_{t+i}\right) .
$$

The discount function is the quasi-hyperbolic function described above. Note that the discount factor between adjacent periods $n$ and $n+1$

38. In our model, bequest receipts are exogenously specified. We assume that the difference between exogenous bequest receipts and endogenous accidental bequests reflects estate taxes. Note that consumers would leave no accidental bequests if a sufficiently fair annuity market existed. 
represents the weight placed on utils at time $n+1$ relative to the weight placed on utils at time $n$. From the perspective of self $t$, the discount factor between periods $t$ and $t+1$ is $\beta \delta$, but the discount factor that applies between any two later periods is $\delta$. Since we take $\beta$ to be less than one, this implies a short-term discount rate greater than the longterm discount rate.

Later selves will not validate these preferences. Continuing to assume 100 percent survival, the total utility of self $t+1$ is given by

$$
U_{t+1}=u\left(C_{t+1}\right)+\beta \sum_{i=1}^{\mathrm{T}+\mathrm{N}-(t+1)} \delta^{i} u\left(C_{t+1+i}\right) .
$$

From the perspective of self $t+1, \beta \delta$ is the relevant discount factor between periods $t+1$ and $t+2$. Hence selves $t$ and $t+1$ disagree about the desired level of patience at time $t+1$.

When the survival hazard rates are included, this discount structure is only slightly altered. From the perspective of self $t$, the discount factor at time $t+1$ is $\delta s_{t+1}$; from self $t+2$ 's perspective, it is $\beta \delta s_{t+2}$.

EQUILIBRIUM. The dynamic inconsistency in preferences implies that the consumption problem can not be treated as a straightforward dynamic optimization problem. Late selves will not implement the policies that are optimal from the perspective of early selves. Following the work of Strotz, we model consumption choices as an intrapersonal game. ${ }^{39}$ Selves $\{20,21, \ldots, T+N-1, T+N\}$ are the players. Taking the strategies of other selves as given, self $t$ picks a strategy for time $t$ that is optimal from its own perspective. This strategy is a mapping from the state variables, $\{t, X, Z, Y\}$, to $\{C, X, Z\}$. An equilibrium is a fixed point in the strategy space, such that all strategies are optimal given the strategies of the other players. We restrict our focus to Markov equilibria and solve for the equilibrium strategies using a numerically implemented backwards induction algorithm.

Our choice of the quasi-hyperbolic discount function simplifies the induction algorithm. Let $V_{t, t+1}$ represent the time $t+1$ continuation payoff function of self $t$. Thus the objective function of self $t$ is

$$
u\left(C_{t}\right)+\beta \delta s_{t+1} E_{t}\left[V_{t, t+1}\left(X_{t+1}, Z_{t+1}, Y_{t+1}\right)\right] .
$$

39. Strotz (1956). 
Self $t$ chooses $C_{\mathrm{t}}$ to maximize this expression. The time $t$ continuation payoff function of self $t-1$ can be calculated as

$$
V_{t-1, t}\left(X_{t}, Z_{t}, Y_{t}\right)=u\left(C_{t}\right)+\delta s_{t+1} E_{t}\left[V_{t, t+1}\left(X_{t+1}, Z_{t+1}, Y_{t+1}\right)\right],
$$

where $C_{t}$ is the consumption chosen by self $t$. The induction continues in this way. The dynamic inconsistency in preferences is evident from the fact that a $\beta$ term appears in equation 7 , reflecting the discount factor of self $t$ between periods $t$ and $t+1$, but does not appear in equation 8 , since self $t-1$ does not use the $\beta$ factor to discount between periods $t$ and $t+1$.

Equations 7 and 8 jointly define a functional equation that is not a contraction mapping. Hence the standard dynamic programming results do not apply to this problem. Specifically, $V$ does not inherit concavity from $u$, the objective function is not single peaked, and the policy functions are in general discontinuous and nonmonotonic. ${ }^{40}$ We adopt a numerically efficient solution algorithm, based on local grid searches, which iterates our functional equation in the presence of these nonstandard properties. We document some of the nonstandard properties below.

\section{Calibration}

In this section we discuss our calibration decisions, except for the choice of preference parameters. Most of this analysis is standard, and those who desire instantaneous gratification may jump to the discussion of preference parameter calibration without loss of continuity.

DEMOGRAPHICS. In our model, consumers live for a maximum of ninety years $(T+N)$, although they do not enter the work force or make economically meaningful decisions until age twenty. The conditional hazard rates of survival are taken from the life tables of the U.S. National Center for Health Statistics, which report the probability of living to age $t+1$, conditional on having lived to age $t \cdot{ }^{41}$ This oneyear survival probability is close to 1 through age seventy, drops to 96.3 percent by age eighty, and to 67.6 percent by age eighty-nine.

40. See Laibson (1997b).

41. U.S. National Center for Health Statistics (1994). 
Following Engen, Gale, and Scholz, we use survival rates for a single individual, even though the consumers in our model are in fact abstractions of multiperson households. Conceptually, our model assumes that households are of fixed size, and that all members of the household die when the head dies. We chose not to model the mortality of both spouses, to avoid an additional state variable. ${ }^{42}$

We calculate educational group population weights from the Michigan Panel Study of Income Dynamics (PSID), and replicate the assumption of Engen, Gale, and Scholz that these weights are approximately 0.25 for high school dropouts, 0.50 for high school graduates, and 0.25 for college graduates.

LABOR AND PENSION INCOME. We define income as pretax nonasset income. We include labor income and transfers such as aid to families with dependent children, supplemental security income, workers' compensation, and unemployment insurance. Our definition is therefore broader than that of Engen and Gale, who use only labor earnings, or that of Hubbard, Skinner, and Zeldes, who add only unemployment insurance payments to labor income. ${ }^{43}$

The sample of households is taken from the PSID. We use the family files for the interview years between 1980 and 1992. We exclude all households where the head is younger than twenty years of age, that report annual income of less than $\$ 1,000$ (in 1990 dollars, deflated by the Consumer Price Index for urban consumers), or that have any crucial variable missing. ${ }^{44}$ To calculate preretirement income, we follow the approach of Bernheim, Skinner, and Steven Weinberg, who define a year as preretirement if any household member works 1,500 hours or more in that or any subsequent year. ${ }^{45} \mathrm{~A}$ household is retired if no

42. Our approach engenders two subtle biases in opposite directions. On the one hand, it may yield too much simulated retirement saving, because the model implicitly rules out insurance effects that arise when spouses have independent mortality outcomes; an $n$-person marriage creates a partial annuity that becomes perfect as $n$ goes to infinity. On the other hand, our mortality assumption may imply too little simulated retirement saving, because widows and widowers have expenses that fell by less than 50 percent when their spouses died.

43. Engen and Gale (1993); Hubbard, Skinner, and Zeldes (1994, 1995).

44. We believe that reported income of less than $\$ 1,000$ is likely to reflect a coding or reporting error. Recall that by our definition, income includes all government transfers.

45. Bernheim, Skinner, and Weinberg (1997). 
member works more than 500 hours in the current year or in any year in the future. ${ }^{46}$

We estimate the regression equation

$$
\begin{aligned}
y_{i t}=\alpha_{1}(F S)_{i t}+\left(1, \text { age, } \text { age }^{2}, \text { age }^{3}\right) & \boldsymbol{\alpha}_{2}+\alpha_{3}(T E)_{i t} \\
& +(\text { cohort dummies }) \boldsymbol{\alpha}_{\mathbf{4}}+\xi_{i t}
\end{aligned}
$$

by weighted least squares, using the PSID population weights. We estimate the equation twice, once for households in the labor force and once for retired households. Log income of individual $i$ at time $t$ is determined by a family size effect $(F S)_{i t}$, a polynomial in age, a time effect $(T E)_{i t}$, and a cohort effect. We specify the polynomial as a cubic for the preretirement regression and linear for the postretirement regression. Following Pierre-Olivier Gourinchas and Jonathan Parker, and to circumvent the problem that age, time, and birth year are perfectly correlated, we assume that the time effect is related to the business cycle and can be proxied by the unemployment rate. ${ }^{47} \mathrm{We}$ use the unemployment rate in the household's state of residence, taken from the worldwide web page of the Bureau of Labor Statistics. Our cohort effects control for birth year, to account for permanent differences in productivity that affect cohorts in different ways. ${ }^{48}$ We use five-year age cohorts, the oldest born in the period 1910-14 and the youngest born in 1970-74. Table 1 reports the income regressions for each educational group.

We calculate $f^{W}$ and $f^{R}$ - the polynomials in the model of the previous section-by setting the cohort, family size, and unemployment effects equal to the sample means. This allows us to recover the age-specific effect for a household that has a constant size, experiences no business cycle effects, and has a constant cohort effect over the life cycle. ${ }^{49}$ Figure 2 plots the exponentiated values of $f^{w}$ and $f^{R}$ for the three educational categories.

To study the stochastic component of preretirement nonasset house-

46. Household-years that meet neither of these conditions are dropped from the regression analysis.

47. Gourinchas and Parker (1997).

48. See Attanasio and Weber (1993) for a discussion of cohort effects.

49. Our model precludes variation in household size over the life cycle. If we were to include family size effects, the simulations would generate lower saving among young households. 
Table 1. Estimated Age-Income Profiles from Regressions ${ }^{\mathrm{a}}$

\begin{tabular}{|c|c|c|c|}
\hline $\begin{array}{l}\text { Independent } \\
\text { variable }\end{array}$ & $\begin{array}{c}\text { High school } \\
\text { dropouts }\end{array}$ & $\begin{array}{l}\text { High school } \\
\text { graduates }\end{array}$ & $\begin{array}{l}\text { College } \\
\text { graduates }\end{array}$ \\
\hline \multicolumn{4}{|c|}{ Labor force households ${ }^{\mathrm{b}}$} \\
\hline Age & $\begin{array}{c}0.059 \\
(0.033)\end{array}$ & $\begin{array}{c}0.058 \\
(0.018)\end{array}$ & $\begin{array}{c}0.224 \\
(0.026)\end{array}$ \\
\hline $\mathrm{Age}^{2} / 100$ & $\begin{array}{c}-0.034 \\
(0.079)\end{array}$ & $\begin{array}{c}-0.017 \\
(0.044)\end{array}$ & $\begin{array}{c}-0.388 \\
(0.061)\end{array}$ \\
\hline $\mathrm{Age}^{3} / 10,000$ & $\begin{array}{r}-0.030 \\
(0.061)\end{array}$ & $\begin{array}{c}-0.055 \\
(0.034)\end{array}$ & $\begin{array}{c}0.211 \\
(0.045)\end{array}$ \\
\hline Other effects ${ }^{\mathrm{c}}$ & 8.557 & 8.835 & 6.776 \\
\hline $\begin{array}{l}\text { Retired housel } \\
\text { Age }\end{array}$ & $\begin{array}{r}-0.007 \\
(0.003)\end{array}$ & $\begin{array}{r}-0.008 \\
(0.004)\end{array}$ & $\begin{array}{r}-0.034 \\
(0.009)\end{array}$ \\
\hline Other effects ${ }^{c}$ & 9.673 & 10.158 & 12.399 \\
\hline $\begin{array}{l}\text { Source: Authors' } \\
\text { a. Dependent va } \\
\text { parentheses. } \\
\text { b. A household i } \\
\text { c. Includes a con } \\
\text { state of residence, } \\
\text { d. A household i }\end{array}$ & $\begin{array}{l}\text { d on data from the } \\
\text { ral log of nonasse } \\
\text { e if any member } \\
\text { ects of cohort dur } \\
\text { ch regressor set eq } \\
\text { mber works more }\end{array}$ & $\begin{array}{l}\text { Study of Income } \\
\text { me. Panel spans } 1 \\
\text { s in the current ye } \\
\text { me, and the unemp } \\
\text { mean. } \\
\text { the current year o }\end{array}$ & $\begin{array}{l}1980-92 \text {. } \\
\text { d errors are in } \\
\text { e year. } \\
\text { he household's } \\
\text { ear. }\end{array}$ \\
\hline
\end{tabular}

hold income, we exploit the panel dimension of the PSID. We model the unexplained part of measured nonasset income $\left(\xi_{i t}\right)$ as the sum of an individual fixed effect, a first order autoregressive process $\left(y_{i t}^{W}\right)$, and a purely transitory shock $\left(v_{i t}\right)$, which represents measurement error:

$$
\xi_{i t}=\vartheta_{i}+u_{i t}^{W}+v_{i t}=\vartheta_{i}+\alpha u_{i, t-1}^{W}+\epsilon_{i t}^{W}+v_{i t}
$$

The individual fixed effect is included to account for permanent differences in income that are not completely captured by the educational categories, such as differences in human capital and earning ability. It is necessary to include the individual effect in this equation to correctly estimate the persistence of income shocks. However, we set it equal to zero in our actual simulations. This latter decision is dictated by computational considerations, since our problem is not scalable and would have to be solved for every value of the fixed effect.

Let $\sigma_{v}^{2}$ be the variance of the transitory shock $v$, and let $\sigma_{W}^{2}$ be the variance of $\epsilon^{W}$. Also, let $\operatorname{Cov}_{k} \equiv E\left(\Delta \xi_{t} \Delta \xi_{t-k}\right)$ represent the theoretical autocovariances of $\Delta \xi$. Then 
Figure 2. Estimated Age-Income Profiles ${ }^{a}$

Income (thousands of 1990 dollars)

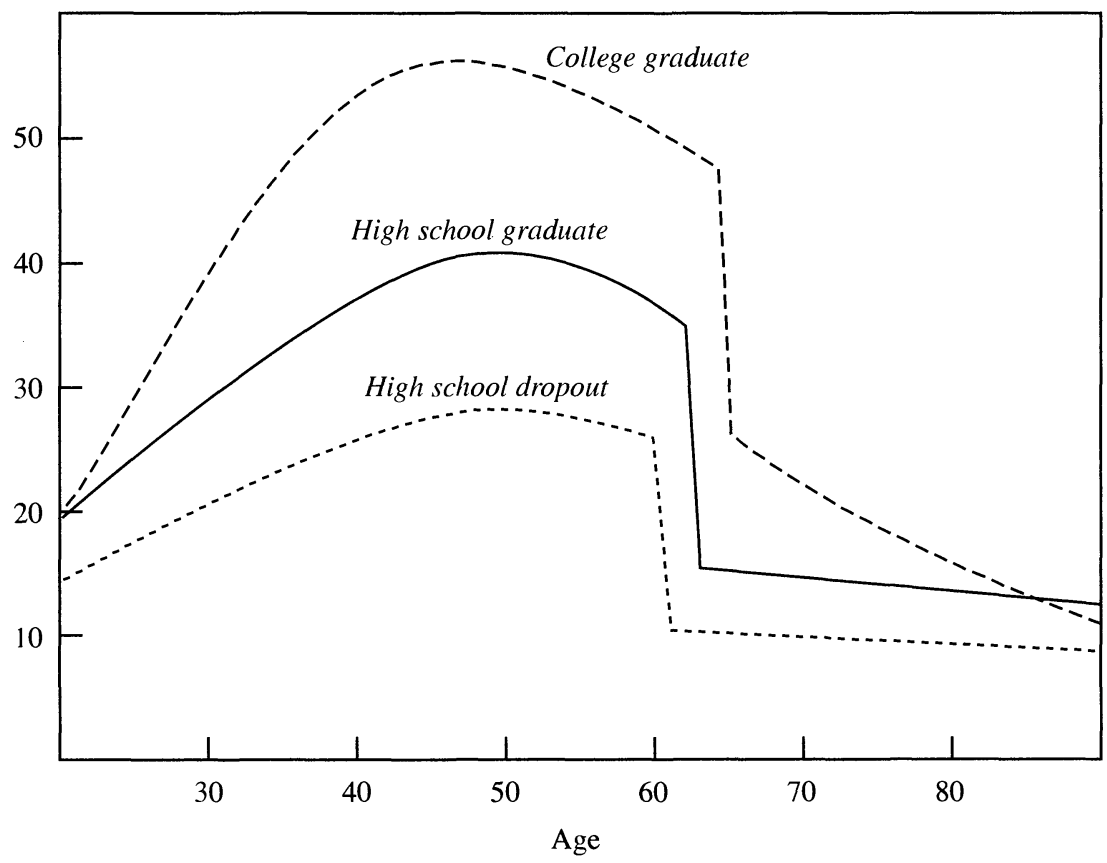

Source: See table 1.

a. Figure plots estimated nonasset household income, by age and educational group. Values are calculated from a regression of the natural log of income on a cubic polynomial in age, cohort dummies, family size, and the unemployment rate in the household's state of residence. Figure plots age effects, with other regressors set equal to their means. See table 1 for details.

$$
\begin{aligned}
\operatorname{Cov}_{0}= & 2 \sigma_{w}^{2} /(1+\alpha)+2 \sigma_{v}^{2} \\
\operatorname{Cov}_{1}= & -\sigma_{w}^{2}(1-\alpha) /(1+\alpha)-\sigma_{v}^{2} \\
& \vdots \\
\operatorname{Cov}_{d}= & -\sigma_{w}^{2} \alpha^{d-1}(1-\alpha) /(1+\alpha) .
\end{aligned}
$$

We estimate the parameters $\sigma_{w}^{2}, \sigma_{v}^{2}$, and $\alpha$ using weighted generalized method of moments (GMM), minimizing the distance between the theoretical and empirical first twelve autocovariances. The estimated parameters are presented in table 2. Because we include an individual fixed effect (and possibly also because of the different definition of income), these estimated processes are much less persistent than those estimated by Hubbard, Skinner, and Zeldes, and a little less persistent 
Table 2. Estimated Age-Income Process Parameters for Households in the Labor Force $^{\text {a }}$

\begin{tabular}{lccc}
\hline Parameter & $\begin{array}{c}\text { High school } \\
\text { dropouts }\end{array}$ & $\begin{array}{c}\text { High school } \\
\text { graduates }\end{array}$ & $\begin{array}{c}\text { College } \\
\text { graduates }\end{array}$ \\
\hline$\alpha$ & 0.511 & 0.688 & 0.686 \\
Variance of $\epsilon$ & $(0.013)$ & $(0.004)$ & $(0.009)$ \\
Variance of $v$ & 0.073 & 0.052 & 0.059 \\
& $(0.012)$ & $(0.005)$ & $(0.005)$ \\
& 0.043 & 0.024 & 0.013 \\
& $(0.008)$ & $(0.003)$ & $(0.007)$ \\
\hline
\end{tabular}

Source: Authors' calculations based on data from the PSID, 1980-92.

a. A household is in the labor force if any member works 1,500 hours in the current year or in any future year. Characteristics are from the following panel regression model:

$y_{i t}=\alpha_{1}(F S)_{i t}+\left(1\right.$, age, age $^{2}$, age $\left.^{3}\right) \boldsymbol{\alpha}_{2}+\alpha_{3}(T E)_{i t}+$ (cohort dummies) $\boldsymbol{\alpha}_{4}+\zeta_{i t}$

$\xi_{i t}=\zeta_{i}+U_{i t}+v_{i t}=\zeta_{i}+\alpha U_{i, t-1}+v_{i, t}$,

where $y_{i t}$ is the natural $\log$ of nonasset income of household $i$ in year $t,(F S)_{i t}$ is a family size effect, $(T E)_{\text {it }}$ is a time effect given by the unemployment rate in the household's home state, and $\zeta_{\text {it }}$ is a disturbance term. The coefficient $\alpha$ and the variances of $\epsilon$ and $\nu$ are estimated using the generalized method of moments. Standard errors are in parentheses.

than that used by Engen, Gale, and Scholz. ${ }^{50}$ To calibrate the stochastic component of postretirement income, we set $\sigma_{R}^{2}=0.05$, a value somewhat lower than that of $\sigma_{w}^{2}$. Most authors do not assume any stochastic component in pension income. We do so for technical reasons: income uncertainty reduces behavioral pathologies - such as nonmonotonicities and discontinuities in the consumption function-in dynamic games. ${ }^{51}$

To calculate the typical retirement age by educational group, we look at PSID households that experienced the transition to retirement during the sample period. We record the age of each household head in the last year when any member of the household worked more than 500 hours. We then calculate the mean of these retirement ages within each educational group. Finally, we assume that each of the simulated households retires at the mean age for its respective educational group. For households whose head did not graduate from high school, the simulated retirement age is sixty-one; for those with high school graduate and college graduate heads, the mean ages are sixty-three and sixtyfive, respectively.

Given our income estimates, the implicit mean replacement rates at retirement are 41 percent for the low-education group, 45 percent for high school graduates, and 55 percent for college graduates (or relative to the average of the highest three years' earnings while in the labor

50. Hubbard, Skinner, and Zeldes (1994); Engen, Gale, and Scholz (1994).

51. See Laibson (1997b). 
force, 38 percent, 38 percent, and 47 percent, respectively). The replacement rates at retirement are therefore higher for the collegeeducated group, contrary to the calibration of Engen, Gale, and Scholz. However, since real retirement income falls faster for this group, the ratio of average retirement income to the average of the highest three years' earnings is smaller for highly educated households: 31 percent compared with 41 percent for the other educational categories.

BEQUESTS. To estimate the age distribution of inheritances, we use data from the 1984 PSID. In that year, respondents were asked whether they had received a bequest during the past five years. However, the PSID does not contain information on the source of bequests. In order to correct for intrahousehold bequests, we set to zero the inheritances received by households for which the marital status of the head changed from married to widowed over the previous seven years. ${ }^{52}$

We run a probit regression to estimate age-dependent probabilities of receiving a bequest. The independent variables are a third degree polynomial in age, a constant, and two educational dummy variables. We assume that the age polynomial is the same for each of the three educational groups, but allow for different means. We do not estimate a separate regression for each group, because there are very few observations for some groups at certain ages. The regression results are reported in table 3 , and the probabilities of receiving a bequest are plotted in figure 3. Our estimation procedure yields the expected humpshaped pattern of bequests, but the peak probabilities occur at age sixtyseven, suggesting that the parents of these recipients die in their nineties. This puzzle is mitigated by the fact that, in general, bequests are not received until both parents have died.

We also estimate the age profile of bequest magnitudes (conditional on having received a bequest). To do so, we restrict the sample to households with positive bequests. We estimate a regression for the natural logarithm of bequests on education dummies and a third degree polynomial in age. Figure 4 plots the exponentiation of this polynomial, and table 3 also reports the associated regression results, including the estimated variance of the disturbance term that is used to calibrate $\sigma_{B}^{2}$. The bequest magnitudes show a sharp rise late in life, which is driven

52. Note that this method eliminates spousal bequests irrespective of whether the decedent was formerly the head of the household. The correction eliminates sixty of the 462 reported bequests. 
Table 3. Estimated Age-Bequest Profiles from Regressions

\begin{tabular}{lcc}
\hline \multirow{2}{*}{$\begin{array}{l}\text { Independent } \\
\text { variable }\end{array}$} & \multicolumn{2}{c}{ Dependent variable } \\
\cline { 2 - 3 } & $\begin{array}{c}\text { Probability of }_{\text {bequest }^{\mathrm{a}}} \\
\text { Age }\end{array}$ & $\begin{array}{c}\text { Log size of } \\
\text { bequest }^{\mathrm{b}}\end{array}$ \\
$\mathrm{Age}^{2} / 100$ & -0.056 & 0.379 \\
& $(0.058)$ & $(0.195)$ \\
Age $^{3} / 10,000$ & 0.176 & -0.673 \\
& $(0.124)$ & $(0.415)$ \\
Dummy variables & -0.134 & 0.393 \\
High school dropout & $(0.084)$ & $(0.280)$ \\
High school graduate & & \\
College graduate & -0.698 & 2.217 \\
& $(0.091)$ & $(2.893)$ \\
Constant & -0.375 & 2.737 \\
& $(0.071)$ & $(2.875)$ \\
& & 2.939 \\
\end{tabular}

Summary statistic

Variance of error term

0.09

Source: Authors' calculations based on data from the PSID, 1984.

a. Coefficients from a probit model. Dependent variable is equal to 1 if the household received at least one bequest during $1980-84$, and to zero otherwise. Spousal bequests are excluded. Standard errors are in parentheses.

b. Dependent variable is the natural log of bequests received by the household during 1980-84. Panel is restricted to observations in which a positive bequest occurs. Households whose head is older than eighty years and spousal bequests are excluded. Standard errors are in parentheses.

by the actual reported bequests of the elderly and is not due to an endpoint polynomial effect. ${ }^{53}$

TAXES. We assume a progressive tax structure with marginal tax rates of 15 percent for income up to $\$ 41,200 ; 28$ percent for income between $\$ 41,200$ and $\$ 99,600$; and 31 percent for income above $\$ 99,600$. We also allow for a standard deduction of $\$ 6,900$ and a personal exemption of $\$ 2,650$. Contributions to the DC pension are tax-deductible, and withdrawals are taxed at the relevant marginal tax rate. This structure mimics the 1997 federal tax rates for married couples filing jointly,

53. We restrict our bequest magnitude regression to households whose head is aged eighty or younger, and then extrapolate the curve out through age ninety. When we ran the regression for the complete population, the rapid rise in the bequest magnitude function late in life was even more dramatic. There is a small number of very old households that report receiving very large bequests. 
Figure 3. Estimated Probability of Receiving a Bequest, by Age ${ }^{\text {a }}$ Probability

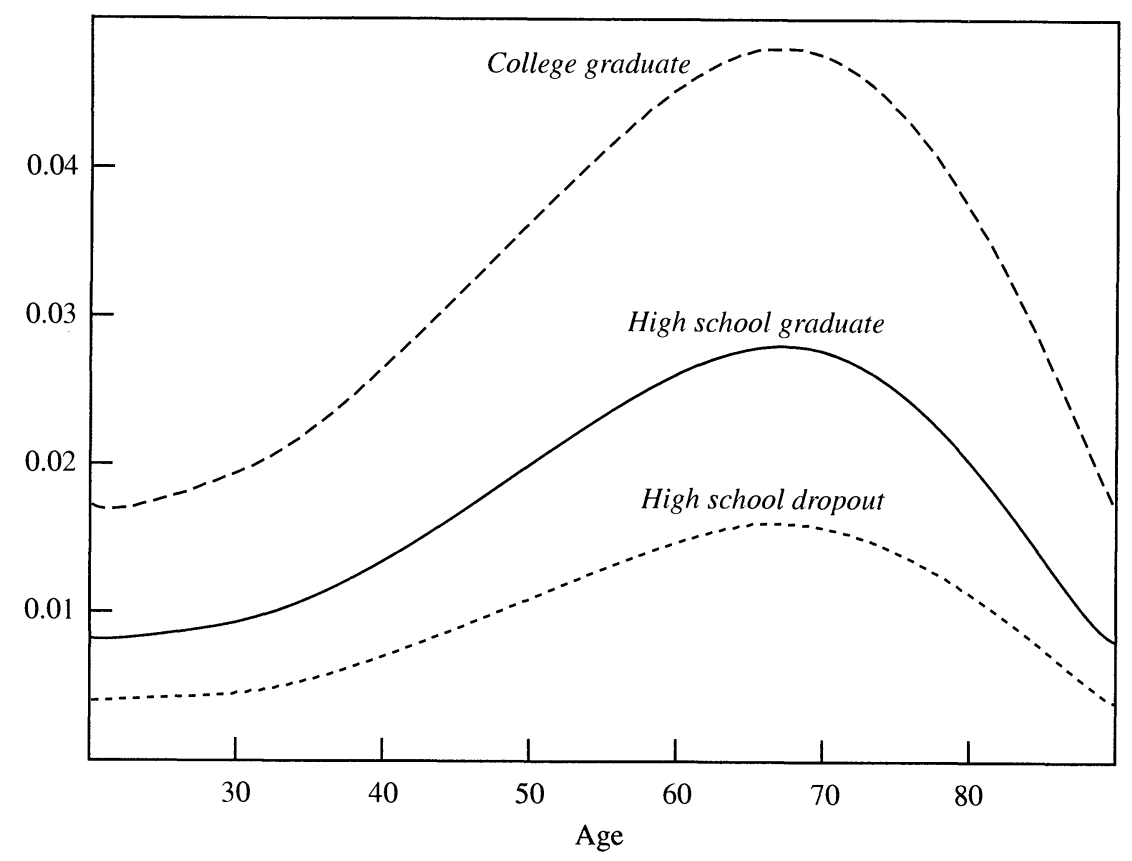

Source: See table 3.

a. Figure plots the probability of receiving a bequest, by age and educational group. Values are calculated from a probit regression on a cubic polynomial in age and educational dummies; see table 3 for details.

except that we excluded the 36 percent and 39.6 percent tax brackets, since almost none of our simulated consumers receives enough income to qualify for these higher brackets. ${ }^{54}$

ASSETS AND THE DYNAMIC BUDGET CONSTRAINT. We set the value of the pretax real interest rate equal to 5 percent, consistent with Engen, Gale, and Scholz. Further, we assume that employers match 50 percent of DC plan contributions up to the first 6 percent of pay (that is, $\phi=$ $0.5, \psi=0.06$ ). This is by far the most common matching arrangement for $401(\mathrm{k})$ plans, and is reported by 21 percent of the firms in a survey

54. The 36 percent bracket starts at an income level of $\$ 151,750$. 
Figure 4. Estimated Age-Bequest Profiles ${ }^{a}$

Bequest (thousands of 1990 dollars)

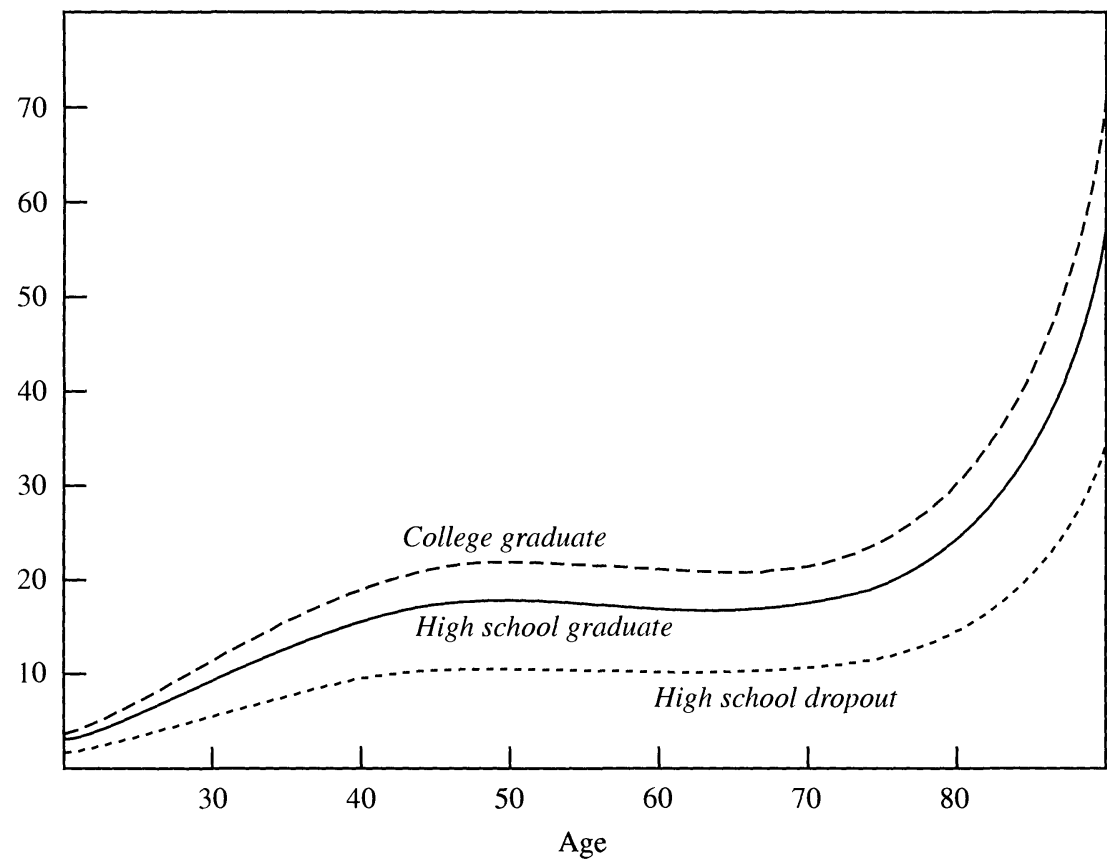

Source: See table 3.

a. Figure plots, by age and educational group, the magnitude of bequests received, conditional on receiving a positive bequest. Values are calculated from a regression of the natural log of bequests on a cubic polynomial in age and educational dummies; see table 3 for details.

of such plans conducted by Hewitt Associates. ${ }^{55}$ We also consider the no match case (that is, $\phi=0$ ).

\section{Preference Parameters}

In this section we describe our choice of preference parameters.

\section{Coefficient of Relative Risk Aversion}

We adopt a utility function with a constant coefficient of relative risk aversion. In the benchmark calibration, we set the coefficient of relative

55. Hewitt Associates (1997). 
risk aversion, $\rho$, equal to 1 (log utility). To support this choice, we offer four observations. First, estimation procedures that do not require linearization or aggregation of the Euler equation have yielded estimated values below one for the coefficient of relative risk aversion. Gourinchas and Parker, for example, report a point estimate of 0.5. ${ }^{56}$

Second, estimation procedures that are based on first order linearization of the Euler equation and focus on consumers with high levels of liquid wealth-effectively controlling for second order terms-have yielded values near 1 for the coefficient of relative risk aversion. For example, Zeldes runs separate analyses for consumers who are liquidity constrained and those who are not. ${ }^{57}$ Assuming that the second order terms in the Euler equation are small for the unconstrained consumers, one can calculate estimates of the coefficient of relative risk aversion for those consumers: Zeldes's point estimates imply values that lie between 0.7 and 2.3. John Shea also splits his sample into constrained and unconstrained consumers, and his point estimates from the highwealth consumers imply values that lie between 0.2 and $0.4 .^{58}$ Neither author's results are estimated with high precision, however. ${ }^{59}$

Third, estimation procedures that are based on linearization of the Euler equation but do not control for second order terms yield highly mixed results. ${ }^{60}$ Fourth, such estimation procedures, which rely on variation in the aftertax interest rate to measure the elasticity of intertemporal substitution, do not identify the value of the coefficient of relative risk aversion. This point has recently been established by Carroll, who shows that the response of liquidity-constrained consumers-

56. Gourinchas and Parker (1997). Hansen and Singleton (1982) use a GMM framework to estimate $\rho$ with aggregate data. They report point estimates between 0.6 and 1 , but we are skeptical of the representative agent methodology that they use.

57. Zeldes (1989).

58. Shea (1995).

59. We are skeptical of the analyses of Zeldes and Shea, because they identify variation in the interest rate by using marginal tax rates. This technique implicitly assumes that the aftertax rate of return falls with income-a hypothesis that our accountants do not accept.

60. Hall's (1988) results imply that the measured elasticity of intertemporal substitution is probably between 0 and 0.2 . This finding is supported by Campbell and Mankiw (1989). But it is contradicted by Mankiw, Rotemberg, and Summers (1985), who find that the measured elasticity of intertemporal substitution is greater than unity, and by Beaudry and van Wincoop (1996), who find that it is equal to unity. Note that in a world of complete markets, the measured elasticity of intertemporal substitution is equal to the inverse of the coefficient of relative risk aversion. 
for example, buffer stock consumers-to changes in the interest rate will be muted, implying that the measured elasticity of intertemporal substitution will be less than the inverse of the coefficient of relative risk aversion. ${ }^{61}$ We have confirmed Carroll's finding and quantify the effect in a life cycle context. With $\rho$ equal to 1 , the measured elasiticity of intertemporal substitution in our hyperbolic model is 0.22 , which is consistent with the available empirical evidence. We return to this result below, in describing the properties of our simulated model.

The coefficient of relative risk aversion governs risk aversion, prudence, and the willingness of consumers to substitute consumption intertemporally. If $\rho$ is relatively large, household saving decisions will be relatively insensitive to the introduction of a tax-deferred saving instrument that raises the aftertax rate of return. Also, a higher $\rho$ generates more precautionary savings for the same level of income uncertainty, increasing the opportunities for asset shifting. Hence the choice of this parameter has important implications for the efficacy of a DC plan.

We also consider the case when $\rho$ is equal to 3 , both to demonstrate that our results are highly sensitive to the choice of $\rho$, and so that our results can be compared with those of Engen, Gale, and Scholz.

\section{Time Preference Parameter $\beta$}

We simulate below hyperbolic economies and exponential economies. In doing so, we assume that an economy is either populated exclusively by hyperbolic consumers - with $\beta$ equal to 0.85 - or exclusively by exponential consumers-with $\beta$ equal to 1 .

For the hyperbolic simulations, we would have preferred to have set $\beta$ much lower-approximately equal to 0.6 - as Laibson has done in previous work on undersaving. ${ }^{62}$ Most of the experimental evidence suggests that the one-year discount rate is at least 40 percent.$^{63}$ However, a value of 0.6 generates pathologies in discrete time simulations: strongly nonmonotonic and noncontinuous consumption functions. Such effects are commonplace in dynamic games such as the intrapersonal game that we consider. ${ }^{64}$ In our simulations, these pathologies

61. Carroll (1997b).

62. Laibson (1996).

63. See Ainslie (1992) for a review.

64. See Laibson (1997b) for an analysis of these effects. 
vanish as $\beta$ approaches unity. Specifically, we find that strong pathologies only arise for values of $\beta$ below 0.8 , which motivates our decision to adopt a value of 0.85 .

It has recently been numerically shown that such pathologies are sensitive to the amount of stochastic variation in the income process: increasing the income variation drives out the pathologies ${ }^{65}$ However, we choose not to pursue this "fix," since in our model the income processes are exogenously calibrated.

It can also be shown that the discontinuities vanish if the model is implemented in continuous time ${ }^{66}$ Hence the discrete time framework that we use implicitly limits the range of the parameter space that can be used to generate sensible results. Nevertheless, it is possible to get some idea of how the model would perform if the value of $\beta$ were below 0.85 . Specifically, one can rerun the simulations for values of $\beta$ in the neighborhood of 0.85 - say 0.8 - and use the local change in results to estimate the effect of much lower values. We pursue this extrapolation exercise below and find that the hyperbolic effects increase approximately linearly in the gap between $\beta$ and 1 .

\section{Time Preference Parameter $\delta$}

Having fixed all of the other parameters, we are left with three free parameters in the hyperbolic economy- $\delta_{\text {hyperbolic }}^{N H S}, \delta_{\text {hyperbolic }}^{H S}, \delta_{\text {hyperbolic }}^{\text {COLL }}$ and three free parameters in the exponential economy- $\delta_{\text {exponential }}^{N H S}$, $\delta_{\text {exponential }}^{H S}, \delta_{\text {exponential }}^{C O L L}$. The superscripts $N H S, H S$, and COLL represent the three educational categories, did not graduate from high school, high school graduate, and college graduate, respectively. We pick values of $\delta$ so that our simulations replicate actual levels of preretirement wealth holding, according to data taken from the Federal Reserve's Survey of Consumer Finances (SCF) for 1983. Specifically, we pick $\delta$ such that the simulated median ratio of wealth to income for individuals between the ages of fifty and fifty-nine matches the actual median in the data.

Although IRAs and 401(k)s were introduced in the 1970s_-in 1974 and 1978, respectively-their use was not initially widespread. Eligibility for IRAs was made universal in 1982, and only 13.3 percent of households with at least one employed member were eligible for

65. See Laibson (1997b).

66. At least in theory, the nonmonotonicities may persist. 
Table 4. Calibrated Long-Term Discount Rates ${ }^{\mathrm{a}}$

Rate

\begin{tabular}{lccccc}
\hline & \multicolumn{2}{c}{ Exponential consumers } & & \multicolumn{2}{c}{ Hyperbolic consumers } \\
\cline { 2 - 2 } Education & CRRA $=1^{\mathrm{b}}$ & CRRA $=3^{\mathrm{b}}$ & & CRRA $=1^{\mathrm{b}}$ & CRRA $=3^{\mathrm{b}}$ \\
\hline High school dropouts & 0.0490 & 0.0870 & & 0.0360 & 0.0745 \\
High school graduates & 0.0385 & 0.0590 & & 0.0275 & 0.0485 \\
College graduates & 0.0305 & 0.0395 & & 0.0205 & 0.0295 \\
\hline
\end{tabular}

Source: Authors' calculations.

a. Table reports the long-term discount rates $(1-\delta)$ generated by the authors' calibration exercise. Rates exclude mortality effects.

b. CRRA denotes coefficient of relative risk aversion in this and following tables and figures, as applicable.

401(k)s in $1984 .{ }^{67} \mathrm{We}$ therefore take the 1983 data as an approximation of a no DC plan steady state. We simulate a no DC plan economy and search for the values of $\delta$ that match the 1983 accumulation levels. We then use the same values of $\delta$ for the DC plan simulations. We choose to calibrate consumer preferences by matching the characteristics of a no DC plan steady state, because the U.S. economy is still in transition from the no DC plan steady state to the DC plan steady state.

In the $1983 \mathrm{SCF}$, the median ratio of net wealth to income is 1.83 for households whose head did not graduate from high school, 2.66 for households whose head's highest educational attainment is a high school diploma, and 3.59 for households whose head has a college degree. ${ }^{68}$ The discount rates $(1-\delta)$ that replicate these wealth-toincome ratios are reported in table 4. Four properties stand out. First, these discount rates fall with educational attainment. Since the shape of the labor income profile is roughly similar across educational groups, a relatively low discount rate is needed to replicate the relatively high wealth-to-income ratio of the highly educated. Second, the discount rates rise with the coefficient of relative risk aversion. Since precautionary saving rises with the coefficient of relative risk aversion, an increase in the discount rate is needed to offset an increase in the coefficient of relative risk aversion. Third, the discount rates for hyperbolic consumers are lower than those for exponential consumers. Since hyperbolic consumers have two sources of discounting, $\beta$ and $\delta$,

67. See Poterba, Venti, and Wise (1995). They consider the population of households whose head is aged between twenty-five and sixty-five, where at least one employed member of the household is not self-employed.

68. Our definition of net worth includes liquid assets and illiquid assets; for more details, see text below. 
the hyperbolic $\delta$ 's must be higher than the exponential $\delta$ 's. Recall that the hyperbolic and exponential discount functions are calibrated to generate the same amount of preretirement wealth accumulation. In this manner, we "equalize" the underlying willingness to save of the exponential and the hyperbolic consumers before we introduce the DC plan. Fourth, all of the calibrated long-term discount rates are sensible, falling between 0.02 and 0.09 . Note, however, that they do not include mortality effects, which add roughly another 0.01 , generating net discount rates.

Our calibration of preference parameters can be compared with that of Engen, Gale, and Scholz. These authors do not adopt different discount factors for households with different levels of educational attainment, but we compare our high school calibration to their aggregate calibration (recall that the high school group represents half of U.S. households). For exponential consumers with $\rho$ equal to 3 , we adopt a high school discount rate of 0.059 , significantly larger than Engen, Gale, and Scholz's discount rate of 0.04. This difference makes the DC plan more effective in our simulations, since households with relatively high discount rates have lower levels of accumulation and are less likely to hit the DC plan contribution caps, strengthening the substitution effect.

\section{The Calibrated Economy without a Defined Contribution Plan}

In this section we analyze the properties of our calibrated economies without a DC plan, and all discussion pertains to these economies, unless otherwise noted. Our first finding is that the hyperbolic and exponential economies are observationally very similar. Figure 5 plots the average levels of consumption, pretax income, and asset accumulation of exponential, log utility consumers in the high school graduate group. The corresponding graphs for the other educational groups are qualitatively similar. Figure 6 plots the path of a single exponential consumer. These figures are similar to their hyperbolic analogs, figures 7 and 8; at first glance, it is hard to differentiate between them. The only discernible contrast is that hyperbolic consumers hold less buffer stock wealth early in life than do exponential consumers. Figure 9 plots the consumption functions of an exponential consumer and a hyperbolic 
Figure 5. Simulated Average Liquid Asset, Income, and Consumption Paths, Exponential Households ${ }^{a}$

Thousands of 1990 dollars

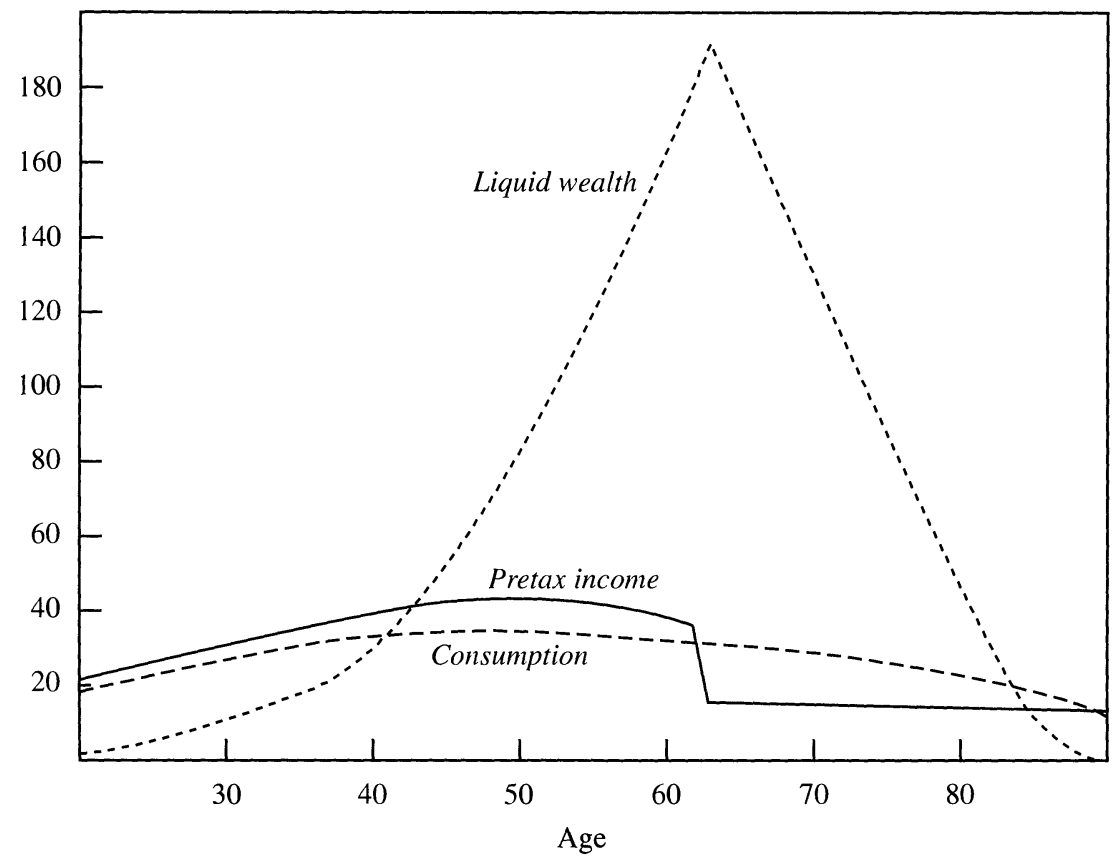

Source: Author's' simulations.

a. Figure plots average values for households with high school graduate head. The coefficient of relative risk aversion is equal to 1 .

one. The rough similarity of these functions further underscores the difficulty of distinguishing exponential from hyperbolic consumers. ${ }^{69}$

Our calibrated exponential and hyperbolic economies replicate empirical life-cycle patterns documented by other authors. ${ }^{70}$ Consumption closely tracks income, rising early in life and then falling, as "hump" saving accelerates in the two decades before retirement (see figures 5 and 7). Comovement between consumption and income is also apparent at higher frequencies (see figures 6 and 8). These basic empirical reg-

69. The hyperbolic consumption function is nonmonotonic, but this pathology vanishes as one increases the fineness of the partition of the state space and increases the number of states in the discrete approximation of the stochastic income process.

70. See Carroll (1992, 1997a); Gourinchas and Parker (1997); Hubbard, Skinner, and Zeldes (1994). 
Figure 6. Simulated Liquid Asset, Income, and Consumption Paths of One Exponential Household ${ }^{a}$

Thousands of 1990 dollars

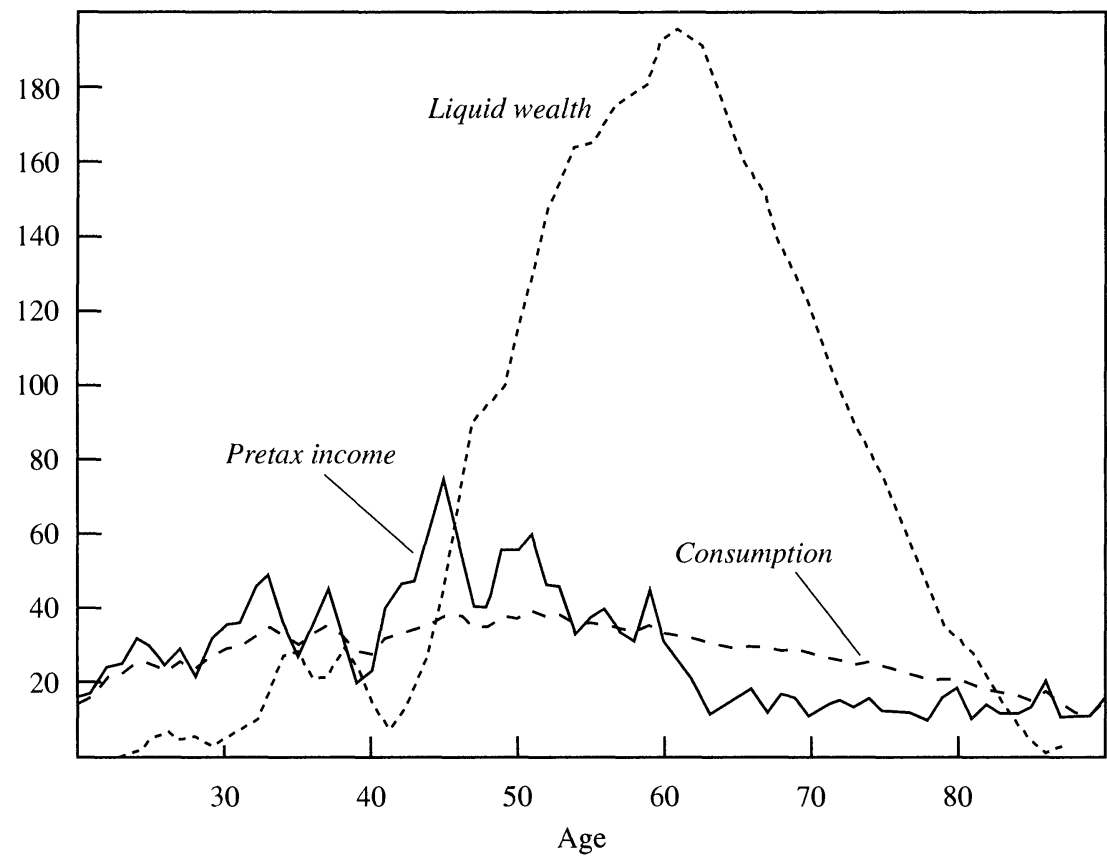

Source: Authors' simulations.

a. Figure plots values for a household with high school graduate head. The coefficient of relative risk aversion is equal to I.

ularities are consistent with both the exponential and the hyperbolic versions of the buffer stock model.

The exponential and hyperbolic models also imply similar levels of sensitivity to interest rate changes. Table 5 reports the measured elasticity of intertemporal substitution for both models. Conceptually, the measured elasticity of intertemporal substitution is the derivative

$$
\frac{d\left(\Delta \ln C_{i t}\right)}{d R}
$$

The table reports the average value of this derivative over the life cycle (weighted with survivorship probabilities), in the neighborhood of $R$ equal to 1.05 . Our numbers are equivalent to running an ordinary least 
Figure 7. Simulated Average Liquid Asset, Income, and Consumption Paths, Hyperbolic Households ${ }^{a}$

Thousands of 1990 dollars

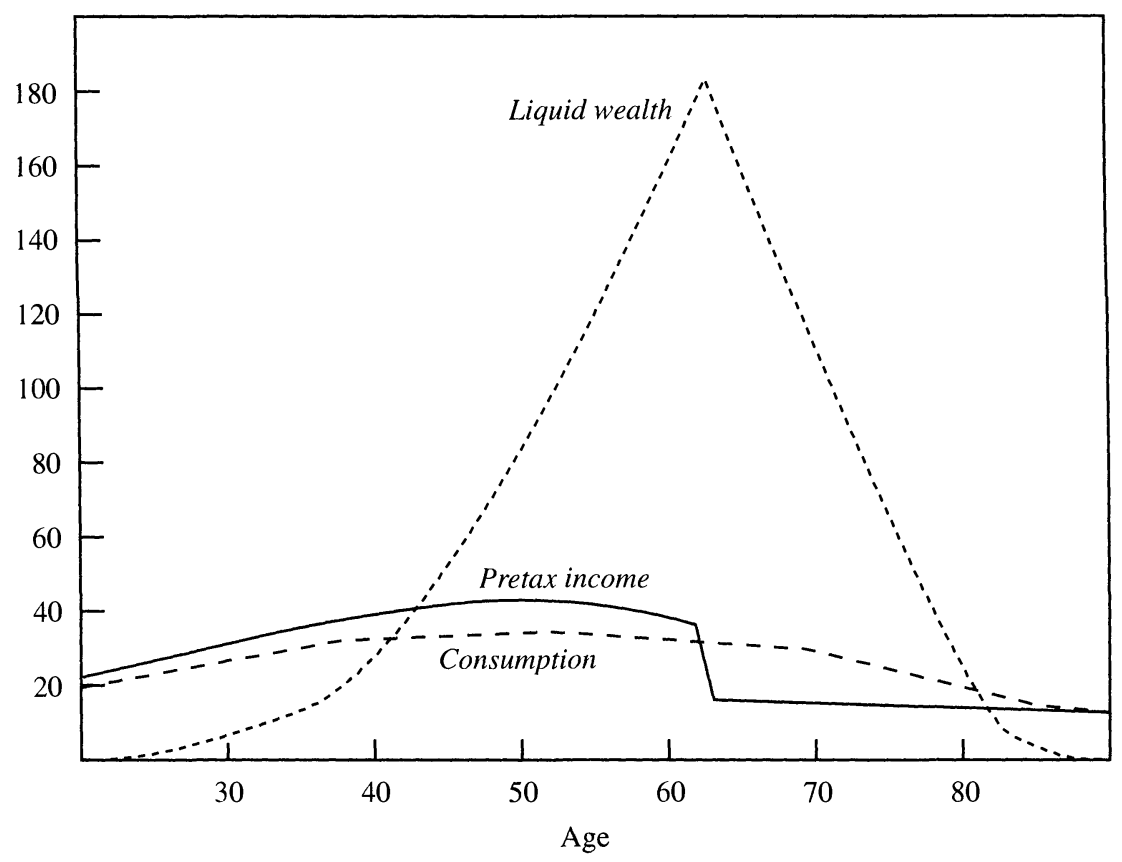

Source: Author's' simulations.

a. Figure plots average values for households with high school graduate heads.

squares regression of $\Delta \ln C_{i t}$ on a constant and the deterministic interest rate. ${ }^{71}$

When $\rho$ is equal to 1 , the measured elasticities of intertemporal substitution are 0.27 for the exponential model and 0.22 for the hyperbolic model. When $\rho$ is equal to 3 , they fall to 0.16 for the exponential model and 0.15 for the hyperbolic model. These values are well below the inverse of the coefficients of relative risk aversion, since, at least early in life, our households make choices in a buffer stock framework, implying that the slope of the consumption path is initially determined

71. We obtain almost identical numbers when we replace individual consumption growth, $\Delta \ln C_{i t}$, with the growth rate of average consumption within a cohort, $\Delta \ln \left(\sum C_{i t}\right)$. 
Figure 8. Simulated Liquid Asset, Income, and Consumption Paths of One Hyperbolic Household ${ }^{a}$

Thousands of 1990 dollars

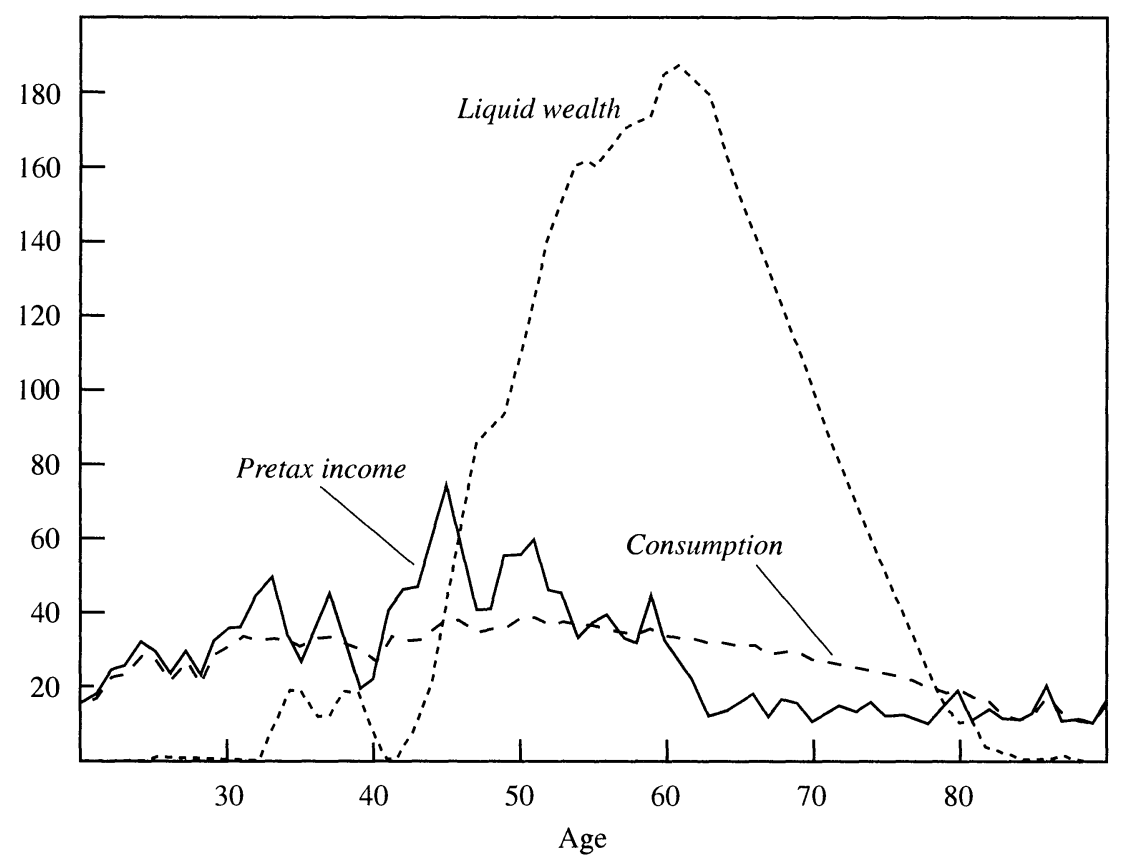

Source: Authors' simulations.

a. Figure plots values for a household with high school graduate head.

partly by the slope of the income path, rather than exclusively by the interest rate. ${ }^{72}$ As education increases-corresponding to a fall in the calibrated discount rates - the measured elasticity of intertemporal substitution rises. Patient households are less likely to be constrained by their income paths. Finally, although the measured hyperbolic elasticity of intertemporal substitution is close to the measured exponential elasticity of intertemporal substitution, the former is slightly smaller. This systematic gap reflects the fact that hyperbolic agents are much more likely to hit binding liquidity constraints.

In the body of this section we discuss two features of our simulations that distinguish the hyperbolic model from its exponential precursors:

72. See Carroll (1997b). 
Figure 9. Consumption Functions of Exponential and Hyperbolic Households ${ }^{a}$

Consumption (thousands of 1990 dollars)

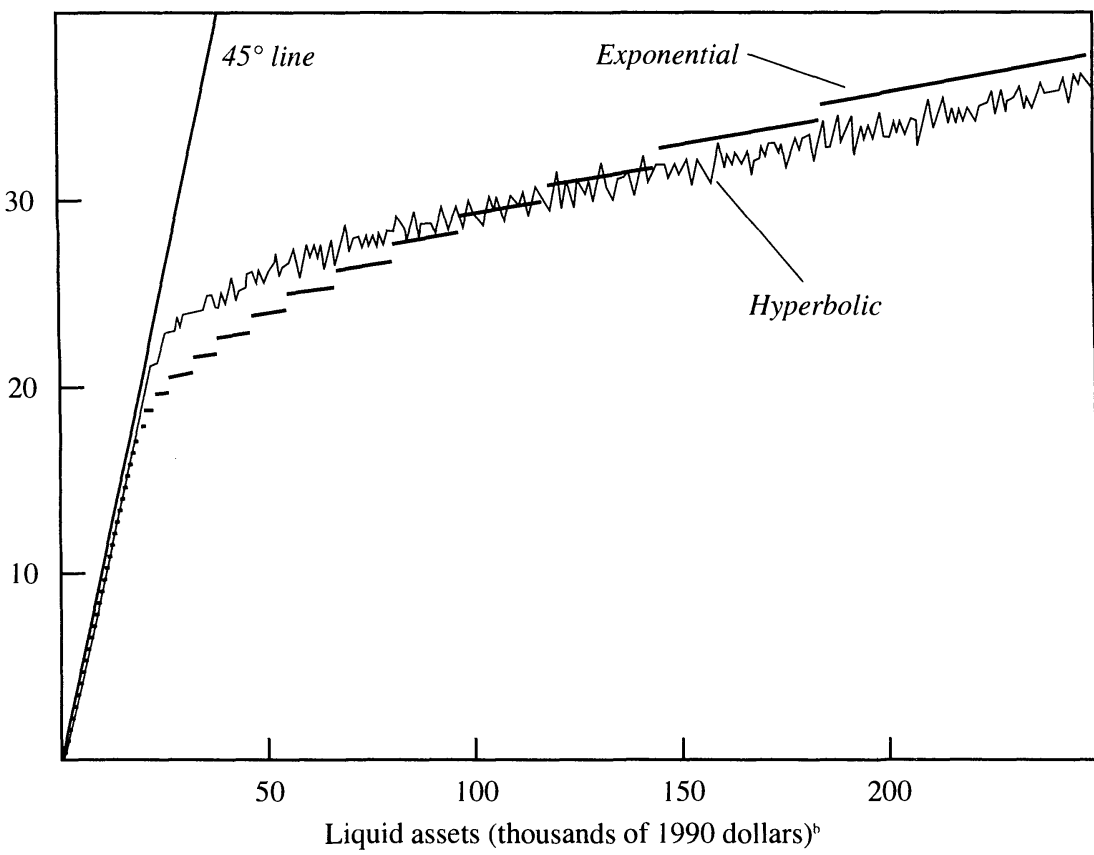

a. Figure plots consumption functions for exponential and hyperbolic households with median income among households whose heads are aged twenty and are high school graduates.

b. Includes liquid savings and current disposable income.

Table 5. Average Elasticities of Intertemporal Substitution ${ }^{\mathrm{a}}$

\begin{tabular}{lccccc}
\hline & \multicolumn{2}{c}{ Exponential consumers } & & \multicolumn{2}{c}{ Hyperbolic consumers } \\
\cline { 2 - 3 } Education & CRRA $=1$ & CRRA $=3$ & & CRRA $=1$ & CRRA $=3$ \\
\hline High school dropouts & 0.18 & 0.12 & & 0.15 & 0.12 \\
High school graduates & 0.25 & 0.16 & & 0.20 & 0.15 \\
College graduates & 0.40 & 0.18 & & 0.31 & 0.16 \\
Weighted average $^{\mathrm{b}}$ & 0.27 & 0.16 & & 0.22 & 0.15 \\
\hline
\end{tabular}

Source: Authors' simulations

a. Conceptually, the elasticity of intertemporal substitution is measured as the derivative

$$
\frac{d\left(\Delta \ln C_{i t}\right)}{d R},
$$

where $C_{i t}$ is consumption of individual $i$ at age $t$, and $R=1+r$ is the gross interest rate. Table reports the observed average value of this derivative over the life cycle of simulated individuals in three educational groups (weighting with survivorship probabilities), in the neighborhood of $R=1.05$.

b. Uses population weights. 
binding liquidity constraints and missing precautionary saving effects. Before discussing these phenomena, we introduce an analytic tool that provides the intuition for our analysis.

\section{The Generalized Euler Equation}

We present an heuristic derivation of a marginal condition that characterizes the equilibrium path of the hyperbolic economy. ${ }^{73}$ The heuristic derivation is based on a classical perturbation argument. The marginal benefit of postponing $\Delta>0$ units of consumption generates a stream of utility perturbations from the perspective of self $t$. At time $t$,

$$
\Delta u^{\prime}\left(C_{t}\right)
$$

utils are lost. Self $t$ expects to gain

$$
E_{t}\left[\beta \delta\left(\frac{\partial C_{t+1}}{\partial X_{t+1}}\right) R \Delta u^{\prime}\left(C_{t+1}\right)\right]
$$

utils at time $t+1$, assuming that the hazard rate of survival is unity, to reduce notation. Note that $\frac{\partial C_{t+j}}{\partial X_{t+j}}$ is the marginal consumption rate at period $t+j$. Self $t$ expects to gain

$$
E_{t}\left[\beta \delta^{2}\left(\frac{\partial C_{t+2}}{\partial X_{t+2}}\right)\left(1-\frac{\partial C_{t+1}}{\partial X_{t+1}}\right) R^{2} \Delta u^{\prime}\left(C_{t+2}\right)\right]
$$

utils at time $t+2$; and so on. The net effect sums to

$$
-\Delta u^{\prime}\left(C_{t}\right)+E_{t}\left\{\beta \sum_{i=1}^{\mathrm{T}+\mathrm{N}-t} \delta^{i}\left(\frac{\partial C_{t+i}}{\partial X_{t+i}}\right)\left[\prod_{j=1}^{i-1}\left(1-\frac{\partial C_{t+j}}{\partial X_{t+j}}\right)\right] R^{i} \Delta u^{\prime}\left(C_{t+i}\right)\right\} .
$$

Setting this expression less than or equal to zero and dividing by $\Delta$ yields an Euler equation:

$$
u^{\prime}\left(C_{t}\right) \geq E_{t}\left\{\beta \sum_{i=1}^{\mathrm{T}+\mathrm{N}-t} \delta^{i}\left(\frac{\partial C_{t+i}}{\partial X_{t+i}}\right)\left[\prod_{j=1}^{i-1}\left(1-\frac{\partial C_{t+j}}{\partial X_{t+j}}\right)\right] R^{i} u^{\prime}\left(C_{t+i}\right)\right\} .
$$

73. See Laibson (1996) for an earlier incarnation of this heuristic argument, and Laibson (1997b) for numerical confirmation that the Euler equation does in fact characterize the equilibrium path. See Harris and Laibson (1998) for an analytic approach. 
One could repeat this argument for $\Delta<0$ (assuming that the agent is never perfectly liquidity constrained), which would enable one to substitute an equality for the inequality in equation 11 . Consider the analogous Euler equation for period $t+1$ :

$$
\begin{aligned}
& u^{\prime}\left(C_{t+1}\right)= \\
& E_{t+1}\left\{\beta \sum_{i=1}^{T+N-(t+1)}\left(\delta^{i} \frac{\partial C_{t+1+i}}{\partial X_{t+1+i}}\right)\left[\prod_{j=1}^{i-1}\left(1-\frac{\partial C_{t+1+j}}{\partial X_{t+1+j}}\right)\right] R^{i} u^{\prime}\left(C_{t+1+i}\right)\right\} .
\end{aligned}
$$

Application of the law of iterated expectations and substitution of equation 12 in equation 11 yields

$$
\begin{aligned}
u^{\prime}\left(C_{t}\right)= & \\
& E_{t}\left\{\left[\left(\frac{\partial C_{t+1}\left(X_{t+1}\right)}{\partial X_{t+1}}\right) \beta \delta+\left(1-\frac{\partial C_{t+1}\left(X_{t+1}\right)}{\partial X_{t+1}}\right) \delta\right] R u^{\prime}\left(C_{t+1}\right)\right\},
\end{aligned}
$$

which Laibson refers to elsewhere as the generalized Euler equation. ${ }^{74}$ Note that equation 13 is identical to a standard Euler equation, except that the term in square brackets replaces the constant discount factor of the classical equation. The discounting term in the generalized Euler equation,

$$
\left[\left(\frac{\partial C_{t+1}\left(X_{t+1}\right)}{\partial X_{t+1}}\right) \beta \delta+\left(1-\frac{\partial C_{t+1}\left(X_{t+1}\right)}{\partial X_{t+1}}\right) \delta\right],
$$

is stochastic and varies linearly with next period's marginal propensity to consume. When $\beta$ is equal to 1 , this bracketed term is equal to $\delta-$ the standard exponential discounting case. When $\beta$ is less than 1 , this bracketed term is a weighted average of the one-period discount factor, $\beta \delta$, and the discount factor that applies in all future periods, $\delta$. The respective weights are tomorrow's marginal propensity to consume,

$$
\left(\frac{\partial C_{t+1}\left(X_{t+1}\right)}{\partial X_{t+1}}\right) \text {, and }\left(1-\frac{\partial C_{t+1}\left(X_{t+1}\right)}{\partial X_{t+1}}\right) \text {. }
$$

74. Laibson (1996). 
To interpret equation 13 and the time-varying stochastic discount factor, it is helpful to consider the polar cases of marginal propensities to consume equal to one and to zero. First, consider a consumer who is certain to be liquidity constrained next period; that is, $C_{t+1}=X_{t+1}$, implying a marginal propensity to consume of unity. In this scenario, any savings set aside at time $t$ will be spent in period $t+1$, implying that self $t$ effectively faces a two-period game. The Euler equation that characterizes self $t$ 's equilibrium action can be expressed as

$$
u^{\prime}\left(C_{t}\right) \geq E_{t}\left[R \beta \delta u^{\prime}\left(C_{t+1}\right)\right]
$$

where the hazard rate of survival, $s_{t}$, has again been set to unity, to simplify notation. Equation 15 holds with equality when savings are positive at time $t$. This equation can be derived directly with a simple perturbation argument. Self $t$ can use a marginal dollar to generate $u^{\prime}\left(C_{t}\right)$ utils at time $t$ or $E_{t}\left[R u^{\prime}\left(C_{t+1}\right)\right]$ expected utils at time $t+1$. The utils at time $t+1$ must be discounted, yielding the final equation. Note that equation 15 implies a great deal of impatience. The one-period discount factor is $\beta \delta$, implying a discount rate of roughly 20 percent, given our calibration values.

Now consider the case of a zero marginal propensity to consume. The generalized Euler equation reduces to

$$
u^{\prime}\left(C_{t}\right) \geq E_{t}\left[R \delta u^{\prime}\left(C_{t+1}\right)\right],
$$

which is identical to the classical Euler equation for a model with a discount factor of $\delta$. The intuition behind this case is less straightforward and is best understood by considering the general properties of the intrapersonal strategic conflict that arises with hyperbolic preferences.

From the perspective of self $t$, marginal utility in period $t+1$ is too low relative to marginal utility during subsequent periods: self $t+1$ " "underweights"' the future by factor $\beta$. Self $t$ would like to transfer resources to those future periods after $t+1$. When the marginal propensity to consume of self $t+1$ falls (holding all else equal), such transfers can be made more efficiently. Hence a low marginal propensity to consume in period $t+1$ is associated with less consumption at time $t$. As the marginal propensity to consume in period $t+1$ goes to zero, this transfer effect perfectly offsets the effect of $\beta$ less than 1 , recovering the classical Euler equation. 
For intermediate values of the marginal propensity to consume, the relevant endogenous discount factor is a weighted average of $\beta \delta$ and $\delta$, where the relevant weights are

$$
\left(\frac{\partial C_{t+1}\left(X_{t+1}\right)}{\partial X_{t+1}}\right) \text { and }\left(1-\frac{\partial C_{t+1}\left(X_{t+1}\right)}{\partial X_{t+1}}\right) \text {. }
$$

Consumers will exhibit a great deal of endogenous heterogeneity in implicit patience levels over the life cycle. For consumers in our high school graduate group with coefficient of relative risk aversion equal to 1 , endogenous discount factors vary from $\beta \delta$ equal to $0.8266(0.85 \times$ 0.9725 ) to $\delta$ equal to 0.9725 . The range of variation would be even more dramatic if we had adopted a lower value for $\beta$.

This wide range of discount factors implies that hyperbolic agents occasionally behave very impatiently-and in doing so, are likely to meet binding liquidity constraints-while at other times they demonstrate a willingness to accumulate large stocks of wealth. In this framework, low levels of cash on hand are self-reinforcing: they imply a higher expected marginal propensity to consume (since consumption functions in buffer stock models are concave), which, in turn, lowers the endogenous discount factor. ${ }^{75}$ Hence, hyperbolic consumers with low levels of cash on hand tend to act like consumers with extremely high discount rates, increasing the likelihood that their liquidity constraints will turn out to be binding.

An alternative way to see these effects is to compare the consumption functions of exponential and hyperbolic agents. As can be seen from figure 9, hyperbolic agents are relatively more impatient at low levels of wealth holding - in this region the hyperbolic consumption function lies above the exponential function-and conversely, more patient at high levels of wealth holding. In summary, at low levels of wealth, hyperbolic consumers act like exponential consumers with low levels of patience. At high levels of wealth, hyperbolic consumers act like exponential consumers with high levels of patience.

75. For a proof that consumption functions are concave when consumers have exponential discount functions, see Carroll and Kimball (1996). Their proof does not carry over to the hyperbolic case. Nevertheless, in hyperbolic models, consumption functions are approximately concave; see figure 9. 


\section{Binding Liquidity Constraints}

Although we choose our calibration values so that exponential and hyperbolic consumers accumulate the same median level of preretirement assets, our results show that the hyperbolic consumers are much more likely to find themselves close to or at binding liquidity constraints. Figures 10 to 12 graph the percentage of exponential and hyperbolic households that are effectively liquidity constrained: that is, for households whose head did not graduate from high school, asset holdings of less than $\$ 250$; for households whose head has a high school diploma only, asset holdings of less than $\$ 400$; and for households whose head graduated from college, asset holdings of less than $\$ 500 .{ }^{76}$ We show results for coefficient of relative risk aversion equal to 1 and equal to 3. In all cases, the hyperbolic percentages lie well above the exponential percentages. Consider the first panel of figure 11, which plots the results for households in the high school graduate group with a coefficient of relative risk aversion equal to 1 . At age thirty-five, 40 percent of the hyperbolic consumers have less than $\$ 400$ in wealth, compared with only 21 percent of exponential consumers.

It is useful to compare these results with the percentages of liquidityconstrained consumers reported in the Survey of Consumer Finances. This exercise is not straightforward, however, since the SCF data are not directly comparable with the output from our simulations. Our timing assumption, equation 5 , implies that a consumer who always sets annual consumption equal to annual aftertax income (and never receives a bequest), will never have any positive asset holdings.

In the real world, by contrast, income is received at discrete intervals and consumption is implemented continuously. If workers are paid once a month, a consumer who spends all of his aftertax income will have average wealth holdings of two weeks of income. If this consumer saves part of his income for a major expenditure (for example, a vacation or Christmas gifts), his average holdings will be even greater. We adjust

76. Our cutoff of $\$ 250$ for households whose heads did not graduate from high school reflects the fact that in our simulations, households are constrained to lie on an asset grid. Since the grid for this educational group takes values $\{\$ 0, \$ 500, \$ 1000, \ldots\}$, we think of all consumers at 0 as having less than $\$ 250$ dollars in assets. The analogous grids for households in the high school graduate and college graduate groups increase in increments of $\$ 800$ and $\$ 1,000$, respectively. 
Figure 10. Share of High School Dropouts Who Are Liquidity Constrained, by Age

Percent of households
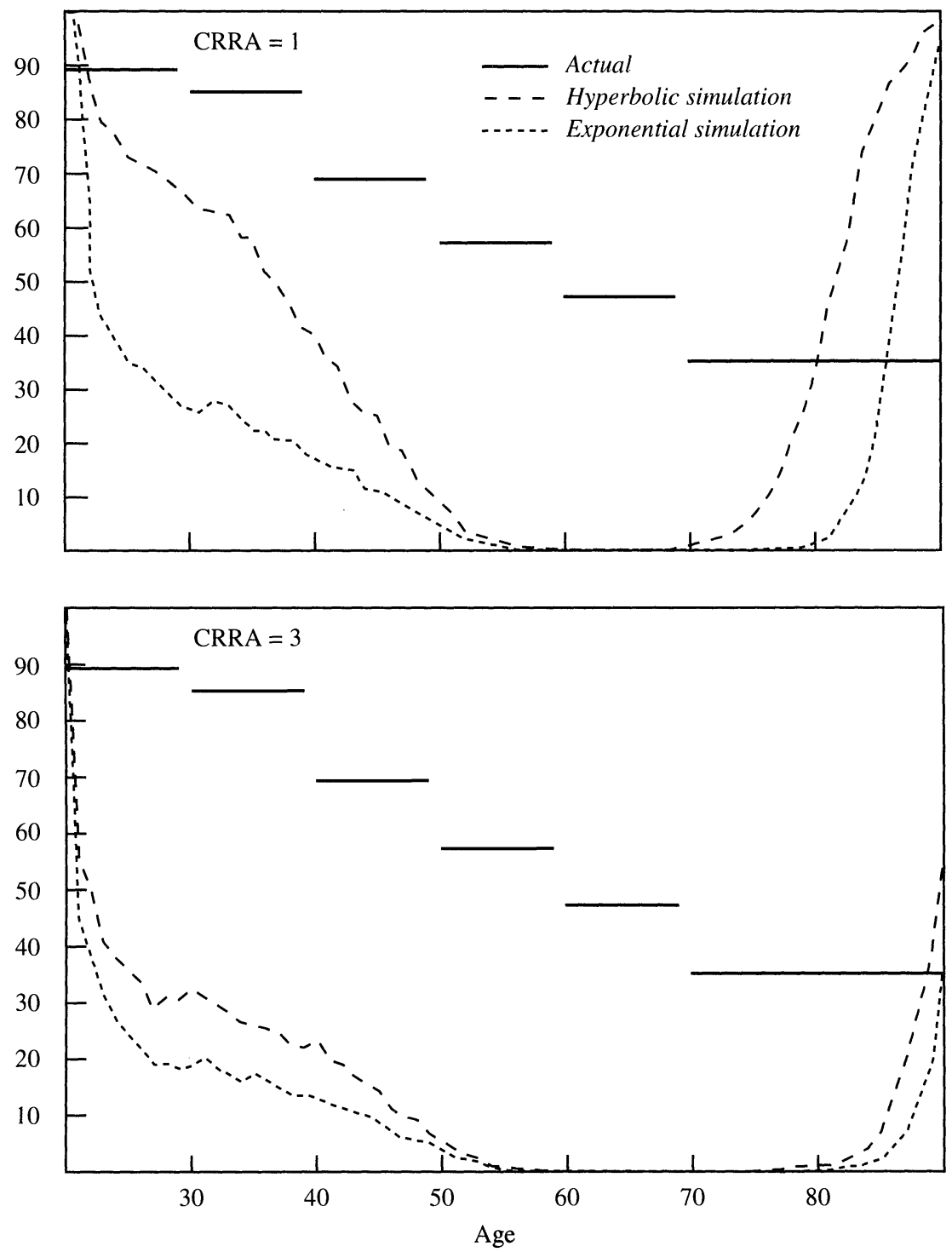

Source: Authors' simulations and the Federal Reserve's Survey of Consumer Finances (SCF), 1983

a. Figure plots percent of households with high school dropout heads that are liquidity constrained (less than $\$ 250$ in liquid assets) in the actual data and in the simulated hyperbolic and exponential economies. 
Figure 11. Share of High School Graduates Who Are Liquidity Constrained, by Age

Percent of households
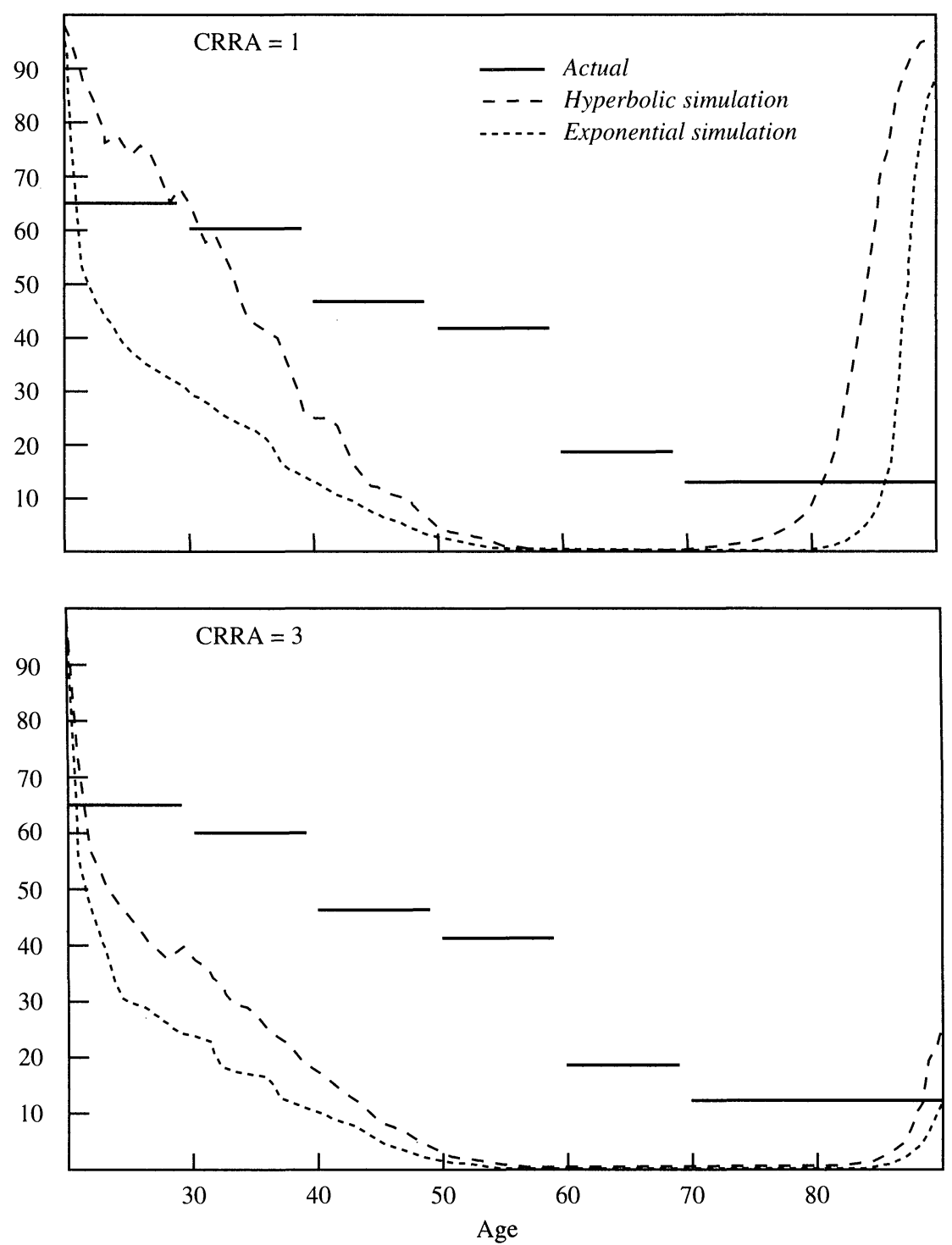

Source: Authors' simulations and SCF, 1983.

a. Figure plots percent of households with high school graduate heads that are liquidity constrained (less than $\$ 400$ in liquid assets) in the actual data and in the simulated hyperbolic and exponential economies. 
Figure 12. Share of College Graduates Who Are Liquidity Constrained, by Age ${ }^{\mathrm{a}}$

Percent of households
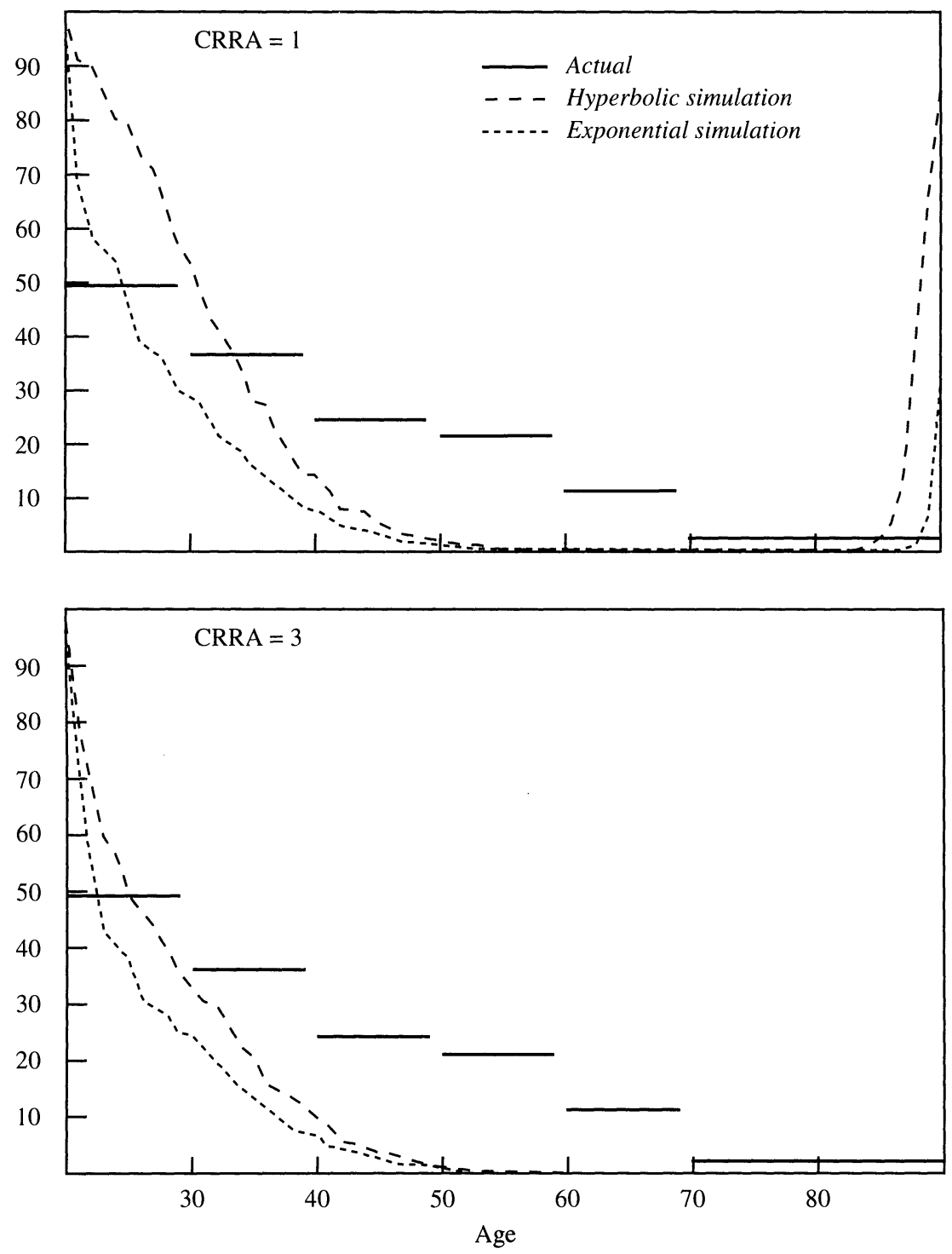

Source: Authors' simulations and SCF, 1983

a. Figure plots percent of households with college graduate heads that are liquidity constrained (less than $\$ 500$ in liquid assets) in the actual data and in the simulated hyperbolic and exponential economies. 
the SCF data to remove such intrayear savings. In tables 6 to 8 we report the percentage of households that are liquidity constrained-that is, households that hold assets valued below $n$ weeks of aftertax income, where $n=1,2,3,4$.

Another question that arises when comparing our results with the SCF data is whether a constrained consumer is one with low net worth or one with low liquid assets. Our definition of net worth includes liquid assets-checking accounts, savings accounts, money market accounts, call accounts, certificates of deposit, bonds, stocks, mutual funds, and cash, less credit card debt-and illiquid assets-IRAs, DC pension plans, life insurance, trusts, annuities, vehicles, home equity, real estate, business equity, jewelry, furniture, antiques, and home durables, less education loans. Few of these illiquid assets can be used to generate immediate liquidity without incurring substantial transaction costs. Indeed, many have commitment properties, which would make them appealing to hyperbolic consumers who do not want easy access to their money. We believe that a consumer may face an economically meaningful liquidity constraint even if he or she has many of the illiquid assets listed above.

Figures 10 to 12 also plot the percentage of liquidity-constrained consumers from the SCF (using the liquid asset data from the sixth row of tables 6 to 8). In each case, the percentage of liquidity-constrained consumers tends to lie above both simulation lines, but the hyperbolic line is closer to the actual data than the exponential line. When $\rho$ is equal to 1 , the hyperbolic line generally lies slightly below the actual data. When $\rho$ is equal to 3 , both the hyperbolic and exponential lines fall well below the actual data, although the hyperbolic line is closer.

These results are only suggestive, however, since the simulated percentages of liquidity-constrained consumers are downward biased (for both exponential and hyperbolic cases). Our benchmark simulations assume that there is only one asset and that it is liquid. Since illiquid and liquid assets are partial substitutes, our simulations bias upward the accumulation of liquid assets for both hyperbolic and exponential consumers. Future work should evaluate the simulated percentage of liquidity-constrained consumers in an economy with both liquid assets and illiquid assets such as real estate and durables. 


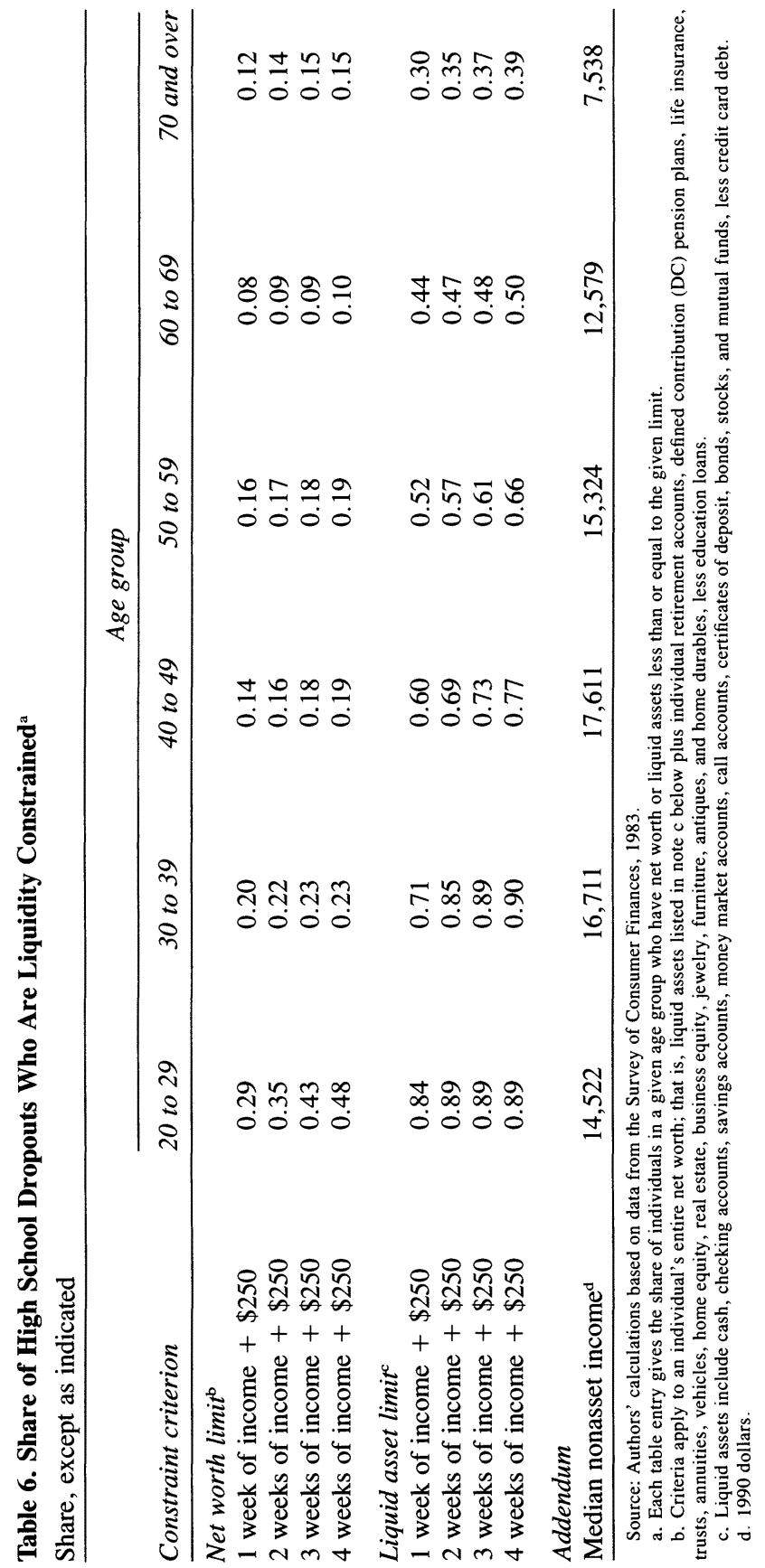




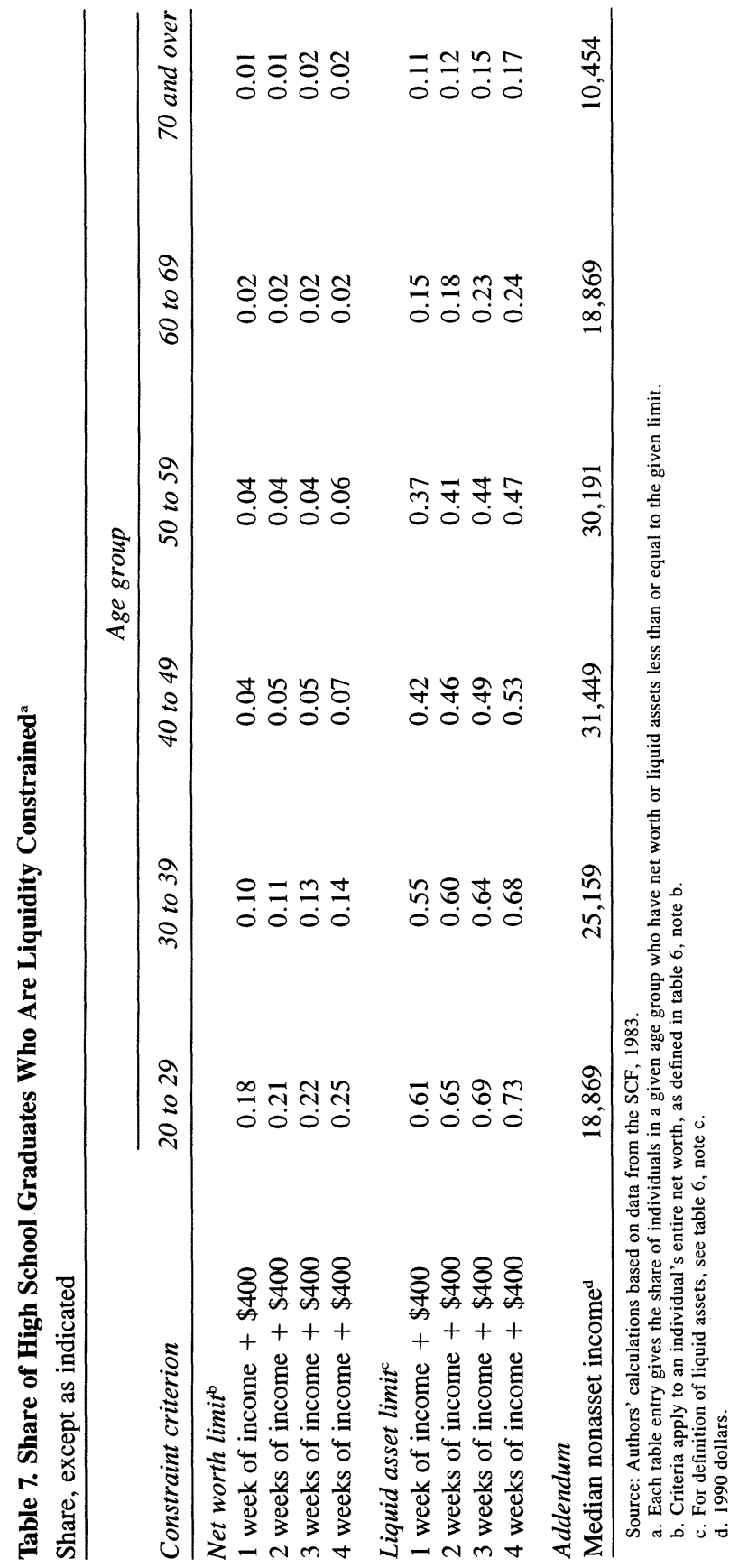




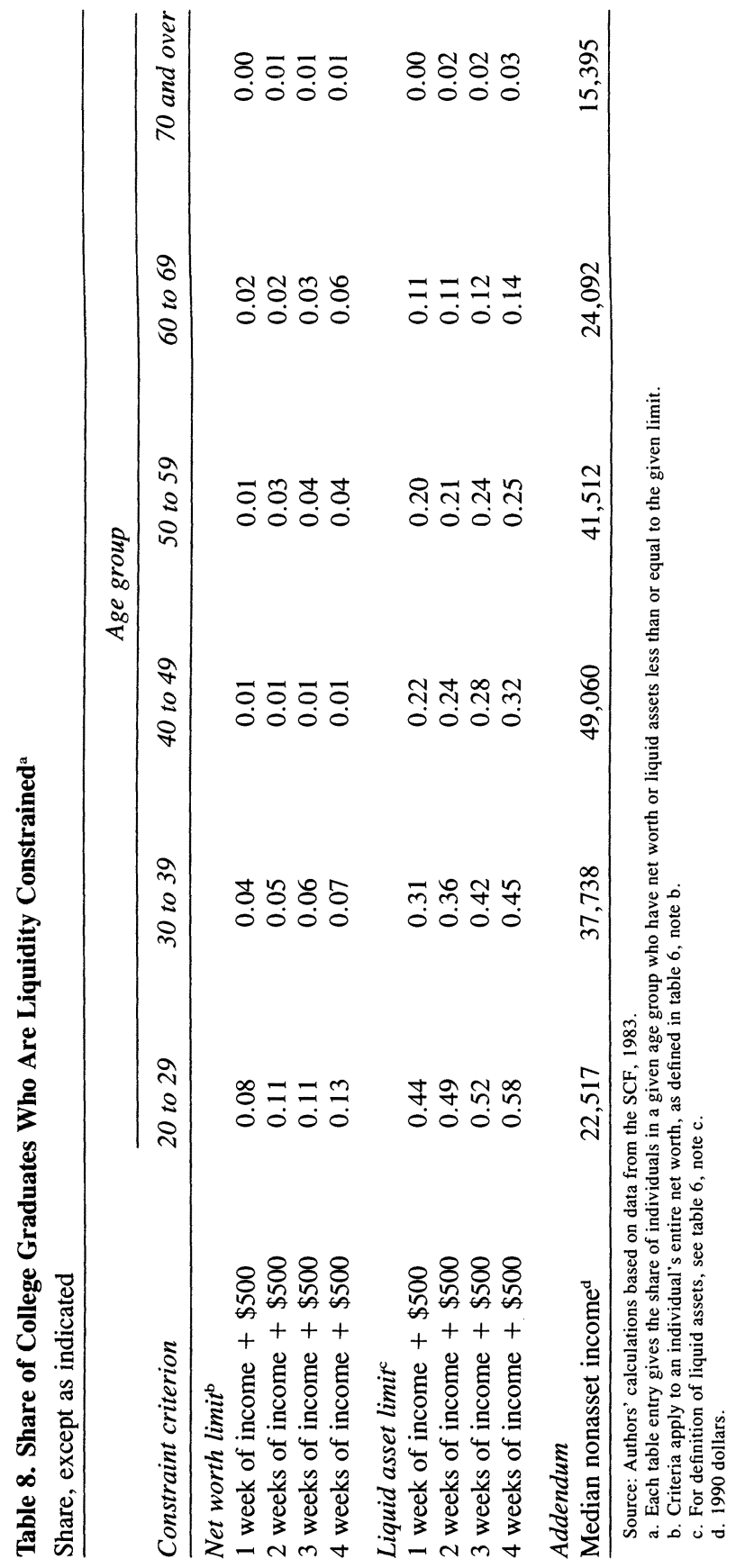




\section{Precautionary Saving}

Since Robert Hall's original work in the late 1970s, it has become standard practice to work with Taylor expansions of the Euler equation. ${ }^{77}$ The current consensus calls for second order terms to be included in the approximation. We undertake such analysis on the data generated by the exponential and the hyperbolic simulations. Specifically, we estimate the second order equation

$$
\left(\frac{C_{t+1}-C_{t}}{C_{t}}\right)=\frac{1}{\rho}\left(1-\frac{1}{R \delta}\right)+\frac{\rho+1}{2} E_{t}\left[\left(\frac{C_{t+1}-C_{t}}{C_{t}}\right)^{2}\right]+\epsilon_{t+1}
$$

Dynan derives this equation from the classical Euler equation $(\beta=1)$, by expanding $C_{t+1}$ around $C_{t} \cdot{ }^{78}$ She finds that the estimates of $\rho-$ imputed from the coefficient on the conditional variance term-are negative, and hence anomalously low. We show that the direction of the bias in Dynan's findings is predicted by the generalized Euler equation. We then estimate Dynan's equation with our simulated data.

A second order Taylor expansion of the generalized Euler equation yields

$$
\begin{aligned}
E_{t}\left(\frac{C_{t+1}-C_{t}}{C_{t}}\right)= & \frac{1}{\rho}\left(1-\frac{1}{R \delta}\right)+ \\
& \frac{1}{\rho} \frac{1}{R \delta}(\beta-1) E_{t}\left(\frac{\partial C_{t+1}\left(X_{t+1}\right)}{\partial X_{t+1}}\right)+O(2)+\epsilon_{t+1},
\end{aligned}
$$

where $\frac{\partial C_{t+1}\left(X_{t+1}\right)}{\partial X_{t+1}}$ has been expanded around zero, and $O(2)$ has been substituted for second order terms (including the one in equation 16). The first order expression $\frac{1}{\rho} \frac{1}{R \delta}(\beta-1) E_{t}\left(\frac{\partial C_{t+1}\left(X_{t+1}\right)}{\partial X_{t+1}}\right)$, which appears in equation 17 , vanishes in the exponential case $(\beta=1)$. In the hyperbolic case, this new first order term is easy to interpret. Recall that when the marginal propensity to consume is expected to be high next

78. Dynan (1993). 
period, the discount factor in the generalized Euler equation falls, pulling down the expected slope of the consumption path.

Estimates of $\rho$ inferred from regression analysis of equation 16 will be affected by omitted variable bias when $\beta$ is less than 1. Assuming that first order omitted variables dominate second order omitted variables, the direction of this bias is given by the covariation of $\frac{\rho+1}{2} E_{t}\left[\left(\frac{C_{t+1}-C_{t}}{C_{t}}\right)^{2}\right]$ and $\frac{1}{\rho} \frac{1}{R \delta}(\beta-1) E_{t}\left(\frac{\partial C_{t+1}\left(X_{t+1}\right)}{\partial X_{t+1}}\right)$. To sign this covariation, note that the conditional variability of consumption growth is high when the buffer stock of assets is low, and low assets imply a high marginal propensity to consume (see figure 10). Finally, recall that $(\beta-1)$ is less than zero, implying that the covariation between $\frac{\rho+1}{2} E_{t}\left[\left(\frac{C_{t+1}-C_{t}}{C_{t}}\right)^{2}\right]$ and $\frac{1}{\rho} \frac{1}{R \delta}(\beta-1) E_{t}\left(\frac{\partial C_{t+1}\left(X_{t+1}\right)}{\partial X_{t+1}}\right)$ is negative. Omitted variable bias implies that estimates of equation 16 will yield low or even negative estimates of $\frac{\rho+1}{2}$, as Dynan finds using data from the Consumer Expenditure Survey of the Bureau of Labor Statistics.

We confirm these intuitions with our simulated data through regression analysis of equation 16 . We operationalize this regression by using instrumental variables to estimate

$$
\left(\frac{C_{t+1}-C_{t}}{C_{t}}\right)=\alpha_{0}+\alpha_{1}\left(\frac{C_{t+1}-C_{t}}{C_{t}}\right)^{2}+\epsilon_{t+1} .
$$

To instrument for $\left(\frac{C_{t+1}-C_{t}}{C_{t}}\right)$, we follow Dynan and use education dummies and gross savings at time $t .{ }^{79}$ Table 9 reports the resulting inferred values of $\rho$ using data from the exponential and the hyperbolic simulations, for both $\rho$ equal to 1 and $\rho$ equal to 3 .

The findings reported in table 9 confirm that the anomaly reported by Dynan is predicted by the hyperbolic model. First, in every case the imputed value of $\rho$ is lower in the regression using hyperbolic simulated data than in the regression using analogous exponential data. Moreover,

79. Dynan also uses education, occupation, and number of earners in the household, but she omits education and occupation for some of her estimates. 


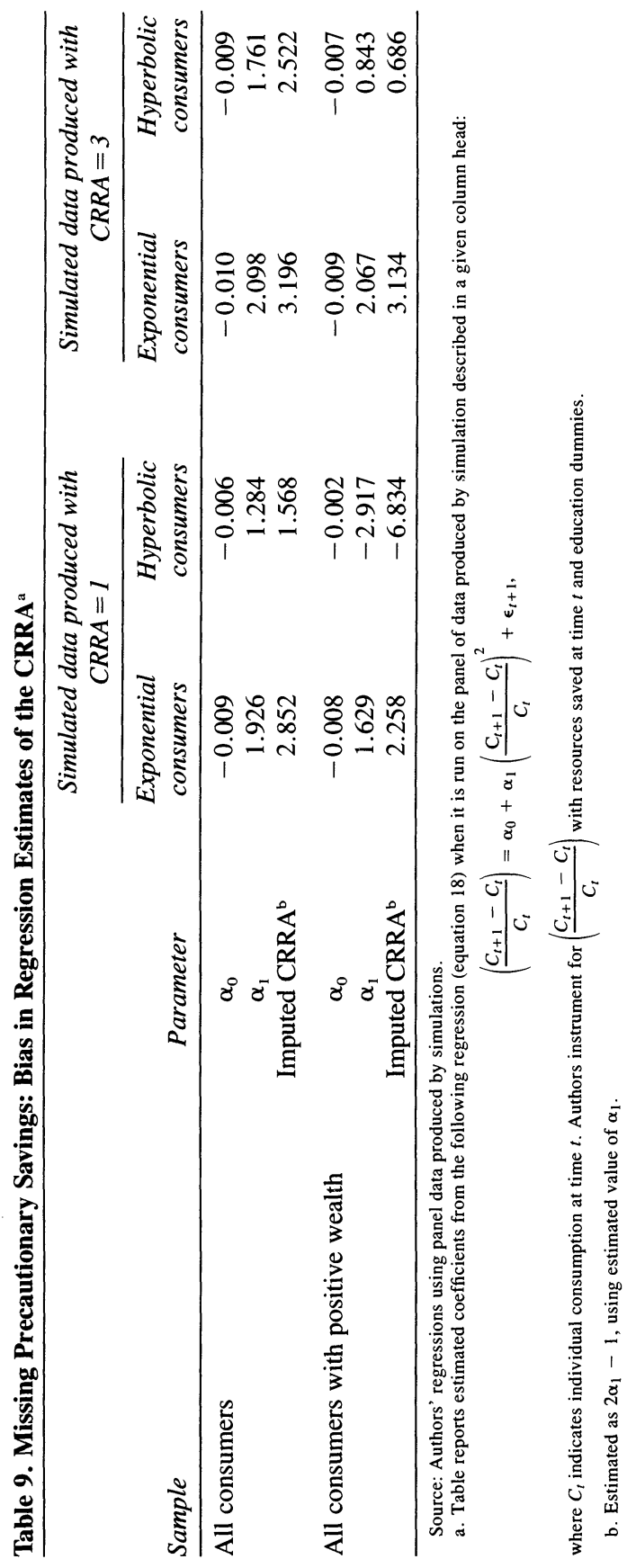


in every case the exponential data yield an imputed value of $\rho$ above the true value, presumably a bias generated by the second order approximation in the derivation of the linearized Euler equation; while in three of the four cases the hyperbolic data yield an imputed value below the true value.$^{80}$ Hence hyperbolic discounting explains-at least qualitatively-Dynan's results. ${ }^{81}$ However, our imputed values for $\rho$ do not line up neatly with hers, since most of her point estimates fall between $-1 / 2$ and -1 .

\section{The Economy with a Defined Contribution Plan}

In this section we analyze the properties of our exponential and hyperbolic economies with a second asset: a DC pension plan. We first consider a perfect commitment technology in the one asset economy.

\section{Perfect Commitment}

Hyperbolic households would like to save more than they do. If they could costlessly and perfectly commit later selves, they would lock in the contingent policy rules of an exponential household with a discount rate taken from the appropriate cell in table 4. For example, a hyperbolic household in the high school graduate group with coefficient of relative risk aversion equal to 1 , would choose to implement policies associated with an exponential household with a discount rate of 0.0275 .

The contrasts between the perfect commitment case and the no commitment case are striking. Average wealth accumulated peaks at $\$ 298,000$ with commitment, 62 percent higher than the peak of $\$ 184,000$ with no commitment. Perfect commitment also generates large welfare gains. From the perspective of the nineteen-year-old self, the ability to perfectly commit all future selves is as valuable as receiv-

80. See Carroll (1997b) for more evidence on the inadequacies of the linearized Euler equation; our results support his. Carroll also finds that estimating the linearized Euler equation on simulated exponential data yields regression coefficients that imply too high a value for $\rho$.

81. Carroll $(1992,1997$ a) proposes an alternative explanation, based on heterogeneous discount rates. Consumers with high discount rates will have high levels of consumption variability (and those with low discount rates will have low levels of variability). Omitting the heterogeneous discount rates from the regression will bias $\alpha_{1}$ downward. 
ing a one-time tax-free windfall equal to 36 percent of consumption at age twenty. ${ }^{82}$ The welfare gains evaluated from the perspective of later selves are substantially larger, since later selves benefit the most from the higher rates of accumulation early in life.

For households with coefficient of relative risk aversion equal to 3 , the impact of perfect commitment is smaller: peak accumulation rises by only 15 percent and the welfare effect is equivalent to only 2 percent of consumption at age twenty. This contrast between the different values of the coefficient of relative risk aversion is reflected in all the results presented below. Commitment-even if perfect-is not valuable to households with a relatively high coefficient of relative risk aversion, implying that they also will not value the cruder commitment properties in DC plans.

\section{Institutional Features of $401(k)$ Plans}

While perfect commitment devices are not available in practice, partial commitment devices are common. Consumers can use illiquid assets, particularly DC pension plans, to constrain future choice sets. $401(\mathrm{k})$ plans provide an interesting case in point. However, they do not provide a clean case study of commitment, because their appeal is enhanced by the tax break on capital income that they offer. In the rest of this section, we evaluate the efficacy of $401(\mathrm{k})$ plans for exponential and hyperbolic consumers.

A wide range of mechanisms induce employees to contribute to 401(k) plans and to resist withdrawing their accumulating balances. First, tax deferral and employer matching give employees strong incentives to contribute. In a 1997 survey conducted by Hewitt Associates, 81 percent of plans reported that the employer contribution was contingent on the employee contribution, and 21 percent of all plans reported matching contributions from employers of 50 percent up to 6 percent of income.$^{83}$ This was by far the most common employer arrangement among the plans surveyed.

Second, the standard plan compels participants to set up an automatic

82. We assume that the windfall is received in the consumer's twentieth year and is expressed as a percentage of consumption at age twenty. Note that this is the first year in which consumption choices are made; that is, the first year of economic life.

83. Hewitt Associates (1997). 
deposit system. In many cases, it is difficult or impossible to change the preset deposit levels on short notice. Even if a participant can make a change quickly, the results are unlikely to show up in cash holdings until the next pay cycle, which may be a month or two away. Since most of the steep drop in hyperbolic discount functions comes at horizons of approximately one week, a one month delay in implementation is more than enough to convince a hyperbolic consumer not to break into a nest egg. ${ }^{84}$

Third, 401(k) assets are partially protected from splurges, because withdrawals from the accounts can be freely made only if the account holder is over fifty-nine and a half years old. For younger consumers, withdrawals are only allowed in cases of financial hardship or when a worker separates from a firm, and even then generate a 10 percent penalty. In most other cases, the withdrawal penalty is 100 percent. Fourth, for consumers who will be limit contributors in the future, withdrawals cannot be paid back into the account, implying that such consumers are penalized by the loss of future tax deferrals, as well as the original 10 percent withdrawal penalty.

However, the recent trend toward the establishment of 401(k) loan provisions has undermined the effectiveness of these plans as a commitment device. Almost all ( 90 percent) of the plans surveyed by Hewitt Associates have begun to allow participants to use their $401(\mathrm{k})$ balance as collateral for a loan. ${ }^{85}$ Such loan provisions are generally highly restrictive and costly. For example, loans must be less than 50 percent of the vested account balance (employer contributions are often not counted as collateral) and less than $\$ 50,000$ in value, and they must be paid back in five years (ten years for home loans). Ninety-seven percent of plans restrict the number and type of loans, and 46 percent of plans only allow one outstanding loan. ${ }^{86}$ And the typical plan charges an interest rate 1 percentage point over the prime rate. ${ }^{87}$ According to EBRI data, 33 percent of participants have loans against their plan, with an average balance of $\$ 2,500 .{ }^{88}$

We do not model all of the institutional features of $401(\mathrm{k})$ plans.

84. See Laibson (1997a).

85. Hewitt Associates (1997). In 1991, the corresponding number was 67 percent.

86. Hewitt Associates (1997).

87. Hewitt Associates (1995).

88. This fact was brought to our attention by Eric Engen and William Gale. 
Computational limitations on the feasible number of state variables dictated some simplification. Most important, our model neglects the automatic deposit feature of $401(\mathrm{k}) \mathrm{s}$ and also the loan provisions. These choices mimic those of Engen, Gale, and Scholz.

\section{Conceptual Framework for the 401(k) Simulations}

Our analysis is an exercise in comparative statics. We compare an economy that has never had and will never have DC plans with one in which DC plans have always been and will always be available. Because we do not evaluate the transition path between steady states, our analysis does not have direct implications for the short-run impact of saving policies. ${ }^{89}$ Rather, the analysis is useful for highlighting the long-run differences between exponential and hyperbolic models.

Because it is not entirely clear what the institutional properties of a DC plan system would actually be, we consider a range of arrangements. First, we vary the early withdrawal penalty rate between 0.10 and 0.50; and we consider even more values in the robustness checks described below. If plan sponsors enforce the financial distress rules strictly, denying almost all applications, a penalty rate of 1.00 may be the correct modeling assumption. If their enforcement is weak and they sign off on almost all applications, no matter what their intrinsic merit, a penalty rate of 0.10 would be appropriate. Second, we vary the employer matching rate between 0 and 0.50 , assuming that employers match up to 6 percent of income. We explore these variations both to gain insight into existing heterogeneity among DC plans and to evaluate the long-run effects of potential changes to existing rules and practice.

We begin our analysis with representative examples of our simulations, postponing a summary of our various cases until after we introduce an aggregation framework. Figure 13 represents the life-cycle choices of exponential households in the high school graduate group with coefficient of relative risk aversion equal to 1 , who have access to a DC plan with a 0 percent match and a 10 percent penalty for early withdrawal. The figure plots average liquid wealth $(X)$, average DC plan wealth $(Z)$, average labor income $(Y)$, and average consumption

89. Many authors have shown that the short-run effects of changes in tax policy often go in the opposite direction to the long-run impacts; see, for example, Engen, Gale, and Scholz (1994). 
Figure 13. Simulated Asset, Income, and Consumption Paths of Exponential Households, Defined Contribution Plan Available ${ }^{a}$

Thousands of 1990 dollars

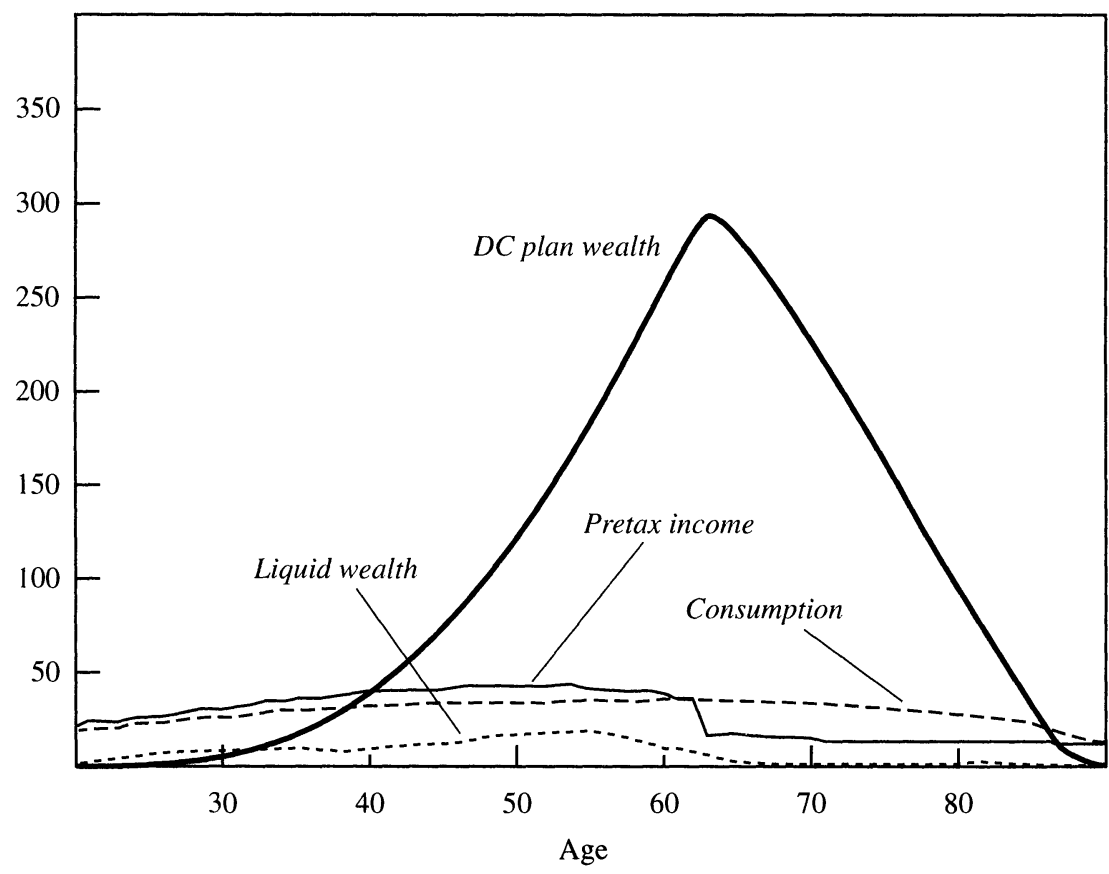

Source: Authors' simulations.

a. Figure plots life-cycle average consumption, pretax labor income, liquid wealth, and wealth in the DC plan for households with high school graduate heads. The DC plan has a 10 percent early withdrawal penalty and no employer match. The coefficient of relative risk aversion is equal to 1 .

(C) over the life cycle. Figure 14 represents these life-cycle choices for the corresponding hyperbolic households.

Four properties stand out in figures 13 and 14. First, most accumulation occurs in DC plan wealth. Second, total accumulation is dramatically larger than in the economy without DC plans (compare with figures 5 and 7); we quantify this difference below. Third, hyperbolic consumers hold lower levels of liquid assets and higher levels of illiquid assets than exponential consumers. Fourth, growth in DC plan holdings slows after age sixty (when the early withdrawal penalty drops to zero), and DC plan holdings start to fall at retirement. Similar patterns are apparent in the other cases that we consider. 
Figure 14. Simulated Asset, Income, and Consumption Paths of Hyperbolic Households, Defined Contribution Plan Available ${ }^{a}$

Thousands of 1990 dollars

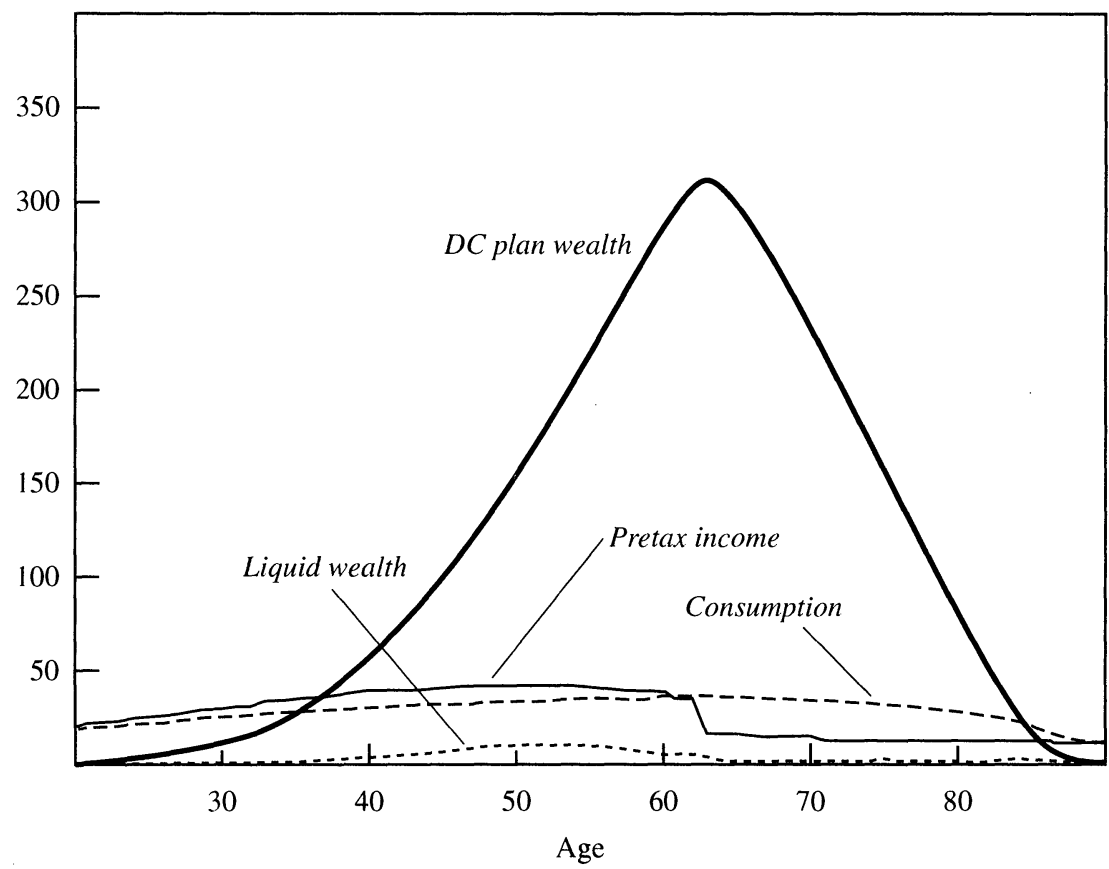

Source: Authors' simulations.

a. Figure plots life-cycle average consumption, pretax labor income, liquid wealth, and wealth in the DC plan for households with high school graduate heads. The DC plan has a 10 percent early withdrawal penalty and no employer match. The coefticient of relative risk aversion is equal to 1 .

All of the magnitudes plotted in figures 13 and 14 are based on per capita definitions. Linking these per capita magnitudes to national aggregates requires weighting with survival rates and cohort sizes. Aggregation is achieved through a simple overlapping generations model.

\section{Aggregation}

We rule out general equilibrium effects by assuming an open economy with a fixed world interest rate. We assume that the economy is composed of overlapping generations. Intercohort population grows at 1 percent per year; that is, the cohort born in year $t$ is 1 percent larger than the cohort born in year $t-1$. Intercohort per capita magnitudes 
grow at 2 percent per year; that is, the outcome variables, such as pretax income at age thirty-five and taxes paid at age thirty-five, of the cohort born in year $t$ are 2 percent larger than the same outcome variables of the cohort born in year $t-1$. The latter assumption is slightly distortionary, because it implies that tax brackets are cohort specific.

We also assume that the government adjusts expenditures to maintain a balanced budget and carries no debt in steady state. This assumption engenders a bias against finding that DC plans increase net national saving when the coefficient of relative risk aversion is equal to 1 , and for finding that they do so when the coefficient of relative risk aversion is equal to 3 . This bias arises because when the coefficient of relative risk aversion is equal to 1 , all of the economies with DC plans have higher aggregate government tax receipts than the corresponding economies without DC plans, and when the coefficient of relative risk aversion is equal to 3 , they have lower receipts (see tables 11 and 14 below). To compensate for this revenue effect, we simply assume that the government runs a balanced budget. Note, however, that we only undertake steady-state analysis. Any negative effects on government saving that occur during the transition are not captured in our steady state simulations. These transition effects will reduce government saving, offsetting or adding to, respectively, the biases described above.

Our balanced budget assumption also engenders a bias against finding that DC plans are particularly effective in hyperbolic economies. This is because introducing the DC plan causes revenue to rise by a greater amount, or fall by a smaller amount, in the hyperbolic economies than in the exponential economies (see tables 11 and 14 below). This bias occurs with both values of the coefficient of relative risk aversion.

We summarize our steady-state analysis with three statistics: the aggregate saving rate, the ratio of government tax revenue to labor income, and the percentage of DC plan wealth accumulation that represents additional saving relative to the economy without a DC plan. Formally, we define aggregate income as

$$
(G N P)_{t}=Y_{t}+M_{t}+\frac{r}{R}\left(X_{t}+Z_{t}\right),
$$

where $Y_{t}$ represents aggregate labor income receipts excluding matching payments, $M_{t}$ represents aggregate employer matching payments, $X_{t}$ 
represents the aggregate stock of the liquid asset, $Z_{t}$ represents the aggregate stock of the DC plan, $r$ represents the interest rate, and $R$ is equal to $1+r$. Note that $Y_{t}$ includes defined benefit pension plans, private and public, since we assume these are funded out of wages on a pay-as-you-go basis.

Saving is the residual between income and consumption, both private and public:

$$
S_{t}=(G N P)_{t}-C_{t}-G_{t},
$$

where $C_{t}$ represents aggregate private consumption and $G_{t}$ represents aggregate government consumption. The balanced budget assumption implies that

$$
G_{t}=T_{t}+E_{t}-B_{t+1},
$$

where $T_{t}$ represents taxes paid at time $t, E_{t}$ represents the value of estates left at time $t$, and $B_{t+1}$ represents the value of bequests received at the start of period $t+1$. The difference, $E_{t}-B_{t+1}$, represents bequest taxes (not included in $T_{t}$ ), which turn out to be positive in our simulations. ${ }^{90}$

The aggregate saving rate is given by

$$
\frac{S_{t}}{(G N P)_{t}}
$$

The ratio of government receipts to total labor income is given by

$$
\frac{G_{t}}{Y_{t}+M_{t}}
$$

Note that the denominator of this ratio is the same in the hyperbolic and exponential economies $-Y$ falls to offset the average match. Finally, the percentage of DC plan wealth accumulation that represents new national saving relative to the no DC plan economy is given by

$$
\frac{X_{t}+Z_{t}-\tilde{X}_{t}}{Z_{t}},
$$

90. The estate tax rate implied by our analysis varies between 50 percent and 75 percent. This is high, but not as high as it looks, because it includes income taxes on $401(\mathrm{k})$ assets, which are payable on the death of the consumer. 
where $\tilde{X}_{t}$ represents the amount of aggregate liquid assets accumulated in the economy without a DC plan.

\section{Results for Coefficient of Relative Risk Aversion Equal to 1}

Table 10 reports saving rates in the no DC plan and DC plan overlapping generations economies with coefficient of relative risk aversion equal to 1 . Saving rates are reported for each educational group and for the whole economy. We first consider the results for the exponential households.

The exponential economy without a DC plan has a steady-state aggregate saving rate of 4.14 percent. The corresponding rates for the DC plan exponential economies are very different. Consider the case of 50 percent employer matching. With a 10 percent withdrawal penalty, the saving rate rises to 7.63 percent; with a 50 percent penalty, it rises to 8.35 percent. These represent increases of 84.3 percent and 101.7 percent, respectively. With no matching, the percentage increases are smaller, although still quite large. With a 10 percent penalty, the aggregate saving rate increases by 60.6 percent; with a 50 percent penalty, it increases by 64.3 percent.

One would intuitively expect DC plans to have a bigger impact on hyperbolic economies, since hyperbolic households value commitment. Table 10 confirms this conjecture. With 50 percent employer matching and a 10 percent withdrawal penalty, the aggregate saving rate increases by 99.2 percent; and with a 50 percent penalty, it increases by 134.0 percent. With no matching and a 10 percent penalty, the aggregate saving rate increases by 81.1 percent; and with a 50 percent penalty, it increases by 102.8 percent. These results are even larger than the saving increases recorded by the exponential households. Defined contribution plans generally double the net saving rates in hyperbolic economies relative to exponential economies.

Three additional features stand out in the simulation results. First, the college graduate group generally realizes the smallest DC plan effects in percentage terms. Because these households have the highest income levels and are the most patient, they are most likely to hit the contribution caps, thereby mitigating the substitution effect. However, the DC plan effects do not fall monotonically with education. In many cases, they are stronger for the high school graduate group than for the 


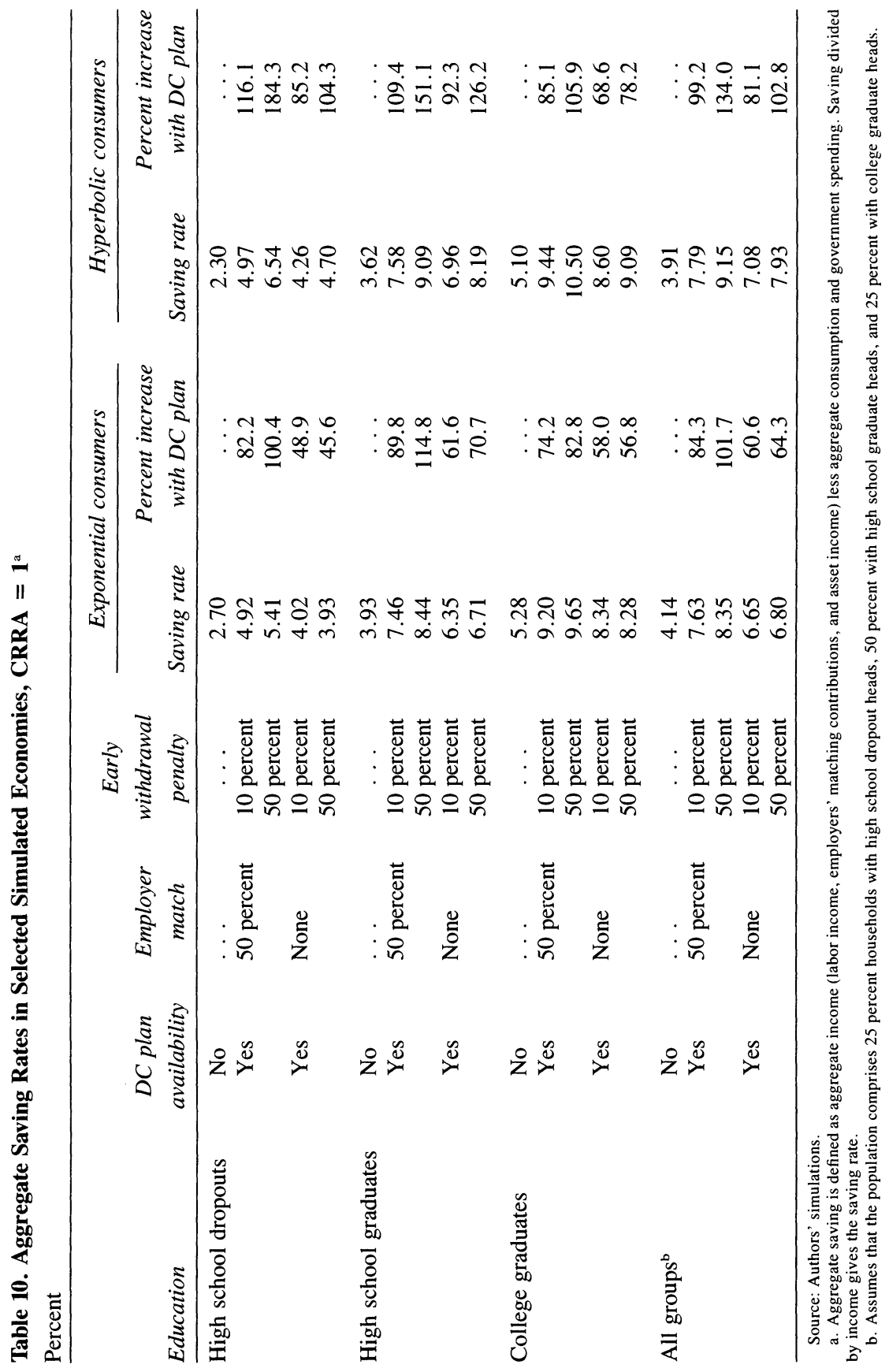


households whose head did not graduate from high school, probably reflecting the fact that the DC plan generates more tax relief for the high school graduate group.

Second, hyperbolic consumers respond relatively well to higher penalties for early withdrawal. In the case of 50 percent employer matching, when the penalty rises from 10 percent to 50 percent, the hyperbolic saving rate rises from 7.79 percent to 9.15 percent (a 17.5 percent increase), while the exponential saving rate only rises from 7.63 percent to 8.35 percent (a 9.4 percent increase). Likewise, in the no matching case, when the penalty rises from 10 percent to 50 percent, the hyperbolic saving rate rises from 7.08 percent to 7.93 percent (a 12.0 percent increase), while the exponential saving rate rises from 6.65 percent to 6.80 percent (a 2.3 percent increase).

Third, hyperbolic consumers are relatively less sensitive to the elimination of employer matching. In the case of a 10 percent withdrawal penalty, removing the match reduces the hyperbolic saving rate from 7.79 percent to 7.08 percent (a 9.1 percent decrease), while the exponential saving rate falls from 7.63 percent to 6.65 percent (a 12.8 percent decrease). Likewise, in the case of a 50 percent penalty, removing the match reduces the hyperbolic saving rate from 9.15 percent to 7.93 percent (a 13.3 percent decrease), while the exponential saving rate falls from 8.35 percent to 6.80 percent (an 18.6 percent decrease). In the no match condition, exponential consumers have relatively weak incentives to invest. They gain only the tax deferral and pay the price of lost liquidity. By contrast, hyperbolic consumers both gain the tax deferral and partially benefit from the lost liquidity.

Turning to the government sector, table 11 reports government revenue as a percentage of labor income. Our balanced budget assumption implies that government revenue equals government consumption, generating a cost or benefit of the DC plan regime that is not captured in the higher saving rate. In all of our simulations with coefficient of relative risk aversion equal to 1 , the DC plan economy is associated with higher government revenues, and these effects are strongest for the hyperbolic consumers. If some of this increased revenue were channeled into saving instead of government consumption, national saving would rise even higher in the DC plan regime. These increases in revenue are substantial, representing approximately 1 percent of labor income. 


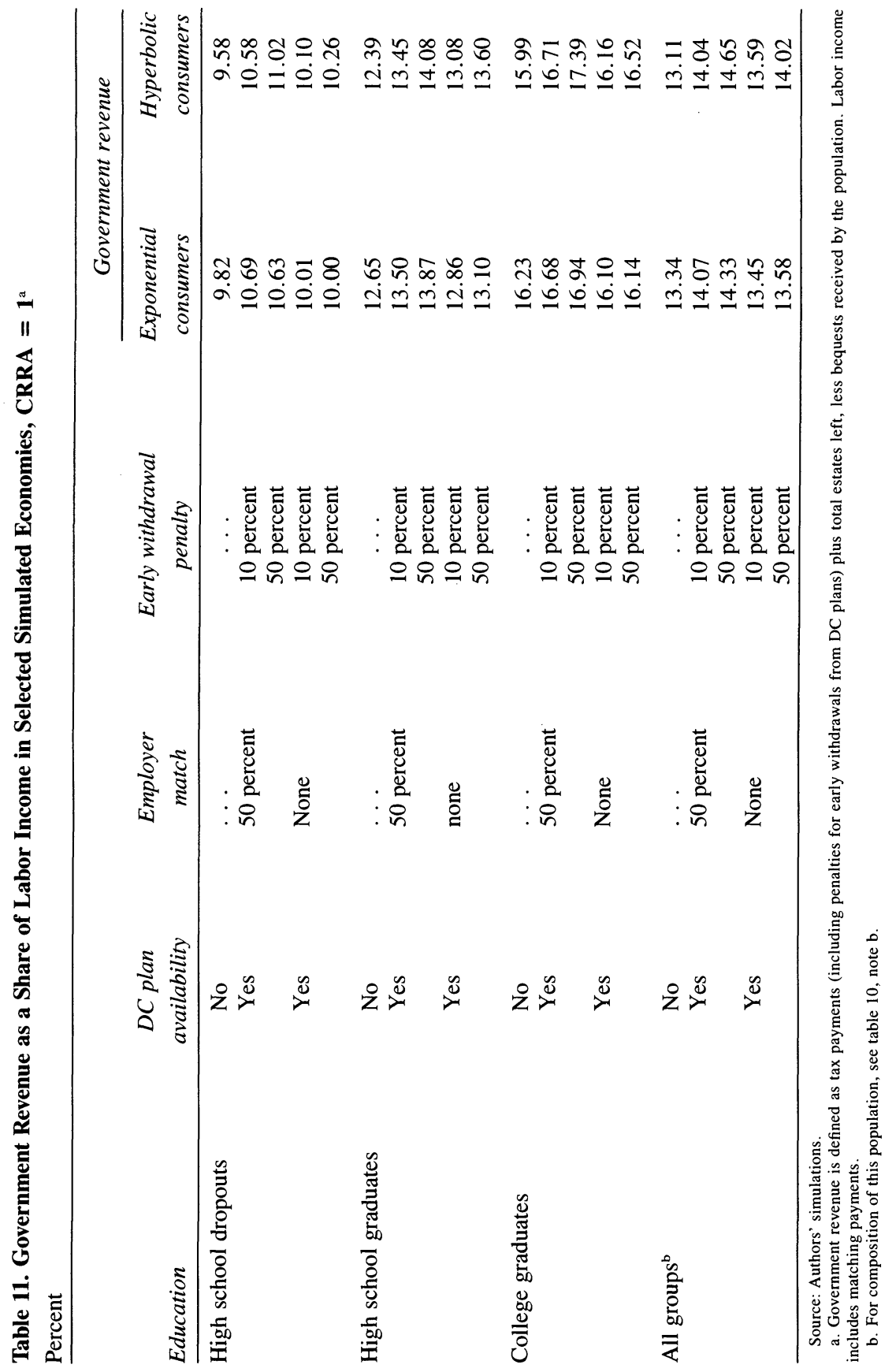


In table 12 we report the percentage of DC plan accumulation that represents new savings:

$$
\frac{X_{t}+Z_{t}-\tilde{X}_{t}}{Z_{t}}
$$

Note that total new savings is equal to the stock of DC plan wealth multiplied by the ratio reported in table 12 :

$$
Z_{t}\left(\frac{X_{t}+Z_{t}-\tilde{X}_{t}}{Z_{t}}\right) \text {. }
$$

This table demonstrates that, in general, values of $\left(X_{t}+Z_{t}-\tilde{X}_{t}\right) / Z_{t}$ are higher for hyperbolic than for exponential consumers. Hence hyperbolic consumers save more than exponential consumers both because hyperbolic consumers invest relatively heavily in DC plan accounts and because their DC plan investments exhibit a uniformly higher percentage of new savings.

Finally, our welfare measure is constructed in three steps. We first calculate the average welfare of households of age $t$ for the economies with and without DC plans. Note that average welfare is calculated from the perspective of self $t$. Next, we record the consumption $\left(C_{i t}\right)$ of each household at age $t$. We then find $\lambda_{t}$, such that giving each $t$-yearold household in the no DC plan economy a one-time unexpected aftertax wealth windfall of $\lambda_{t} C_{i t}$ raises average welfare in that economy to the same level as average welfare in the DC plan economy. Thus our welfare measure is $100 \lambda_{t}$. It is defined for each self $\{20,21,22, \ldots$, $\mathrm{T}+\mathrm{N}\}$, but in the interest of brevity we only report it for selves 20 , $40,60,80$.

We report the welfare results in table 13 . These effects are quite large. For example, twenty-year-old hyperbolic high school graduate households in the no DC plan economy need to receive a wealth transfer equal to 70 percent of consumption at age twenty to make them as well off as the average corresponding household in the DC plan economy with 50 percent employer matching and a 10 percent withdrawal penalty. This effect compares favorably with that for similarly situated exponential households, who experience a welfare effect of 22 percent of consumption. Note that the welfare gains for exponential households arise from the reduction in the taxation of capital income. The hyper- 


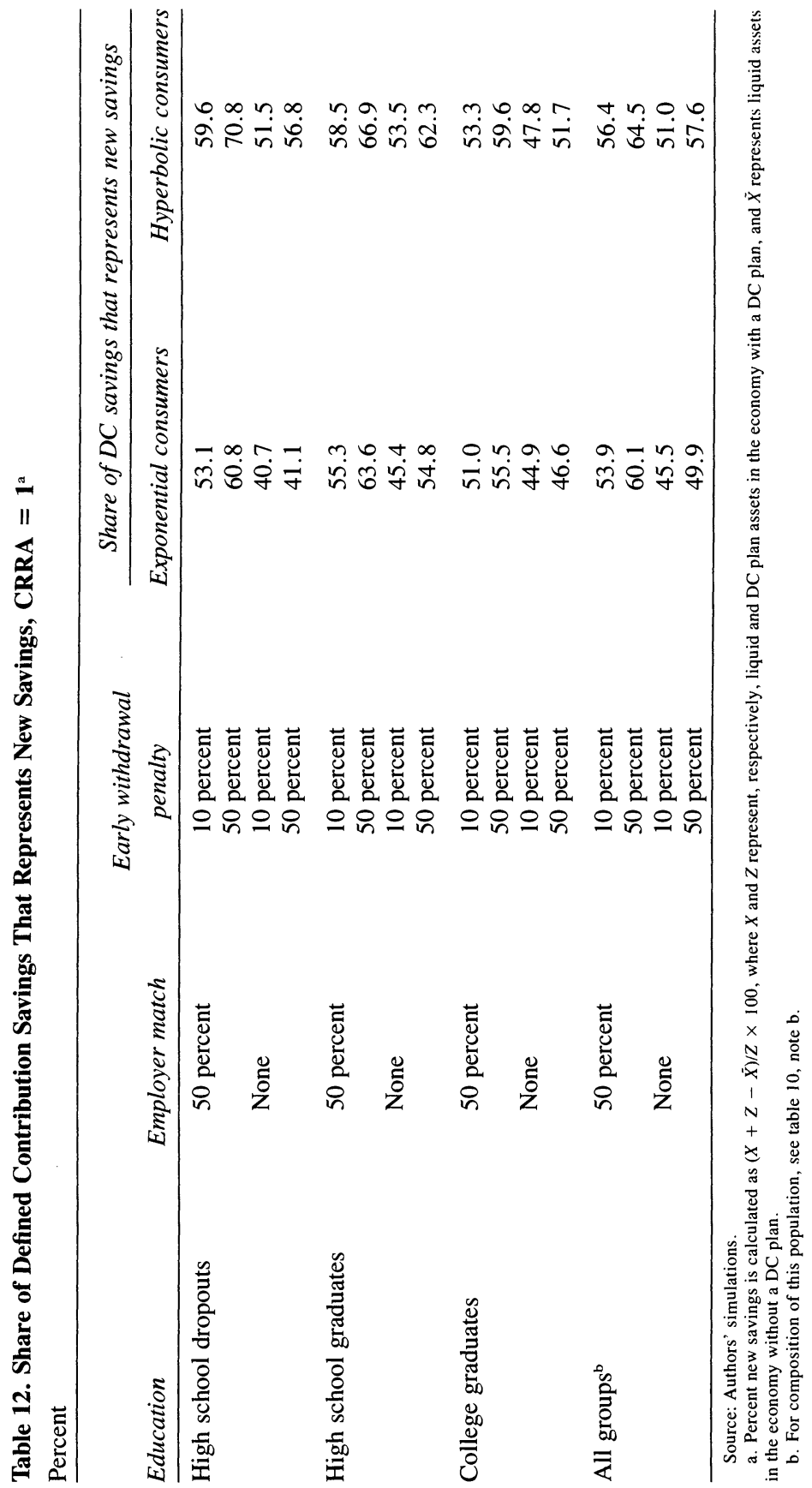




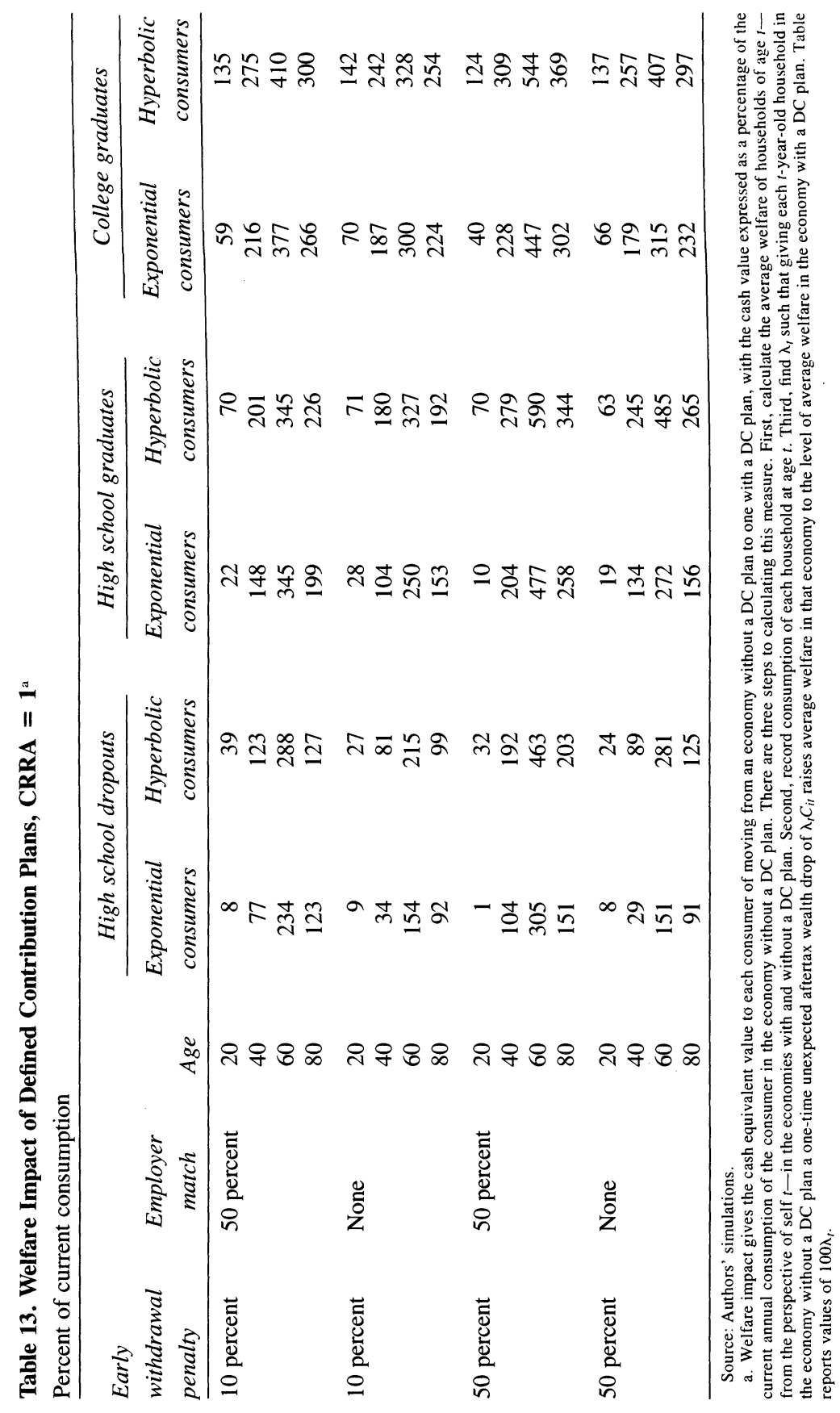


bolic consumers benefit both from this tax reduction and from the commitment properties of the DC plan.

Three patterns stand out in table 13. First, welfare effects are uniformly higher for the hyperbolic households, reflecting the value of commitment. Second, the absolute magnitudes of the welfare effects grow until retirement, since early accumulation disproportionately benefits the later selves who spend those accumulated assets. Third, welfare effects increase monotonically with education, reflecting the fact that more patient consumers can better exploit tax policies that favor accumulation.

\section{Coefficient of Relative Risk Aversion Equal to 3}

We have shown that perfect commitment is much more valuable to hyperbolic consumers with coefficient of relative risk aversion equal to 1 than to those with coefficient of relative risk aversion equal to 3 . The results reported below confirm that the gap between DC plan effects for exponential and hyperbolic consumers shrinks as the coefficient of relative risk aversion increases.

Tables 14 to 17 are analogous to tables 10 to 13 for a coefficient of relative risk aversion equal to 3 . Most of the qualitative results in tables 14 to 17 mirror those in the earlier tables. In particular, hyperbolic households uniformly respond more favorably to DC plans than do exponential households. This is true by almost all measures, including the national saving rate, government revenue, and consumer welfare.

However, the gaps between the exponential and the hyperbolic effects are much smaller in tables 14 to 17 than in tables 10 to 13. For example, when the coefficient of relative risk aversion is equal to 3 , DC plans cause the aggregate saving rate in the exponential economy to rise by between 23.2 percent and 35.5 percent, depending on the institutional assumptions. Likewise, they cause the aggregate saving rate in the hyperbolic economy to rise by between 26.2 percent and 38.2 percent. By contrast, when the coefficient of relative risk aversion is equal to 1 , DC plans cause the aggregate saving rate in the exponential economy to rise by between 60.6 percent and 101.7 percent, whereas they cause the aggregate saving rate in the hyperbolic economy to rise by between 81.1 percent and 134.0 percent.

The choice of the coefficient of relative risk aversion suggests a 


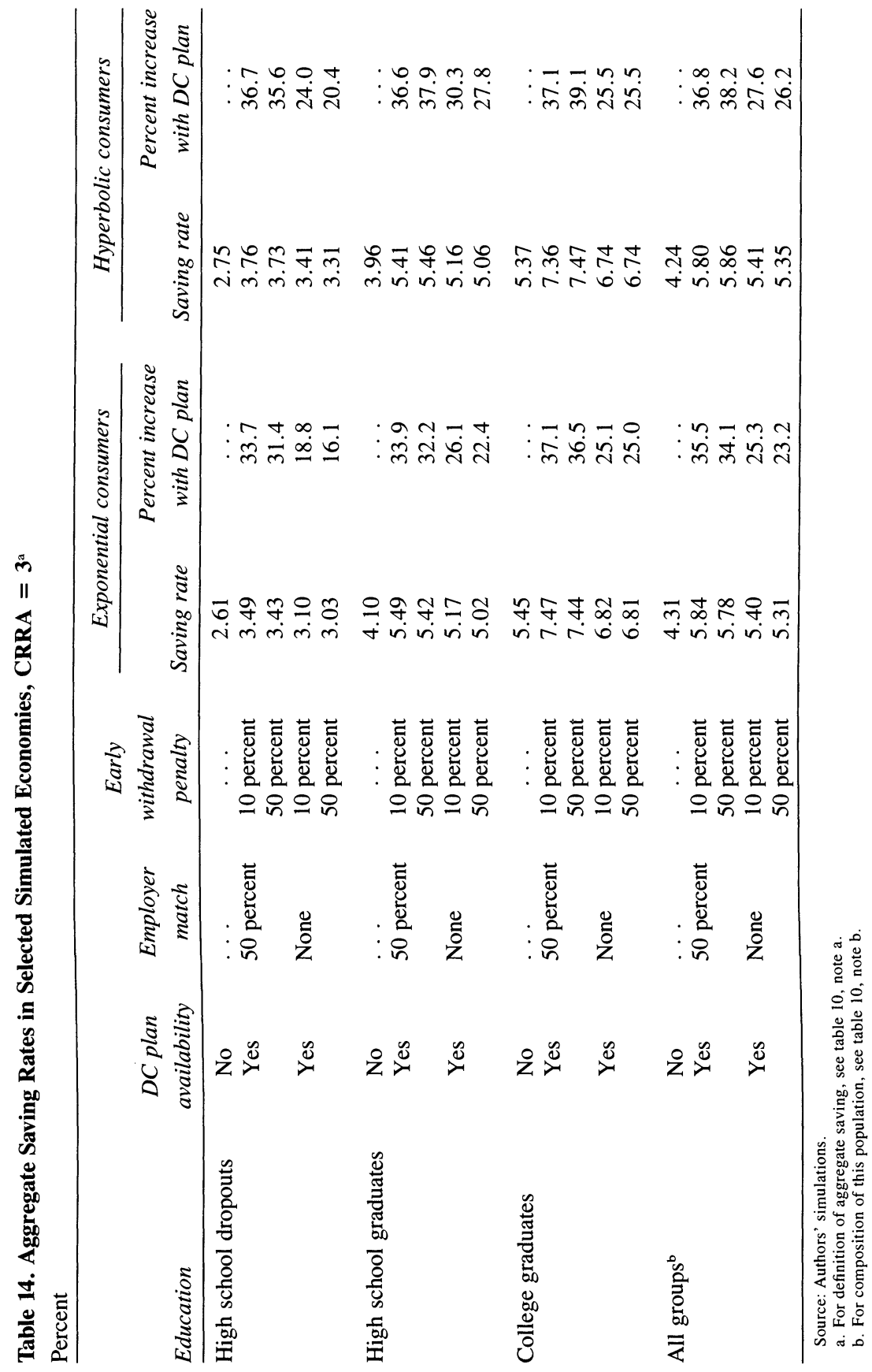




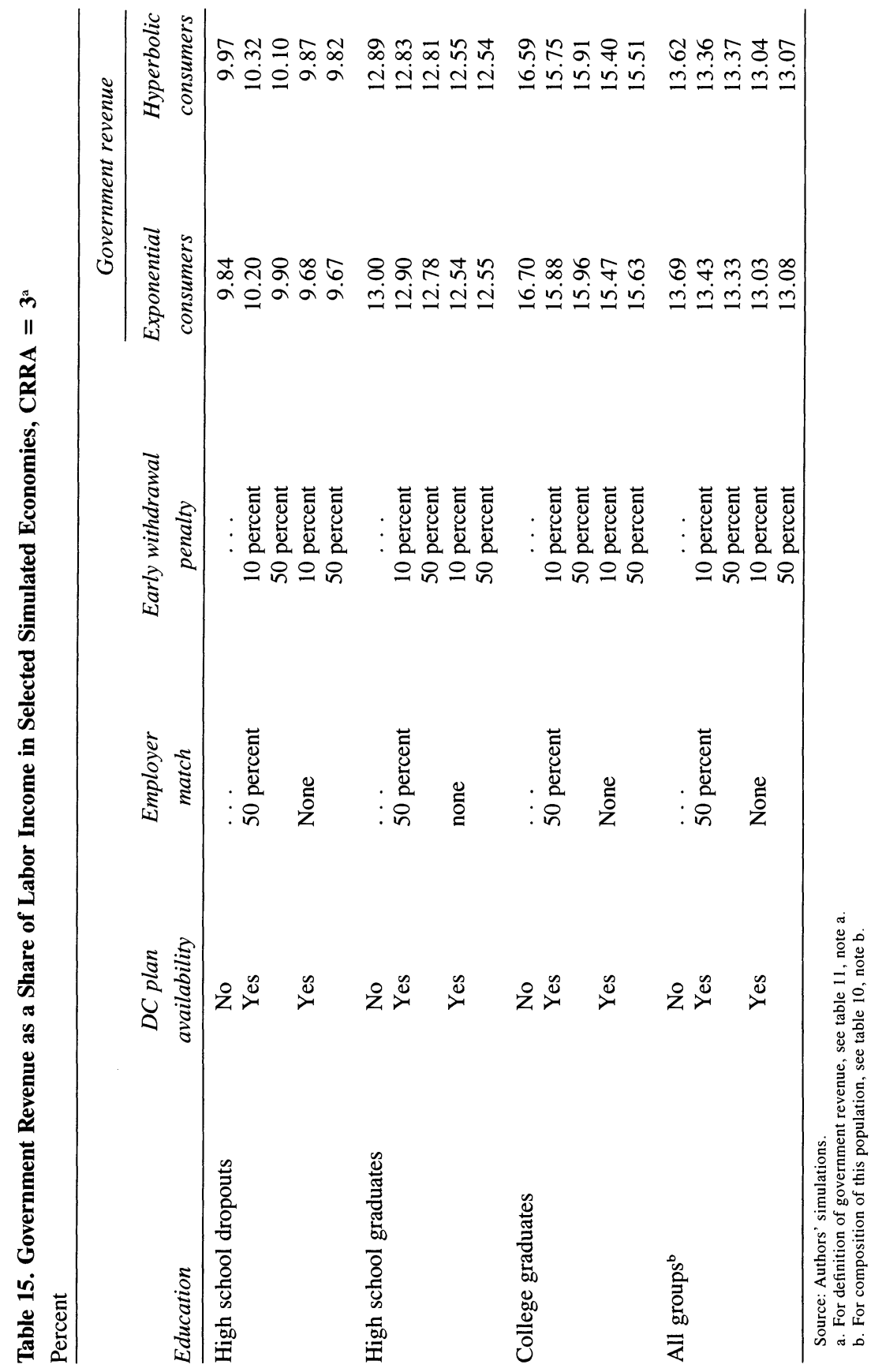




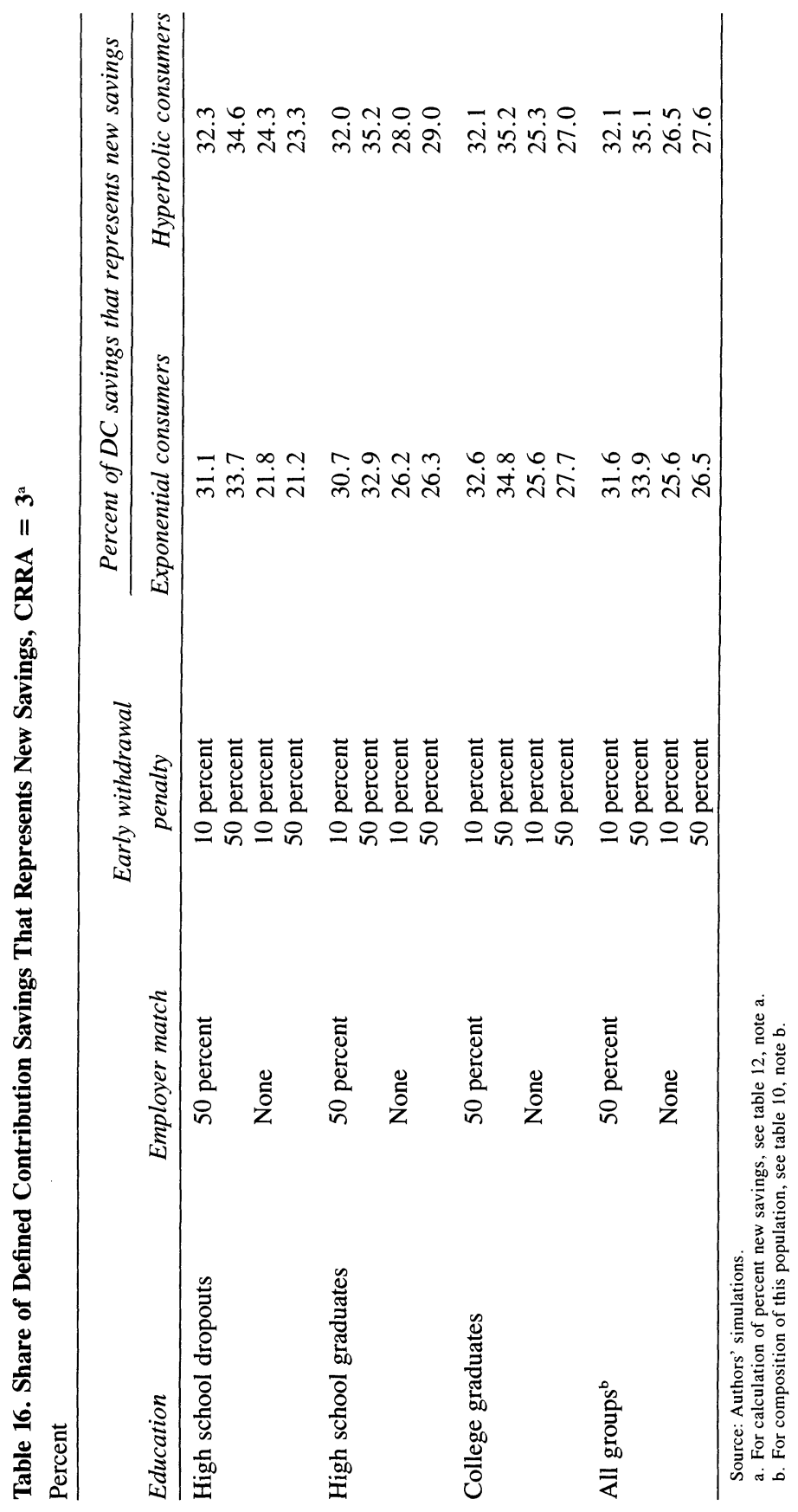




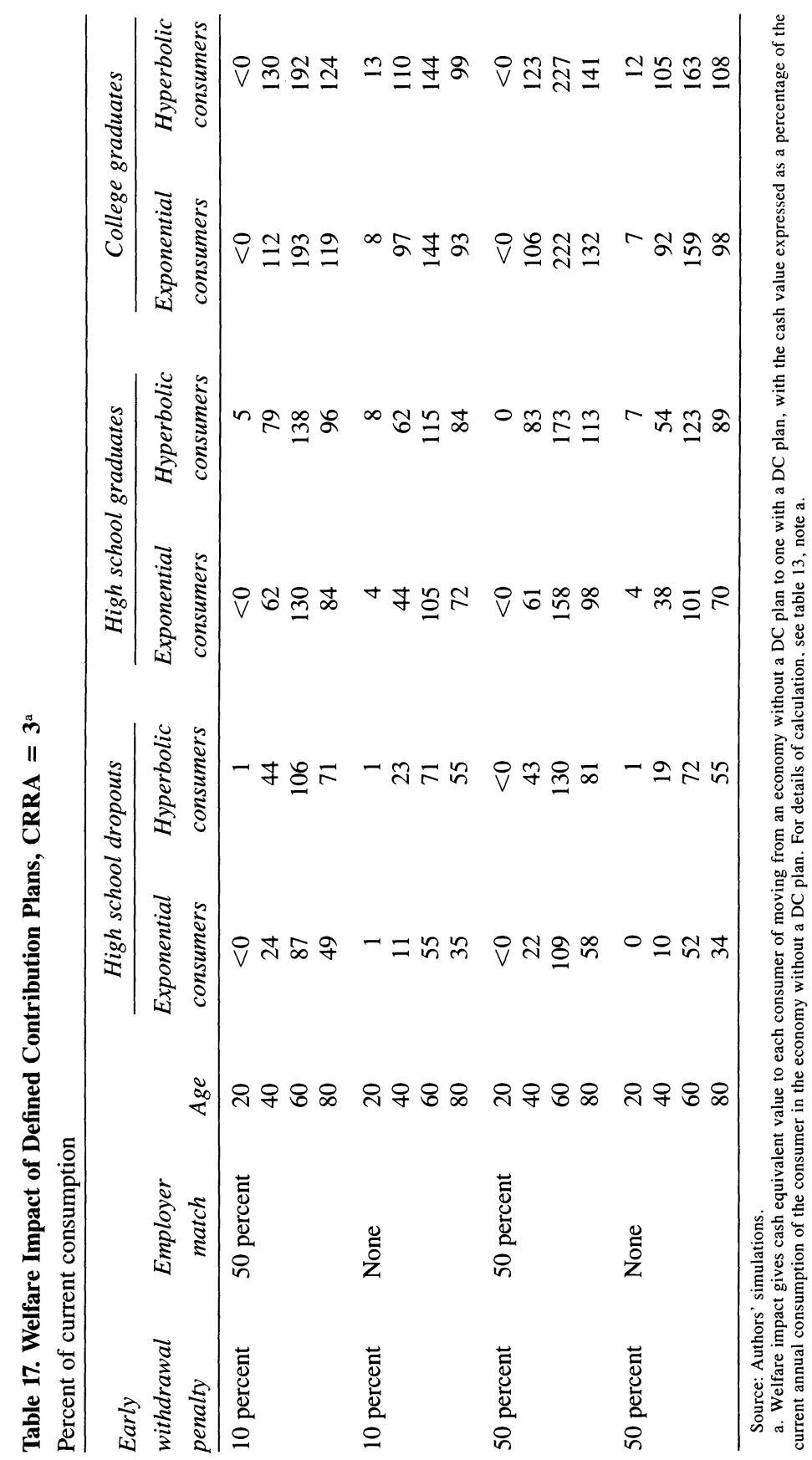


framework for comparing our results with those of Engen, Gale, and Scholz. These authors assume a coefficient of relative risk aversion equal to 3 and report that DC plans generate increases in the steadystate saving rate of between 9.1 percent and 17.2 percent, not far from the range we report above for exponential discounters. ${ }^{91}$ Our work complements theirs, confirming their results and showing how they depend on the coefficient of relative risk aversion. ${ }^{92}$

In summary, when the coefficient of relative risk aversion is close to 3, DC plans are predicted to have limited impact, whether or not preferences are hyperbolic. By contrast, when the coefficient of relative risk aversion is close to unity, such plans will have substantial impact, and their impact will be even greater if discount functions are hyperbolic. Unfortunately, we do not have much insight into the value of the coefficient of relative risk aversion. Our preferred model, with coefficient of relative risk aversion equal to 1 and an implied measured elasticity of intertemporal substitution of 0.22 , is supported by the available empirical evidence. However, it is also possible to make a case for a coefficient of relative risk aversion equal to 3 with an implied elasticity of intertemporal substitution of 0.15 . We hope that future research will be able to pin down these parameters.

\section{Robustness and Extensions}

In this section we consider several extensions to our benckmark model.

\section{Varying the Value of $\beta$}

We have discussed above our reasons for setting $\beta$ equal to 0.85 . While the available experimental evidence supports a much lower cal-

91. Engen, Gale, and Scholz's (1994) analysis is steady state, in the sense that is performed at a seventy-year horizon from the inception of the policy. All consumers alive at this date have had access to $401(\mathrm{k}) \mathrm{s}$ throughout their lives.

92. There are other differences between our model and that of Engen, Gale, and Scholz, but we believe that the coefficient of relative risk aversion assumption is by far the most important. In their model, earnings shocks are more persistent, the contribution cap is lower, the bequest process is perfectly predictable, and the median calibrated discount rate is lower. 
Table 18. Aggregate Saving Rate, Government Revenue, and New Savings for Selected Values of $\boldsymbol{\beta}^{\mathrm{a}}$

Percent

\begin{tabular}{|c|c|c|c|}
\hline \multirow[b]{2}{*}{ Item } & \multicolumn{3}{|c|}{ Value of $\beta$} \\
\hline & 1 & 0.85 & 0.8 \\
\hline \multicolumn{4}{|l|}{ Aggregrate saving rate $e^{b}$} \\
\hline No DC plan & 4.1 & 3.9 & 3.9 \\
\hline With DC plan & 6.7 & 7.1 & 7.3 \\
\hline Percent difference $^{\mathrm{d}}$ & 60.6 & 81.1 & 86.2 \\
\hline \multicolumn{4}{|l|}{ Government revenue $^{\mathrm{e}}$} \\
\hline No DC plan & 13.3 & 13.1 & 13.1 \\
\hline With DC plan ${ }^{\mathrm{c}}$ & 13.5 & 13.6 & 13.7 \\
\hline Percent difference $^{d}$ & 0.8 & 3.7 & 4.6 \\
\hline New savings in DC plan ${ }^{\mathrm{f}}$ & 45.5 & 51.0 & 52.0 \\
\hline \multicolumn{4}{|c|}{$\begin{array}{l}\text { Source: Authors' simulations. } \\
\text { a. All simulations assume a population comprising the three educational groups in proportions specified in table } 10 \text {, } \\
\text { note b. } \\
\text { b. Saving as a percentage of income; see table } 10 \text {, note a. } \\
\text { c. Assumes a } 10 \text { percent penalty for early withdrawal and no employer matching contribution. } \\
\text { d. Percent increase in moving from an economy without a DC plan to an economy with a DC plan. } \\
\text { e. Percent of labor income; see table } 11 \text {, note a. }\end{array}$} \\
\hline
\end{tabular}

ibration, such low values generate pathologies in discrete time models. We now demonstrate how our results would likely change if we were to choose lower values of $\beta$.

We report simulation results for the exponential case, $\beta$ equal to 1 , our benchmark hyperbolic case, $\beta$ equal to 0.85 , and a new case for comparison, $\beta$ equal to 0.80 . We choose to explore this last case because it is close to our hyperbolic benchmark and does not exhibit the pathologies discussed above. For $\beta$ equal to 0.80 , we follow the steps described above for calibrating the preference parameters. Specifically, we solve for longrun discount factors- $\delta_{\beta=0.80}^{N H S}, \delta_{\beta=0.80}^{H S}, \delta_{\beta=0.80}^{C O L L}$-so that these simulations replicate the actual level of preretirement wealth holdings.

In tables 18 and 19 we report analysis for a DC plan with a 10 percent withdrawal penalty and no employer matching. To a first approximation, the DC plan effects are approximately linear in the magnitude of $(1-\beta)$. More precisely, the saving rate effects are slightly concave in $(1-\beta)$, while the welfare effects are generally strongly convex in $(1-\beta)$. For example, introducing the DC plan raises the aggregate saving rate by 60.6 percent in the exponential case, 81.1 percent in our benchmark hyperbolic case, and 86.2 percent in the new comparison 
Table 19. Welfare Impact of Defined Contribution Plans for Selected Values of $\boldsymbol{\beta}^{\text {a }}$ Percent of current consumption

\begin{tabular}{lcrrr}
\hline & & \multicolumn{3}{c}{ Value of $\beta$} \\
\cline { 3 - 5 } Education & Age & \multicolumn{1}{c}{1} & 0.85 & 0.8 \\
\hline High school dropouts & 20 & 9 & 27 & 41 \\
& 40 & 34 & 81 & 95 \\
& 60 & 154 & 215 & 220 \\
High school graduates & 80 & 92 & 99 & 118 \\
& 20 & 104 & 71 & 99 \\
& 40 & 250 & 327 & 202 \\
College graduates & 60 & 153 & 192 & 334 \\
& 80 & 187 & 142 & 240 \\
& 20 & 300 & 242 & 183 \\
& 40 & 224 & 328 & 349 \\
& 60 & 254 & 277 \\
\hline
\end{tabular}

Source: Authors' simulations.

a. Welfare impact gives cash equivalent value to each consumer of moving from an economy without a DC plan to one with a DC plan, with the cash value expressed as a percentage of the current annual consumption of the consumer in the economy without a DC plan. For details of calculation, see table 13, note a. Table assumes a DC plan with a 10 percent penalty for early withdrawal and no employer matching contribution.

case. It generates a welfare gain for twenty-year-old high school graduate households equivalent to 28 percent of consumption in the exponential case, 71 percent of consumption in our benchmark hyperbolic case, and 99 percent of consumption in the new comparison case.

If these results apply globally, the hyperbolic effects-the gap between the hyperbolic and the exponential DC plan simulations-will rise significantly as $\beta$ falls. The available experimental evidence suggests that 0.60 is an appropriate calibration value for $\beta$. If the hyperbolic effects rise linearly with $(1-\beta)$, the true hyperbolic effect is two to three times as large as the effects reported above, where our maintained hypothesis was $\beta$ equal to 0.85 .

\section{Varying the Early Withdrawal Penalty}

In the simulations reported above, we consider withdrawal penalties of 10 percent and 50 percent. In table 20 , we also evaluate a wider range of penalty values - $10,30,50$, and 70 percent-for a representative case, with no employer matching for high school graduate households and coefficient of relative risk aversion equal to 1 . These simulations indicate that 


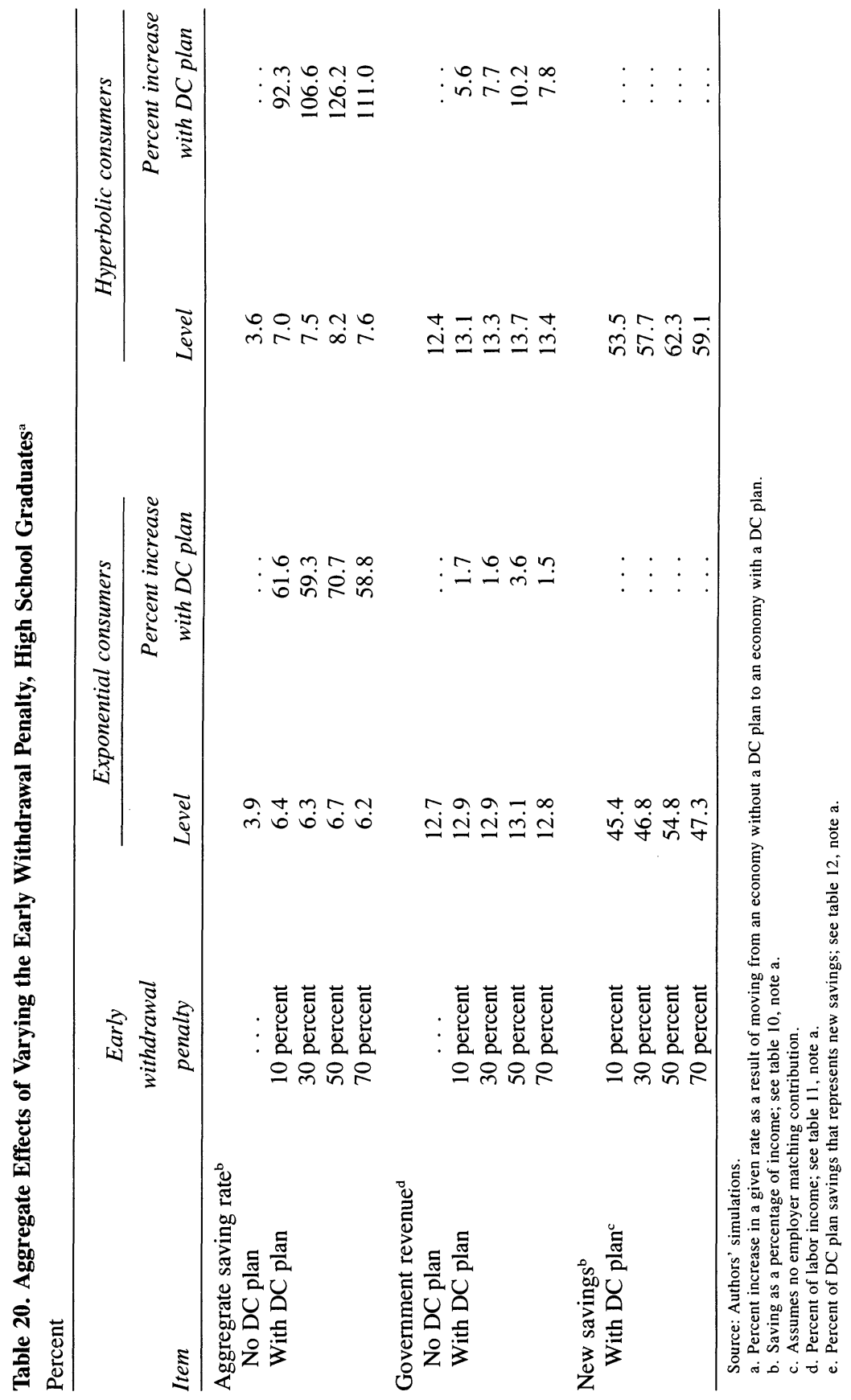


penalties in the neighborhood of 50 percent are optimal if the goal is to raise steady-state national saving. Such a penalty creates a strong incentive to avoid early withdrawals from the DC plan, but it is not so high as to discourage contributions in the first place.

\section{Modeling a World with both Exponential and Hyperbolic Consumers}

All of our simulations are based on the premise that an economy is either completely exponential or completely hyperbolic. However, it is also reasonable to assume that the economy comprises a mixed population of exponential and hyperbolic consumers, where the latter are relatively more impatient than the former.

To simulate this case, we assume that each educational group is evenly divided between exponential and hyperbolic consumers. ${ }^{93}$ Furthermore we assume that within each educational group, exponential and hyperbolic households have the same long-term discount factors: $\delta^{N H S}, \delta^{H S}, \delta^{C O L L}$. For all consumers, we set the coefficient of relative risk aversion equal to 1 . For the exponential consumers, we set $\beta$ equal to 1 , and for the hyperbolic consumers we set $\beta$ equal to 0.85 . We then follow the steps described above for calibrating the preference parameters. We solve for the long-run discount factors, so that the mixed population replicates the actual median level of preretirement wealth holdings. In this way, we obtain long-run discount rates for the three educational groups of $0.0427,0.0335$, and 0.0257 , respectively. As expected, these discount rates lie close to the midpoints of the discount rates for exponential and hyperbolic consumers reported in our original calibration exercise (see table 4). Figure 15 plots the resulting simulations for exponential and hyperbolic consumers in the high school graduate group in the economy without a DC plan. The exponential consumers save far more than the corresponding hyperbolic consumers.

Figure 16 plots the percentage of liquidity-constrained high school graduates in our hybrid simulation for an economy with no defined contribution plan. This graph is comparable to the upper panel of figure 11 , which plots the percentage of liquidity-constrained consumers

93. If education is an endogenous outcome, it might make sense to assume that households in the college graduate group are disproportionately exponential: it may be easier to invest in education if self-control is not a problem. 
Figure 15. Simulated Liquid Asset, Income, and Consumption Paths in a Hybrid World without a Defined Contribution Plan ${ }^{a}$

Thousands of 1990 dollars

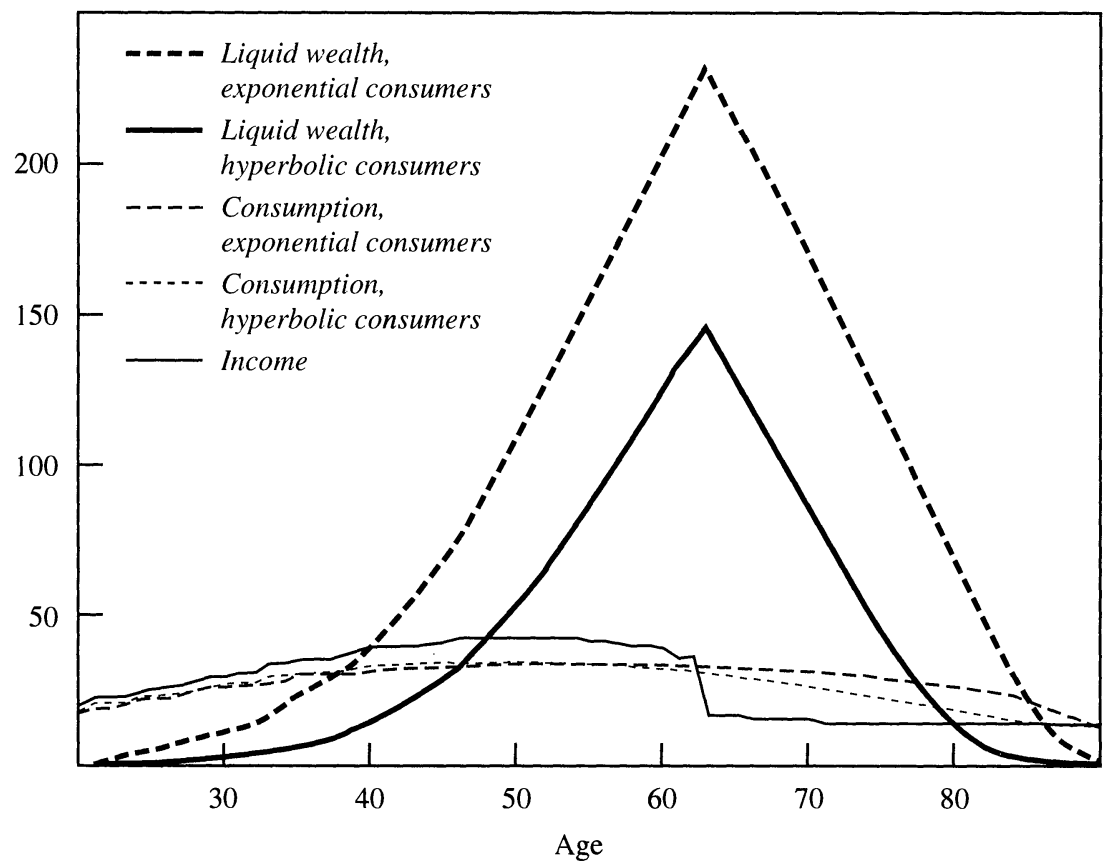

Source: Authors' simulations.

a. Figure plots average consumption, pretax labor income, and liquid wealth for households with high school graduate heads. The population comprises 50 percent exponential and 50 percent hyperbolic households, and the model is calibrated under the assumption that both types of household have the same long-term discount factor $(\delta)$.

in the nonhybrid simulations. Note that the percentage of liquidityconstrained hyperbolic consumers in figure 16 is greater than in figure 11 , since the hyperbolic consumers in the hybrid simulation are more impatient than those in the nonhybrid simulation. Similarly, the percentage of liquidity-constrained exponential consumers in figure 16 is less than in figure 11 , because the exponential consumers in the hybrid simulation are less impatient than those in the nonhybrid simulation.

Using our calibrated hybrid populations, we then evaluate the impact of DC plans. Table 21 reports the results of this simulation. In our hybrid economy, exponential consumers experience an increase of 58.0 percent in the steady-state saving rate, while hyperbolic consumers 
Figure 16. Share of High School Graduates Who Are Liquidity Constrained, Hybrid Economy ${ }^{\mathrm{a}}$

Percent of households

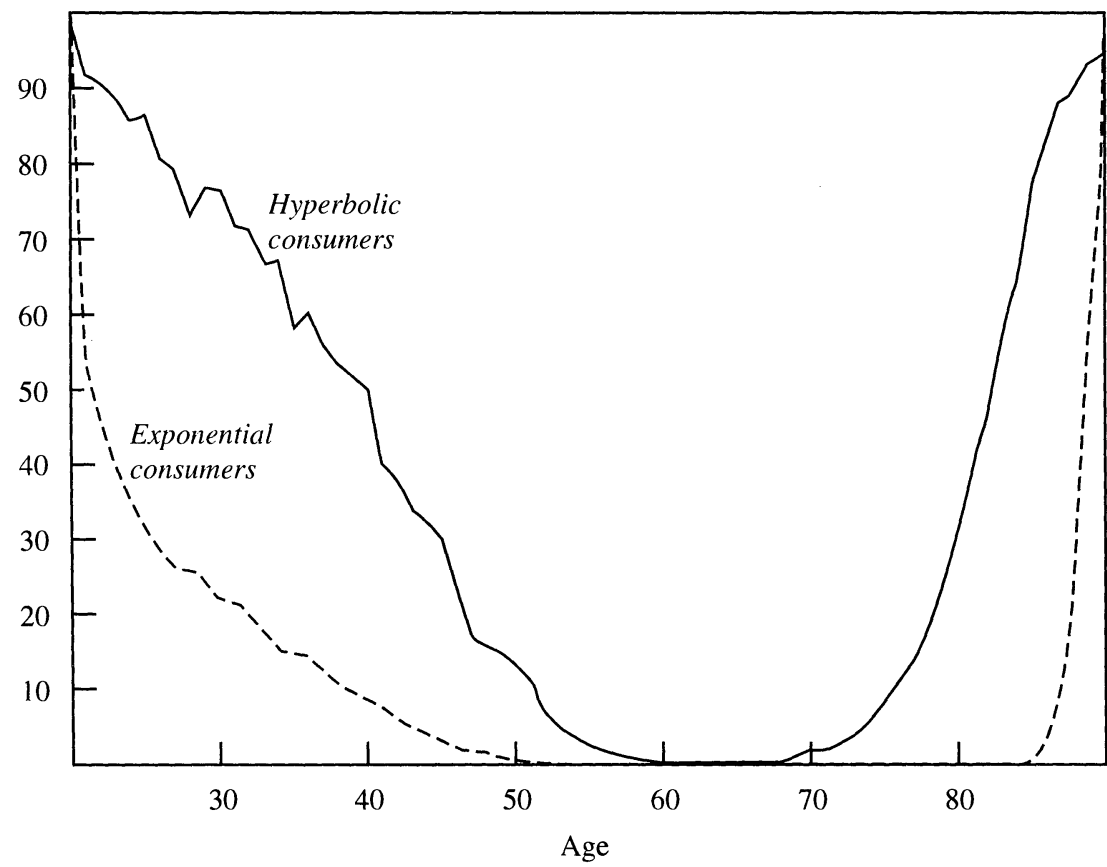

Source: Authors' simulations.

a. Figure plots simulated percent of households in the high school group who are liquidity constrained (less than $\$ 400$ in liquid assets) in the economy in which half of consumers are exponential and half are hyperbolic. The coefficient of relative risk aversion is equal to 1 , and exponential and hyperbolic consumers have the same long-term discount factor ( $\delta$ ).

experience an increase of 86.3 percent, yielding an aggregate increase of 68.0 percent. The corresponding increases in the nonhybrid simulations are 60.6 percent for exponential consumers and 81.1 percent for hyperbolic consumers. As expected, the percentage change in the hybrid simulations is lower for the exponential consumers and higher for the hyperbolic consumers than in the nonhybrid simulations. The reason for this is that in the hybrid simulation the exponential consumers are more patient and the hyperbolic consumers are more impatient than in the nonhybrid simulation, leading to more asset shifting by the former and less by the latter.

The hybrid economy suggests a general point about hyperbolic dis- 
Table 21. Aggregate Impact of Defined Contribution Plans for a Population Comprising Exponential and Hyperbolic Consumers ${ }^{\mathrm{a}}$

Percent

\begin{tabular}{lccc}
\hline Item & $\begin{array}{c}\text { Exponential } \\
\text { consumers }\end{array}$ & $\begin{array}{c}\text { Hyperbolic } \\
\text { consumers }\end{array}$ & $\begin{array}{c}\text { Aggregate } \\
\text { population }\end{array}$ \\
\hline Aggregrate saving rate $^{\mathrm{b}}$ & & & \\
$\quad$ No DC plan & 5.4 & 2.9 & 4.2 \\
With DC plan & 8.5 & 5.5 & 7.0 \\
Percent difference $^{\mathrm{d}}$ & 58.0 & 86.3 & 68.0 \\
Government revenue & & & \\
$\quad$ No DC plan & 14.3 & 12.4 & 13.4 \\
With DC plan $^{\mathrm{c}}$ & 15.5 & 12.7 & 13.6 \\
Percent difference $^{\mathrm{d}}$ & 8.4 & 2.6 & 1.9 \\
${\text { New savings in DC } \text { plan }^{\mathrm{f}}}^{\text {con }}$ & 44.3 & 51.9 & 47.2 \\
\hline
\end{tabular}

Source: Authors' simulations.

a. Table shows the aggregate impact of DC plans under the assumption that the population comprises 50 percent exponential households and 50 percent hyperbolic households. Long-term discount rates are calibrated such that the preretirement median ratio of wealth to income in the simulated no DC plan economy matches the ratio in the data. The underlying longterm discount rates are the same for all consumers within an educational category. For the share of each educational group in the population, see table 10 , note a.

b. Saving as a percentage of income; see table 10 , note a.

c. Assumes a 10 percent penalty for early withdrawal and no employer matching contribution.

d. Percent increase in moving from an economy without a DC plan to an economy with a DC plan.

e. Percent of labor income; see table 11 , note a.

f. Percent of DC plan savings that represents new savings; see table 12 , note a

counting. If hyperbolic discounters are relatively more impatient than exponential discounters (which is true in the hybrid simulation but not in the nonhybrid simulations), DC plans will have a larger percentage impact on hyperbolic households than on exponential households, for two distinct reasons. ${ }^{94}$ First, hyperbolic households value commitment. And second, hyperbolic households are relatively impatient and are therefore less likely to have accumulated assets which they can simply shift into the DC plan.

\section{Conclusions and Directions for Future Research}

In this paper we start by showing that life-cycle consumption and asset accumulation patterns are consistent with a hyperbolic model. At

94. In the nonhybrid simulations, the calibration guarantees that the exponential and hyperbolic consumers accumulate the same amount of preretirement savings if they do not have access to the DC plan. In the nonhybrid simulations, the effects of $\beta_{\text {hyperbolic }}<$ $\beta_{\text {exponential }}$ are offset by setting $\delta_{\text {hyperbolic }}>\delta_{\text {exponential }}$. 
a first glance, the life-cycle choices of hyperbolic and exponential consumers are indistinguishable. However, hyperbolic consumers exhibit some special regularities that enable researchers to distinguish them from their exponential counterparts: they are much more likely to encounter liquidity constraints, and they exhibit the anomalous precautionary saving effects documented by Dynan. ${ }^{95}$ These hyperbolic phenomena are implied by the generalized Euler equation.

We then consider another distinction between hyperbolic and exponential behavior. We show that hyperbolic consumers will react much more favorably to defined contribution pension plans than equivalent exponential consumers. Our benchmark simulations for an exponential economy - with coefficient of relative risk aversion equal to 1 and a measured elasticity of intertemporal substitution of 0.27 -show that DC plans with early withdrawal penalties of between 10 percent and 50 percent raise the steady-state net national saving rate by 61 percent to 102 percent. By contrast, in a hyperbolic economy (with coefficient of relative risk aversion equal to 1 and a measured elasticity of intertemporal substitution of 0.22 ) such plans raise the steady state net national saving rate by 81 percent to 134 percent. These results are sensitive to the calibration of the coefficient of relative risk aversion. Higher values of the coefficient of relative risk aversion significantly reduce the effects of DC plans in both exponential and hyperbolic economies.

This work should be extended in several directions. First, the magnitudes of the effects that we find need to be examined for hyperbolic discounters with values of $\beta$ below those that we consider. We choose relatively high values for this parameter to avoid pathologies. The hyperbolic effects would be much stronger for lower values of $\beta$, and most experimental evidence suggests that a value of 0.6 would best match consumer preferences. For reasons we have discussed above, simulations with low values for $\beta$ need to be implemented in continuous time. ${ }^{96}$

Second, the dynamic process that takes an economy from a steady state without a DC plan to a steady state with a DC plan should be evaluated. As Engen, Gale, and Scholz, and others have pointed out,

95. Dynan (1993).

96. This requires an alternative approximation to the hyperbolic discount function. The quasi-hyperbolic discount function does not have a direct analog in continuous time. 
the short-run effects of a tax incentive often take the opposite sign to the long-run effects. ${ }^{97}$

Third, the set of commitment devices available to hyperbolic consumers in the model should be enriched. We compare a world with no endogenous commitment devices to a world with one endogenous commitment device: a DC pension plan. In the real world, there are a wide range of commitment devices and the introduction of DC plans may simply lead hyperbolic consumers to switch from a preexisting commitment device to this new one.

Fourth, if the economy does not in fact contain good alternative commitment devices, something may be wrong with the hyperbolic model. If consumers have hyperbolic discount functions and are sophisticated, they should want banks or other financial institutions to sell commitment devices. One sees many instruments with commitment properties, but very few that are sold explicitly for this purpose. Perhaps illiquid assets span the commitment space. If they do not, why have banks not filled the gaps? Are consumers too myopic (or too embarrassed) to seek out explicit commitment devices?

Fifth, the other behavioral facets of DC plans should be formally analyzed. To the extent that such plans do raise national saving, they may do so for reasons not modeled in this paper. For example, DC plans simplify the investment process, helping consumers with bounded rationality make good investments; and they make interpersonal comparisons of saving more transparent, perhaps shaming consumers into saving more. Although we do not model automatic deductions in this paper, we believe that this popular feature of DC plans plays a particularly important role in encouraging accumulation. As Public Agenda reports, "Americans overwhelmingly (77 percent) prefer to save for retirement through automatic deductions from their paychecks, with only a fifth (19 percent) preferring to make a savings decision each time they get paid." ${ }^{98}$ It is not known why automatic deductions are attractive. Perhaps they serve as a commitment device. Perhaps they simplify decisionmaking for consumers with bounded rationality. Defined contribution plans use a rich array of psychologically appealing features to induce saving. ${ }^{99}$ Economists should do more to understand these effects.

97. Engen, Gale, and Scholz (1994).

98. Farkas and Johnson (1997, p. 28).

99. See Laibson (1998) for a review of the psychological effects induced by DC plans. 


\section{Comments and Discussion}

Robert E. Hall: This paper combines a staggering amount of empirical and simulation work with a lot of deep thinking about intertemporal consumption choice. Although the idea of temporally inconsistent preferences is not new, the paper advances the empirical application of this line of thought tremendously, and I congratulate the authors for their unusual combination of computational effort guided by intelligence.

Let me start with a discussion of the three-period case with log utility. Using $C_{t}$ to denote consumption in period $t$ and $\beta$ to represent the one-time discount factor, the preferences of the three selves are as follows:

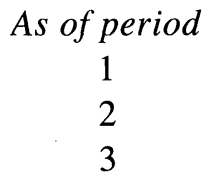

$$
\begin{gathered}
\text { Utility } \\
\ln C_{1}+\beta\left(\ln C_{2}+\ln C_{3}\right) \\
\ln C_{2}+\beta \ln C_{3} \\
\ln C_{3} .
\end{gathered}
$$

There is only one inconsistency: self 1 weights utility in period 2 and in period 3 equally, whereas self 2 puts greater weight on period 2 than on period 3 .

Assume a zero real interest rate. Then the recursive equilibrium with wealth $W$ is 


$$
\begin{gathered}
C_{1}=\left(\frac{1}{1+2 \beta}\right) W \\
C_{2}=\left[\frac{2 \beta}{(1+\beta)(1+2 \beta)}\right] W \\
C_{3}=\left[\frac{2 \beta^{2}}{(1+\beta)(1+2 \beta)}\right] W .
\end{gathered}
$$

Self 3 has a passive role, simply consuming whatever wealth earlier selves have left to it. Self 2 takes the wealth that self 1 leaves and divides it between consumption in periods 2 and 3 , according to its preferences, which are tilted toward immediate consumption. Self 1 considers all available wealth and thinks through the behavior of self 2 in the course of deciding how much to consume in period 1 and how much to leave to self 2 . Notice that consumption declines over time. There is a tendency to spend rather than save.

Now suppose that self 1 can commit future levels of consumption. This would only take a mechanism where self 1 can set aside some wealth that is inaccessible to self 2 but is available to self 3-pretty much the effect of a $401(\mathrm{k})$ plan. The consumption pattern with commitment is as follows:

$$
\begin{gathered}
\tilde{C}_{1}=\left(\frac{1}{1+2 \beta}\right) W=C_{1} \\
\tilde{C}_{2}=\left(\frac{\beta}{1+2 \beta}\right) W=\left(\frac{1+\beta}{2}\right) C_{2}<C_{2} \\
\tilde{C}_{3}=\left(\frac{\beta}{1+2 \beta}\right) W=\left(\frac{1+\beta}{2 \beta}\right) C_{3}>C_{3} .
\end{gathered}
$$

This is the standard consumer problem with log or Cobb-Douglas preferences. Initial consumption is higher, but consumption levels are the same in periods 2 and 3 . Notice that period 1 consumption is the same with and without commitment. The differences occur in period 2, where consumption is lower with commitment, and in period 3 , where consumption is higher.

Commitment results in more midlife saving. As the paper stresses, self 1 will use a $401(\mathrm{k})$ or other commitment mechanism to enforce its 
preferences for equal levels of consumption in all periods other than the first, to prevent the declining profile of consumption that will result from the repeated attempts of later selves to spend more on themselves.

One can consider the selves different consumers, and then apply the standard theory of consumption externalities to think about welfare. Each self has externalities with the consumption levels chosen by future selves. There is no single welfare or utility function that orders lifetime patterns of consumption. Rather, there is only the partial ordering associated with Pareto comparisons. Although with realistic lifetimes the committed path Pareto-dominates the recursive equilibrium, that is not the case in this example. Self 2 receives higher utility in the recursive case.

As in any situation with externalities, a Pareto improvement from the recursive equilibrium is possible. A small shift of consumption from period 1 to period 3 would make all selves better off. Absent commitment, self 1 cannot bring about that shift. Leaving more wealth to self 2 will result in an increase in period 2 consumption, which is already excessive by self 1 's standards. The paper points out that commitment can Pareto-dominate the recursive equilibrium if there are more periods. The correction of the downward bias of consumption over time is beneficial to earlier selves, all of whom place equal weight on later consumption. The resulting higher level of wealth gives more consumption to later selves, so they benefit as well. But my example shows that this is not always the case.

As this paper emphasizes-and the earlier work of Laibson and others on inconsistent preferences demonstrates-panel data on consumption show remarkably little difference between the consistent and inconsistent cases. Both result in similar Euler equations. The paper calls attention to two differences: liquidity constraints are binding for a higher fraction of the population in the inconsistent case, and the Dynan anomaly occurs with inconsistent but not with consistent preferences. The high incidence of complete liquidity constraints-shown as a matter of theory and as a matter of data in figures 10 through $12-$ is a persuasive part of the case in favor of inconsistency, as I read the evidence.

An important finding is the huge benefit enjoyed by inconsistent consumers if they have a commitment mechanism structured roughly like a $401(\mathrm{k})$. Funds can be placed in the account voluntarily, but cannot 
be removed by later selves until retirement age. The $401(\mathrm{k})$ permits earlier selves to flatten the later consumption profile. The very same selves who would withdraw funds from the account if allowed to do so will put funds into the account precisely because later selves are not allowed to withdraw!

Consumers with consistent preferences also benefit from 401(k)s. Thus the widespread use of these accounts is not evidence in favor of inconsistent preferences. But given persuasive other evidence, the social value of these accounts seems to be substantial. And the social cost of provisions that give easier access to them prior to retirement is also high, as the paper stresses. The ideal $401(\mathrm{k})$ is administered by a wise and knowledgeable outsider who will dispense funds for a true emergency but will block requests that would finance higher consumption.

In addition to $401(\mathrm{k}) \mathrm{s}$, the public uses many other commitment mechanisms. Social security is surely the largest of these. People buy taxdeferred annuities and life insurance with committed saving provisions. They join Christmas clubs. They overpay income taxes so as to get refunds. The viability of these financial arrangements and products is the most persuasive evidence in favor of inconsistent preferences. The evidence is all the stronger because these products are such bad deals in comparison with the best ways to save. The typical $401(\mathrm{k})$ offers a variety of mutual funds, each with expenses of around 2 percent of asset value per year (1.2 percent as disclosed expenses and 0.8 percent as hidden soft dollar trading costs). Then, the administrator tacks on another percent or so in fees. These costs take away about half of the expected real return of the saving. And Christmas clubs, tax-deferred annuities, and insurance policies fare even worse. Social security is currently a very poor deal for higher wage workers, even though it was a fantastic deal for earlier generations.

This paper, and all of Laibson's related work on hyperbolic preferences, deals with people who consume too much, in the sense that they would consume less if they had a good commitment mechanism. I wonder, though, if there are not other people with the opposite problem: they are inconsistent in weighting current consumption below any future consumption. These people always plan to consume in the future, but when the future comes around, it seems better to defer consumption even longer. They die with a large fraction of wealth unspent. These people would also benefit from a commitment mechanism, where they 
can commit in one period to consume in later periods. The authors dismiss this possibility at the beginning of the paper as intuitively implausible, but I am not so sure.

William G. Gale: Among the many contributions that this paper makes, two stand out: developing a detailed simulation model of consumption and saving under hyperbolic discounting, and analyzing tax-based saving incentives in that model. I focus on the role of hyperbolic discounting and other assumptions and on the simulation results.

The authors assume that people (a) have hyperbolic discount functions; (b) are "sophisticates," that is, they understand that their longterm discount rates are lower than their short-term rates; and (c) have a constant coefficient of relative risk aversion equal to 1 . Under these assumptions, people have a hard time saving, know they have such a problem, and find commitment devices that help them save to be very valuable. For example, the authors show that the availability of a perfect commitment device would be worth 36 percent of consumption at age twenty.

A key implication of these assumptions is that people would be willing to pay for a commitment mechanism. However, there are almost no examples of popular commitment devices that cost money. The paper notes there were 10 million participants in holiday clubs in 1996. Balances, however, appear to be quite small. Blayne Cutler reports that one bank with a large number of such accounts had average accumulation of $\$ 500$ before being liquidated. ${ }^{1}$ This suggests aggregate accumulation of $\$ 5$ billion before liquidation, which represents only 2 percent of annual personal saving, or 0.02 percent of financial assets. Excess withholding of income taxes can be explained by many factors besides its being a method of forced saving, such as uncertain income or deductions, biased withholding schedules, costs of changing withholding, and costs of audits.

If there were demand for commitment mechanisms, they would be extremely easy to create. Workers could ask their employers for higher penalties or stricter withdrawal procedures on $401(\mathrm{k}) \mathrm{s}$, but typically do not. In fact, firms that want to raise workers' participation rates in

1. Blayne Cutler, “Buy Today, Pay Yesterday,' American Demographics, December 1993 , p. 53. 
401(k) plans often provide more generous provisions for loans and hardship withdrawals; that is, they make $401(\mathrm{k}) \mathrm{s}$ less of a commitment mechanism. Voters could lobby legislators for public policies that raised the penalty on tax-deferred saving, but typically do not. Indeed, the trend in public policy is just the opposite, allowing for increased withdrawals from tax-deferred accounts. ${ }^{2}$

Why won't households pay to commit their future selves? One reason may simply be that the demand for commitment is small. Another may be that households can obtain the level of commitment they desire via tax-favored devices. In fact, almost all popular commitment devices associated with saving — such as housing, pensions, 401(k)s, IRAs, and tax-deferred annuities - possess substantial tax advantages. Even in this case, however, several factors suggest that demand for commitment mechanisms may be small.

First, participation in tax-favored vehicles appears to be closely related to their tax benefits. For example, pension coverage, 401(k) participation (conditional on eligibility), and annuity purchases rise with tax rates. ${ }^{3}$ IRA contributions plummeted after the tax preferences and advertising for such accounts were reduced in 1986, even though the commitment aspects-namely, the early withdrawal penalties-did not change. This suggests that commitment was not what motivated people to participate in the first place. Second, those who participate in saving incentives tend to have relatively large amounts of liquid assets, ${ }^{4}$ suggesting that they do have the self-control to commit to saving without an explicit commitment mechanism. Third, only about 10 percent of households currently contribute to IRAs, even though such accounts provide tax savings for almost all households, and about half of the workforce does not have a $401(\mathrm{k})$ plan or a pension of any kind.

Finally, a strong demand for commitment creates some interesting hypothetical possibilities for economic behavior that are worth considering. For example, with a strong demand for commitment people would be willing to accept a lower rate of return on illiquid assets than on liquid assets; if tax-favored saving incentives did not exist, con-

2. The quote from Public Agenda in the paper's introduction is ambiguous as to whether respondents do not want their own penalties reduced, or whether, as a matter of public policy, they think that lower penalties are a bad idea.

3. Engen, Gale, and Scholz (1994); Gentry and Milano (1998).

4. Engen, Gale, and Scholz (1994). 
sumers would be willing to participate in government-sponsored illiquid accounts that were tax-penalized; and consumers would be willing to sign contracts that stated, "If I take money out of my 401(k) or IRA before age $y$, I will pay $x$ percent of it to . .' That none of these activities can be observed in the real world is not in itself evidence that the demand for commitment is small. After all, several constraints rule out such behavior: competition among lenders, who prefer to issue illiquid assets to minimize withdrawal risks, will generate higher equilibrium returns for illiquid assets than for liquid assets; ${ }^{5}$ the government already offers tax-favored saving accounts; and side contracts of the type specified above are apparently illegal. ${ }^{6}$ Nonetheless, such behavior would be observed if there were a high demand for commitment and if these constraints did not exist. In my view, however, such behavior is not very likely to exist to any great degree, even in the absence of the constraints. This makes me skeptical that the demand for commitment is very large, but analysts can reasonably differ on this point.

Together, these factors present a significant challenge for the authors' set of assumptions. Changing any of the three assumptions would make the model more consistent with the real world. Setting the coefficient of relative risk aversion equal to 3 instead of 1 would reduce the value of commitment to 2 percent, rather than 36 percent, of consumption at age twenty. Assuming that people are exponential discounters eliminates the value of commitment. And as the authors note, assuming that households are naive - that they think they will not have such high short-term discount rates in the future-also eliminates their willingness to commit. Changing any of the three assumptions could also significantly reduce the effects of $401(\mathrm{k}) \mathrm{s}$ on saving, as the authors show and as is discussed below.

The paper contains an interesting discussion of the discrepancy between actual and desired saving rates. This discrepancy no doubt exists, but it may be more difficult to interpret than the authors imply. For example, they conclude that " such systematic, self-acknowledged error contradicts the standard economic model of the maximizing consumer." I believe that this claim is too strong. In conventional theory, the consumer has unlimited wants and limited resources. In equilibrium,

5. I am indebted to David Laibson for this point.

6. Laibson (1997a). 
the consumer sets the marginal rate of substitution between any two goods equal to their price ratios. Thus the consumer has positive marginal utility of consuming more of all goods. If asked whether he would like to save more or "should" save more (or take more leisure, or play more golf), the consumer may well say yes, but that response may simply reflect the existence of trade-offs, rather than regret, or the inability to follow through on commitments. Only if consumers had a bliss point (for example, with quadratic utility), above which the marginal utility of increasing consumption of an item is negative, would life-cycle consumers necessarily be expected to answer in the way the authors describe. More generally, the paper seems to imply that all gaps between actions and intentions are evidence against rational behavior. It seems that other explanations might be worth exploring.

The paper analyzes defined contribution plans that are voluntary and allow tax-deductible employee contributions and matching employer contributions. The only such plans in the real world are 401(k) plans, which apply to the private sector, and their equivalents in the nonprofit and public sectors. Other defined contribution plans may not be voluntary and may not allow for tax-deferred employee contributions. Turning to the paper's results, in the no-401(k) economy, the hyperbolic model generates more borrowing-constrained households than does the exponential model. Which model better fits the real world is unclear. Using data from the 1983 Survey of Consumer Finances, if household borrowing constraints are defined in terms of liquid assets, the hyperbolic results appear to be closer to the SCF data than the exponential results (figures 10 to 12). However, using the same definition, both the hyperbolic discounting and exponential discounting models underpredict borrowing constraints among fifty to fifty-nine year olds by very large margins, even though the models are calibrated explicitly to replicate median wealth near this age. By contrast, if household borrowing constraints are defined in terms of net worth (table 6), both models do much better at predicting borrowing constraints among fifty to fiftynine year olds, but the likelihood of being constrained in the exponential discounting model is generally closer to the SCF data than is the hyperbolic discounting model. The $1983 \mathrm{SCF}$ also provides a third way to measure borrowing constraints, by means of a series of questions 
about borrowing behavior. ${ }^{7}$ Using this definition, about 20 percent of households in the 1983 survey are constrained. This finding appears to be closer to the exponential discounting results than the hyperbolic discounting results.

When $401(\mathrm{k})$ plans are introduced in the model, the results are in some ways similar to the long-term findings of Engen, Gale, and Scholz. ${ }^{8}$ With a 10 percent penalty, a 50 percent match rate, and a coefficient of relative risk aversion of 3 (that is, an intertemporal elasticity of substitution of 0.33), Engen, Gale, and Scholz find that 51 percent of $401(\mathrm{k})$ contributions are net saving in the long-term, and that the national saving rate rises by about 1.0 percentage point. In the Laibson-Repetto-Tobacman model, using similar assumptions and either hyperbolic or exponential discounting, about 32 percent of contributions are net saving (table 16), and private saving rises by about 1.5 percentage points (table 14). The results differ due to less persistent earnings shocks in the present model than in those of Engen, Gale, and Scholz or other papers; a higher $401(\mathrm{k})$ contribution limit; different wage profiles; a different bequest process; and different time preference rates. Nevertheless, the overall similarity in long-term results is striking.

When the coefficient of relative risk aversion is 1 , (that is, when the intertemporal elasticity of substitution is 1$)$, the effects of $401(\mathrm{k}) \mathrm{s}$ are much larger. The proportion of contributions that are net saving is still close to that of Engen, Gale, and Scholz, with estimates of 54 percent in the exponential discounting model and 60 percent in the hyperbolic discounting model (table 12). The major difference is the overall impact on saving, with increases in the saving rate of 3.5 percentage points in the exponential discounting model and 3.9 percentage points in the hyperbolic discounting model (table 10). This indicates the central importance of the assumed value of the intertemporal elasticity of substitution, or equivalently of the risk aversion coefficient.

The intertemporal elasticity of substitution is a "deep structural" parameter. In particular, it measures the curvature of the utility function, when utility depends on consumption in different periods. As such, in a constant relative risk aversion utility function, the intertemporal elasticity of substitution will always be the inverse of the coeffi-

7. See Jappelli (1990).

8. Engen, Gale, and Scholz (1994). 
cient of relative risk aversion. In contrast, the observed response of consumption to the interest rate-what the authors call the measured intertemporal elasticity of substitution-which is reported in table 5 depends on the intertemporal elasticity of substitution, on borrowing constraints, and on other factors. Researchers have attempted to estimate the intertemporal elasticity of substitution with micro-level and macro-level data and have generated a wide variety of estimates. Additionally, it is unclear to what extent researchers have identified the true structural parameter. Nevertheless, several of those who have developed simulation models have surveyed the empirical literature and settled on values of 0.33 or less for the intertemporal elasticity of substitution. ${ }^{9}$ Some interesting recent evidence is presented by Robert Barsky and others, based on a unique set of questions in the Health and Retirement Study. They find that most individuals' responses are consistent with low values of the intertemporal elasticity of substitution: between 0.0 and 0.36 , with a midpoint estimate of 0.18 . They conclude that "virtually no respondents have intertemporal substitution as elastic as that implied by log utility [that is, equal to 1]." 10

Regardless of the value of the intertemporal elasticity of substitution, both the Engen-Gale-Scholz and the Laibson-Repetto-Tobacman models overstate the long-term impact of $401(\mathrm{k}) \mathrm{s}$ on the saving rate. First, both use partial equilibrium models, but increases in saving should to some extent reduce the level of interest rates. Second, both models assume universal eligibility for $401(\mathrm{k}) \mathrm{s}$. Third, for most workers, the effective limits on $401(\mathrm{k}) \mathrm{s}$, as set by their firms, are much lower than $\$ 10,000$. Fourth, neither model allows for net borrowing, in particular, borrowing against the $401(\mathrm{k})$ balance. Fifth, both models assume that other pensions stay intact as $401(\mathrm{k}) \mathrm{s}$ expand, but there has in fact been substantial substitution at the firm level between $401(\mathrm{k}) \mathrm{s}$ and aftertax thrift plans, and between $401(\mathrm{k}) \mathrm{s}$ and defined benefit and non$401(\mathrm{k})$ defined contribution plans. ${ }^{11}$ Sixth, in the real world there are already many other existing illiquid assets. Adding the $n$th illiquid asset would presumably have much less impact on saving, if the key is

9. For example, Auerbach and Kotlikoff (1987); Engen, Gale, and Scholz (1994); Hubbard, Skinner, and Zeldes (1995).

10. Barsky and others (1997, p. 564).

11. See Andrews (1992) for the first case; Papke (1997) for the second. 
commitment mechanism, than adding the first illiquid asset, which is what the models actually examine.

Four additional features of the model merit comment. First, by ignoring the transition to the steady state, the authors overstate government saving in the steady state. During the transition, there will be more tax-deductible contributions than taxable withdrawals, so government will likely generate debt. The model does not account for the costs in steady state of paying off this previously accumulated debt. Thus the apparent increase in government revenues in the steady state may not translate into higher net government saving.

Second, both the hyperbolic discounting and exponential discounting models in this paper appear to contain very high saving elasticities. Saving rises by 100 percent or more as a result of changing the tax treatment of one type of saving and raising the one-period rate of return on that saving from about 3.75 percent (assuming a 25 percent marginal tax rate) to 5.0 percent. This one-third increase in the return, coupled with the 100 percent increase in saving, translates into an elasticity of 3-well above standard empirical estimates.

Third, the results on "percentage changes in aggregate saving" are difficult to interpret. It is never obvious which is the most appropriate real world saving rate to compare with the simulated saving rates. For example, the simulation assumes that defined benefit pensions generate zero net saving, ignores retained earnings, greatly simplifies the implicit treatment of capital depreciation, and does not distinguish housing, other durables, and financial assets. Because the model's pre-401(k) saving rate is only about 4 percent, changing any of these factors would affect the saving rate and therefore affect the percentage change in overall saving. For example, if saving in pensions equals about 4 percent of GDP, as it did in the "pre-401(k) economy" of 1971-80, and these pensions are included in the pre-401(k) saving rate, the percentage increases in aggregate saving would be much lower than reported in the model. ${ }^{12}$ It makes much more sense to focus discussion on percentage point changes in the saving rate (or in the capital output ratio) and the proportion of contributions that are new saving.

Finally, in my view, it is most appropriate to interpret the model as

12. Pension saving 1971-80 is from Sabelhaus (1997). 
indicating the effects of the introduction of illiquid assets in general, rather than the introduction of $401(\mathrm{k})$ or defined contribution plans. In the steady state, a very large portion of assets end up being held as 401(k)s. For example, when the penalty is 10 percent and the match rate is 50 percent, about 85 percent of wealth appears to be in such plans. ${ }^{13}$ This is higher than the figure for all illiquid assets in the modern economy.${ }^{14}$ However, if the model is really one of "illiquidity" rather than " $401(\mathrm{k}) \mathrm{s}$," it is important to note that illiquid assets have existed for a substantial period of time-historically, the two most important have been housing and defined benefit pensions-and that they already account for over two-thirds of wealth. ${ }^{15}$ Thus current saving rates may already reflect the long-term impacts of illiquid assets on the economy.

In summary, this is a fascinating and stimulating paper that develops several new and important directions for the study of saving behavior. It is worth emphasizing that there is a tremendous amount of diversity in households' sophistication, tastes, and motives for saving, and that modeling the effects of voluntary tax-based saving incentives under these circumstances can be quite difficult. There is no doubt, for example, that the authors are correct in saying that some people are extremely unsophisticated in saving, that there are major gaps between stated intentions and actual behavior, and that commitment mechanisms can help some people to save. Yet these findings do not yield clear implications for the effects of existing saving incentives. Households that participate in such plans tend to have large amounts of other saving. Thus it could be that many households are "problem savers" and that many households participate in voluntary saving incentives, but that the two groups have not overlapped very much. It may also be that the paper provides strong motivation for mandatory saving rather than voluntary incentives. It is extremely unlikely that any one model will accurately represent the saving behavior of the entire population.

13. In the exponential discounting model, the pre-401(k) saving rate is 4.14 percent, the post-401(k) saving rate is 7.63 percent (table 10), and 53.9 percent of $401(\mathrm{k})$ contributions are net saving (table 12). This implies that $401(\mathrm{k})$ contributions equal 6.47 [(7.63-4.14)/0.539] percent of GNP, and 84.8 percent $(6.47 / 7.63)$ of all saving, or wealth in the steady state. In the analogous model with hyperbolic discounting, similar calculations indicate that about 88 percent of all saving is in $401(\mathrm{k}) \mathrm{s}$.

14. See Laibson (1997a).

15. Laibson (1997a). 
Nevertheless, contributing a fully detailed, alternative framework to analyze saving and public policy is a significant accomplishment.

I hope that future work along these lines provides information on simulated $401(\mathrm{k})$ participation rates and clarifies the interpretation of the saving rate in the model, which would help provide some perspective on the model fit; models the transition from the short run to the steady state, to provide a sense of what the short- or intermediate-term effects might be and to capture the full effects on government financing; includes analysis of mandatory saving schemes; and models the effects of an illiquid saving account with no employer match and no tax preference. The last item, in particular, would provide some evidence of the value of commitment, per se, that could be compared with real world phenomena. Further research on the intertemporal elasticity of substitution would also be of use. While these issues remain unresolved, the present paper makes a major and welcome contribution toward our understanding of saving behavior and public policy.

George A. Akerlof: This is a very fine paper. It takes an idea that fundamentally revises standard consumer theory and applies it to aggregate saving in the United States. The paper also makes the important technical contribution of implementing new simulation techniques for time-inconsistent consumption paths. These techniques represent a great leap forward in the ability of economists to critique policies that affect saving behavior.

The basic idea behind this paper is that present consumption is particularly salient in consumption choice. This is modeled by the hyperbolic discount model, which says that short-run discount rates are higher than long-run rates of discount. It has been known since the work of Strotz that such variable discounting will create time-inconsistency in decisionmaking. ${ }^{1}$ The contribution of the recent work on procrastination and saving has been to follow Strotz with the assertion that whatever may be the mathematical inconveniences engendered by the timeinconsistency of plans, this is in fact the right way to model saving behavior because it corresponds to actual consumer behavior. Supporting this argument, there is a considerable body of psychological exper-

1. Strotz (1956). 
iment that would motivate such hyperbolic discounting, including data on the discount rates of rats.

In the present paper the authors assume that subjects have correct expectations: they have rational expectations and are aware of their own time inconsistency. As a result, these consumers do not say, "I should spend today, because tomorrow I am going to begin to save." Instead, they say to themselves, "I am impatient today, but I will be equally impatient tomorrow. If I save today, I will be impatient tomorrow and will spend the money tomorrow rather than save it for my retirement, so I might as well spend today.' ' Curiously, that use of perfect foresight is just as self-defeating as assuming incorrectly that today's bad behavior is only an aberration because tomorrow one will be good.

There are two ways out of the dilemma of low saving for the consumers in this model. The first is to precommit to saving. There are many devices that allow such precommitment, either as an individual decision-for example, pension plans-or as a collective decisionfor example, social security. Likewise, one of the attractions of home ownership may be the forced saving entailed in paying off a mortgage. An alternative solution to the dilemma of low saving in the LaibsonRepetto-Tobacman model with perfect foresight is to build up a large stock of liquid assets. In that case, the marginal dollar saved today is not likely to be spent at some nearby time, because of the salience of present purchases, but instead will be spread over a long period, as in the standard version of the permanent income hypothesis. Thus the effects of hyperbolic discounting are small. (This is an implication of the Euler equation.)

The policy innovation of this paper is a shift in emphasis regarding saving behavior. In the traditional models of constant discounting, as opposed to hyperbolic discounting, undersaving occurs because savers face the wrong rate of return. Taxes on capital income generate a gap between society's marginal rate of transformation and consumers' marginal rate of substitution between current and future consumption. Martin Feldstein, in particular, has demonstrated that this gap induces large deadweight losses as a result of even small taxes on capital income. ${ }^{2}$ The present paper, while possibly suggesting a reason for the exacerbation of deadweight losses due to capital income taxation, emphasizes

2. Feldstein (1978). 
another aspect of policy toward saving. It analyzes, for the first time in any realistic way, the gain in utility that will occur if consumers are able to precommit saving behavior.

Three nature facts especially favor this model over traditional models of constant discounting and consistent consumption paths: the popularity of social security, the saving behavior of young workers, and the ubiquity of employer-based pension plans. The hyperbolic model explains the uniform popularity of social security, which acts as a precommitment device to redistribute consumption from times when people would be tempted to overspend-during their working lives-to times when they would otherwise be spending too little-in retirement. Even with the distortions entailed in such taxation with hyperbolic discounting, as in this model, such a transfer is most likely to improve welfare significantly. The hyperbolic discounting model explains, as the standard model will not, why the young as well as the old should be particularly enthusiastic about social security.

A second aspect of reality that is consistent with this model but inconsistent with the standard model is the low levels of liquid assets of younger people. Previous work by Engen shows that with plausibly calibrated parameters, deadweight losses due to taxation of capital income with uncertain labor income are an order of magnitude less than those with certainty-equivalent earnings, if consumption expenditures are liquidity constrained. ${ }^{3}$ This occurs because early in their careers, workers will build up a buffer stock of savings for precautionary motives. In particular, they want to have a nest egg in the event of unemployment. Because these buffer-stock savings are acquired early in workers' careers, and because early savings have a long gestation period before retirement, they will greatly reduce the deadweight loss in the standard (constant discount) model. But the analysis with hyperbolic discounting is very different. Impatient young workers are discouraged from building up liquid assets to spend in the event of job loss, because these liquid assets would be a temptation. Since consumption today is particularly salient, as it would also be in the near future, workers come close to spending all of their income early in their careers. Tables 6 and 7 show that high school dropouts and high school graduates tend to conform to this pattern of saving: they have almost no liquid assets.

3. Engen (1994). 
This important fact is consistent with hyperbolic, but not with constant, discounting. This putative difference between the hyperbolic and the constant discounting models is significant. Enough is known about the asset levels of young people-for example, at the time of divorce-to suggest that the qualitative predictions of the model must be right.

The third nature fact explained by the authors' model is the extent to which employees delegate to their employers the task of setting aside pension funds to save for their retirement. These pension plans are a form of precommitment that would be predicted by the model. Indeed, analysis of the welfare benefits of such pension plans is the central feature of this paper.

It is my duty as a discussant to generate a few quibbles. An important contribution to the literature on saving is that of Bernheim, Skinner, and Weinberg, who find that consumption declines dramatically for every wealth quartile on retirement ${ }^{4}$ Using British data, James Banks, Richard Blundell, and Sarah Tanner similarly find large drops in consumption. ${ }^{5}$ Bernheim, Skinner, and Weinberg argue that the drop in consumption at retirement is much larger than should be expected from work-related expenditures, especially the drop in such nonwork related categories as food consumed at home. These findings strongly suggest the presence of considerable myopia in consumption behavior. The basic Euler equation of the Laibson-Repetto-Tobacman model would seem to be violated by such a large downward discontinuity at retirement. The authors are aware of this problem: they have found that very low values of $\beta$ are capable of producing significant falls in consumption at retirement, but they lead to consumption paths that are otherwise implausible.

Another violation of the Euler condition is suggested by John Shea. ${ }^{6}$ He finds that workers under union contracts with wage cuts reduce their consumption not at the time when the cut is announced, but when the pay cut is actually received.

These deviations from what is easily explained by the authors' model I consider to be rather superficial; but at the same time, they indicate that the model of hyperbolic discounting presented here should be used for general messages about saving behavior only, and should not be

4. Bernheim, Skinner, and Weinberg (1997).

5. Banks, Blundell, and Tanner (1995).

6. Shea (1995). 
taken literally to design policies. For example, the model suggests that workers will voluntarily make rational precommitments if saving plans allow them to do so. The consumption discontinuities at retirement suggest, however, that workers are yet more present-oriented than even the model of this paper would predict. Indeed, naifs have almost no reason to precommit voluntarily: they think that they will behave better next period. And William Gale's comment gives further evidence that people tend not to take advantage of opportunities to precommit. For that reason, those designing policy of, for example, 401(k)s and pension plans should not take the model as the literal truth. It would be a grave error to take away from this paper the message that strengthening precommitment devices of existing programs is all, or even a substantial part, of what is needed to rectify saving policy. There is also a need for nonvoluntary sources of saving, such as often occurs in pension plans.

To summarize, this is a very important paper. It makes operational a new paradigm of consumption behavior that is much more sensitive to the way that people, pigeons, and rats actually behave than is the standard constant discount model. This paradigm suggests welfare gains from policies that commit people to saving (albeit forcibly, rather than voluntarily). Indeed, the institutions that have been either collectively chosen or encouraged by provisions of the tax code to provide for oldage income-in particular, social security and employer-based pension plans-indicate the all-important role of governmental policies in counteracting procrastination in saving.

General discussion: In reply to William Gale's comments about the coefficient of relative risk aversion, Laibson said that previous authors had based their calibration choices on the incorrect assumption that the measured elasticity of intertemporal substitution (the sensitivity of the slope of the consumption path to changes in the real interest rate) equals the true value of the elasticity of intertemporal substitution (the inverse of the coefficient of relative aversion). In a buffer-stock world, the measured elasticity actually lies below the true elasticity. Hence, previous calibrations of the coefficient of relative risk aversion suffered from an upward bias. In addition, Laibson suggested several reasons to be skeptical of the survey evidence of Robert Barsky and others cited by Gale. In particular, their survey biases respondents toward picking 
a relatively or perfectly flat consumption path (due to framing effects, end-point aversion, and discontinuity aversion) for all values of the interest rate.

Christopher Carroll offered an explanation for why the authors found a much larger response to $401(\mathrm{k})$ availability in the exponential model than previous researchers have found. The interest elasticity of saving in a model with exponential discounting and uncertainty depends crucially on whether consumers would save or dissave in the absence of uncertainty, which depends, in turn, on the relationship between interest rates, the time preference rate, and the growth rate of income. As consumers become more "impatient"' in this sense, their interest elasticity of saving approaches zero, since very impatient consumers only hold assets for precautionary reasons, and changing the interest rates has little effect on the precautionary motivation for saving. By contrast, "patient" consumers, who would be savers in the absence of uncertainty, can have extremely high interest elasticities of saving. Carroll inferred that the authors' choices of parameter values, especially for the intertemporal elasticity of substitution, appear to result in consumers who, prior to $401(\mathrm{k})$ availability, are close to the knife edge between patience and impatience. When offered the substantially higher aftertax rate of return of a $401(\mathrm{k})$ plan, they decisively move to the patient side, where the interest elasticity of saving is high.

Benjamin Friedman believed that at many if not most U.S. firms, the great majority of employees are unwilling to participate in $401(\mathrm{k}) \mathrm{s}$ unless they are, in effect, bribed to do so by the matching contributions of their employers. He found this fact problematic, whether from the perspective of tax advantages or an attraction based on commitment. William Gale added other reasons to question how good a commitment mechanism 401(k) plans are. People can and do borrow against 401(k) balances. Households that are eligible for $401(\mathrm{k}) \mathrm{s}$ tend to have higher mortgage debt than other households, controlling for other factors. And people may unintentionally "undo" the saving effects of $401(\mathrm{k}) \mathrm{s}$ by borrowing, even if they do not mean to arbitrage the system. For example, a household that starts contributing to a 401(k) but does not change any consumption behavior would, at the end of the year, end up with more debt. He noted that an earlier paper by David Laibson on hyperbolic discounting, undersaving, and saving policy discusses the 
fact that one can borrow against $401(\mathrm{k}) \mathrm{s}$ and undo the commitment mechanism.

William Dickens believed that the hyperbolic model did not capture the reasons for commitment through instruments such as Christmas clubs and savings bonds. In his view, the main motivation for these forms of investment is to insulate savings from impulse spending. People know that in some periods they will not be able to control themselves, but will spend more than they should. Such episodic and unpredictable behavior is time inconsistent but would require a different theoretical model than the authors' hyperbolic. Gale added that some of the evidence presented in favor of psychological models may be overstated. Whether households are saving enough for retirement is not entirely clear, and there is substantial heterogeneity in saving behavior and the adequacy of wealth preparations. Whether consumers implement downward-sloping consumption profiles is not obvious either. There is some evidence that most working households that are not borrowing constrained exhibit rising consumption profiles.

Gale suggested that household responses on motives for saving in the Survey of Consumer Finances may be a useful source for understanding saving. In the $1995 \mathrm{SCF}, 31$ percent of all households stated that concerns about unemployment or uncertain income were a primary motive for saving - the single most frequent response. This frequency was fairly constant across age groups and also across years. The second most frequent response was saving for retirement, cited as a primary motive by 23 percent of households in the 1995 SCF. Not surprisingly, the frequency of this response increases with age until it drops after age sixty-five. Thus people seem to feel that they are saving predominantly for precautionary reasons and for retirement. One alternative reason for saving suggested by the SCF is: "wise/prudent thing to do; good discipline to save; habit." Only a tiny fraction of households cited this as a primary saving motive in the $1995 \mathrm{SCF}$. Another possible response in the survey is: "don't/can't save; have no money." Only about 6 percent of households under the age of sixty-five gave this response in 1995. Gale reasoned that these findings are not what one would expect from hyperbolic consumers. 


\section{References}

Ainslie, George W. 1975. "'Specious Reward: A Behavioral Theory of Impulsiveness and Impulse Control." Psychological Bulletin 82(4): 463-96.

- 1986. "Beyond Microeconomics: Conflict among Interests in a Multiple Self as a Determinant of Value." In The Multiple Self, edited by Jon Elster. Cambridge University Press.

1992. Picoeconomics. Cambridge University Press.

$\rightarrow$ Akerlof, George A. 1991. "Procrastination and Obedience." American Economic Review, Papers and Proceedings 81(2): 1-19.

American Express Financial Advisors. 1996. "A Common Sense Guide to Personal Money Management." Minneapolis: American Express Financial Corporation.

Andrews, Emily S. 1992. "The Growth and Distribution of 401(k) Plans." In Trends in Pensions 1992, edited by John A. Turner and Daniel J. Beller. Department of Labor, Pension and Welfare Benefits Administration.

Attanasio, Orazio P., and Guglielmo Weber. 1993. "Consumption Growth, the Interest Rate, and Aggregation." Review of Economic Studies 60(3): 631-49.

Auerbach, Alan J., and Laurence J. Kotlikoff. 1987. Dynamic Fiscal Policy. Cambridge University Press.

Banks, James, Richard Blundell, and Sarah Tanner. 1995. "Consumption Growth, Saving and Retirement in the U.K." Ricerche Economiche 49(3): 255-75.

Barro, Robert J. 1997. "Myopia and Inconsistency in the Neoclassical Growth Model." Unpublished paper. Harvard University (September).

Barsky, Robert B., and others. 1997. "Preference Parameters and Behavioral Heterogeneity: An Experimental Approach in the Health and Retirement Study." Quarterly Journal of Economics 112(2): 537-79.

Beaudry, Paul, and Eric van Wincoop. 1996. "The Intertemporal Elasticity of Substitution: An Exploration Using a U.S. Panel of State Data." Economica 63(251): 495-512.

Bernheim, B. Douglas. 1994. "Personal Saving, Information, and Economic Literacy: New Directions for Public Policy." In Tax Policy for Economic Growth in the 1990s. Washington: American Council for Capital Formation.

1995. "Do Households Appreciate Their Financial Vulnerabilities? An Analysis of Actions, Perceptions, and Public Policy." In Tax Policy for Economic Growth in the 1990s. Washington: American Council for Capital Formation.

Bernheim, B. Douglas, Jonathan Skinner, and Steven Weinberg. 1997. "What Accounts for the Variation in Retirement Wealth Among U.S. Households?" 
Working Paper 6227. Cambridge, Mass.: National Bureau of Economic Research (October).

Camerer, Colin, and Teck-Hua Ho. 1997. "Experience-weighted Attraction Learning in Normal-form Games." Working Paper 1003. California Institute of Technology (December).

Campbell, John Y., and N. Gregory Mankiw. 1989. "Consumption, Income, and Interest Rates: Reinterpreting the Time Series Evidence." In NBER Macroeconomics Annual 1989, edited by Olivier Jean Blanchard and Stanley Fischer. MIT Press.

Carroll, Christopher D. 1992. "The Buffer-Stock Theory of Saving: Some Macroeconomic Evidence." BPEA, 2:1992, 61-156. . 1997a. "Buffer-Stock Saving and the Life Cycle/Permanent Income Hypothesis." Quarterly Journal of Economics 112(1): 1-55.

- 1997b. "Death to the Log-Linearized Consumption Euler Equation! (And Very Poor Health to the Second-Order Approximation)." Working Paper 6298. Cambridge, Mass.: National Bureau of Economic Research (December).

Carroll, Christopher D., and Miles S. Kimball. 1996. "On the Concavity of the Consumption Function."' Econometrica 64(4): 981-92.

Chung, Shin-Ho, and Richard J. Herrnstein. 1967. "Choice and Delay of Reinforcement." Journal of the Experimental Analysis of Animal Behavior 10(1): 67-74.

Deaton, Angus. 1991. "Saving and Liquidity Constraints." Econometrica 59(5): 1221-48.

Diamond, Peter, and Botond Köszegi. 1998. "Hyperbolic Discounting and Retirement." Unpublished paper. Massachusetts Institute of Technology (March).

Dynan, Karen E. 1993. “'How Prudent Are Consumers?” Journal of Political Economy 101(6): 1104-13.

Engen, Eric M. 1994. "Precautionary Saving and the Structure of Taxation." Unpublished paper. Federal Reserve Board, Division of Research and Statistics, Fiscal Analysis Section (June).

Engen, Eric M., and William G. Gale. 1993. "IRAs and Saving in a Stochastic Life-Cycle Model." Unpublished paper. University of California, Los Angeles (April).

Engen, Eric M., William G. Gale, and John Karl Scholz. 1994. “Do Saving Incentives Work?'” BPEA 1:1994, 85-180.

- 1996. "The Illusory Effects of Saving Incentives on Saving." Journal of Economic Perspectives 10(4): 113-38.

Erev, Ido, and Alvin E. Roth. 1998. "Modeling How People Play Games: Reinforcement Learning in Experimental Games with Unique, Mixed Strategy Equilibria." American Economic Review (forthcoming). 
Farkas, Steve, and Jean Johnson. 1997. Miles to Go: A Status Report on Americans' Plans for Retirement. New York: Public Agenda.

Feldstein, Martin S. 1978. "The Welfare Cost of Capital Income Taxation.', Journal of Political Economy 86(2, pt. 2): S29-S51.

Gentry, William M., and Joseph Milano. 1998. “Taxes and Investment in Annuities.', Working Paper 6525. Cambridge, Mass.: National Bureau of Economic Research (April).

Gourinchas, Pierre-Olivier, and Jonathan A. Parker. 1997. "Consumption Over the Lifecycle.' Unpublished paper. Massachusetts Institute of Technology (January).

Hall, Robert E. 1978. "Stochastic Implications of the Life Cycle-Permanent Income Hypothesis: Theory and Evidence.' Journal of Political Economy 86(6): 971-87.

- 1988. “'Intertemporal Substitution in Consumption.' Journal of Political Economy 96(2): 339-57.

Hansen, Lars Peter, and Kenneth J. Singleton. 1982. “Generalized Instrumental Variables Estimation of Non Linear Rational Expectations Models.", Econometrica 50(5): 1269-85.

Harris, Christopher, and David I. Laibson. 1998. "Buffer Stock Models, Euler Equations, and Hyperbolic Discounting.' Unpublished paper. Harvard University (January).

Hewitt Associates. 1995. Trends and Experience in 401(k) Plans. Lincolnshire, Ill. Ill.

Hoch, Stephen J., and George Loewenstein. 1991. “Time-Inconsistent Preferences and Consumer Self-Control.', Journal of Consumer Research 17(4): 492-507.

Hubbard, R. Glenn, and Jonathan Skinner. 1996. “Assessing the Effectiveness of Saving Incentives.' Journal of Economic Perspectives 10(4): 73-90.

Hubbard, R. Glenn, Jonathan Skinner, and Stephen P. Zeldes. 1994. "The Importance of Precautionary Motives in Explaining Individual and Aggregate Saving.' Carnegie-Rochester Conference Series on Public Policy 40: 59-125.

1995. “Precautionary Saving and Social Insurance.' Journal of Political Economy 103(2): 360-99.

Jappelli, Tullio. 1990. "Who is Credit Constrained in the U.S. Economy?" Quarterly Journal of Economics 105(1): 219-34.

King, George R., and Alexandra W. Logue. 1987. "Choice in a Self-Control Paradigm with Human Subjects: Effects of Changeover Delay Duration.' Learning and Motivation 18(4): 421-38.

Kirby, Kris N. 1997. “'Bidding on the Future: Evidence against Normative 
Discounting of Delayed Rewards.' Journal of Experimental Psychology 126(1): 54-70.

Kirby, Kris N., and R. J. Herrnstein. 1995. "Preference Reversals Due to Myopic Discounting of Delayed Reward." Psychological Science 6(2): $83-89$.

Kirby, Kris N., and Nino N. Marakovic. 1995. "Modeling Myopic Decisions: Evidence for Hyperbolic Delay-Discounting within Subjects and Amounts." Organizational Behavior and Human Decision Processes 64(1): 22-30.

. 1996. "Delay-discounting Probabilistic Rewards: Rates Decrease as Amounts Increase." Psychonomic Bulletin and Review 3(1): 100-04.

Laibson, David I. 1994. "Self-Control and Saving." Ph.D. dissertation. Massachusetts Institute of Technology (May).

. 1996. "Hyperbolic Discount Functions, Undersaving, and Savings Policy." Working Paper 5635. Cambridge, Mass.: National Bureau of Economic Research.

. 1997a. "Golden Eggs and Hyperbolic Discounting." Quarterly Journal of Economics 112(2): 443-77.

- 1997b. "Hyperbolic Discount Functions and Time Preference Heterogeneity." Unpublished paper. Harvard University (March).

- 1998. "Comment." In Studies in the Economics of Aging, edited by David A. Wise. University of Chicago Press.

Loewenstein, George F., and Dražen Prelec. 1992. "Anomalies in Intertemporal Choice: Evidence and an Interpretation." Quarterly Journal of Economics 107(2): 573-97.

Loewenstein, George F., and Nachum Sicherman. 1991. "Do Workers Prefer Increasing Wage Profiles?' Journal of Labor Economics 9(1): 67-84.

Mankiw, N. Gregory, Julio J. Rotemberg, and Lawrence H. Summers. 1985. "Intertemporal Substitution in Macroeconomics." Quarterly Journal of Economics 100(1): 225-51.

Millar, Andrew, and Douglas J. Navarick. 1984. "Self-Control and Choice in Humans: Effects of Video Game Playing as a Positive Reinforcer.' Learning and Motivation 15(2): 203-18.

Mulligan, Casey B. 1997. “A Logical Economist's Argument Against Hyperbolic Discounting." Unpublished paper. University of Chicago (February).

Navarick, Douglas J. 1982. "Negative Reinforcement and Choice in $\mathrm{Hu}$ mans.' Learning and Motivation 13(3): 361-77.

O’Donoghue, Edward, and Matthew Rabin. 1997a. "Doing It Now or Later." Unpublished paper. Northwestern University (October).

—. 1997b. "Incentives for Procrastinators." Unpublished paper. Northwestern University (February).

Papke, Leslie E. 1997. “'Are 401(k) Plans Replacing Other Employer-Provided 
Pensions? Evidence from Panel Data.' Unpublished paper. Michigan State University (October).

Phelps, Edmund S., and Robert A. Pollak. 1968. "On Second-best National Saving and Game-equilibrium Growth." Review of Economic Studies 35(2): 185-99.

Poterba, James M., Steven F. Venti, and David A. Wise. 1995. "Do 401(k) Contributions Crowd Out Other Personal Saving?'” Journal of Public Economics 58(1): 1-32.

- 1996. "How Retirement Saving Programs Increase Saving." Journal of Economic Perspectives 10(4): 91-112.

Prelec, Dražen. 1989. "Decreasing Impatience: Definition and Consequences." Unpublished paper. Harvard Business School (August).

Read, Daniel, and others. 1998. "Mixing Virtue and Vice: The Combined Effects of the Immediacy Effect and the Desire for Diversity." Unpublished paper. Leeds University Business School (June).

Sabelhaus, John. 1997. "Public Policy and Saving in the United States and Canada." Canadian Journal of Economics 30(2): 253-75.

$\rightarrow$ Schelling, Thomas C. 1984. "Self-Command in Practice, in Policy, and in a Theory of Rational Choice." American Economic Review, Papers and Proceedings 74(2): 1-11.

Shapiro, Matthew D., and Joel Slemrod. 1995. "Consumer Response to the Timing of Income: Evidence from a Change in Tax Withholding." American Economic Review 85(1): 274-83.

Shea, John. 1995. "Union Contracts and the Life-Cycle/Permanent-Income Hypothesis." American Economic Review 85(1): 186-200.

Simmons Market Research Bureau. 1996. The 1996 Study of Media and Markets. New York.

Solnick, Jay V., and others. 1980. "An Experimental Analysis of Impulsivity and Impulse Control in Humans." Learning and Motivation 11(1): 61-77.

Strotz, Robert H. 1956. "Myopia and Inconsistency in Dynamic Utility Maximization."' Review of Economic Studies 23(1): 165-80.

Thaler, Richard H., and Hersch M. Shefrin. 1981. "An Economic Theory of Self-Control." Journal of Political Economy 89(2): 392-406.

U.S. National Center for Health Statistics. 1994. Vital Statistics of the United States, 1994. Department of Health and Human Services.

Zeldes, Stephen P. 1989. "Consumption and Liquidity Constraints: An Empirical Investigation.” Journal of Political Economy 97(2): 305-46. 